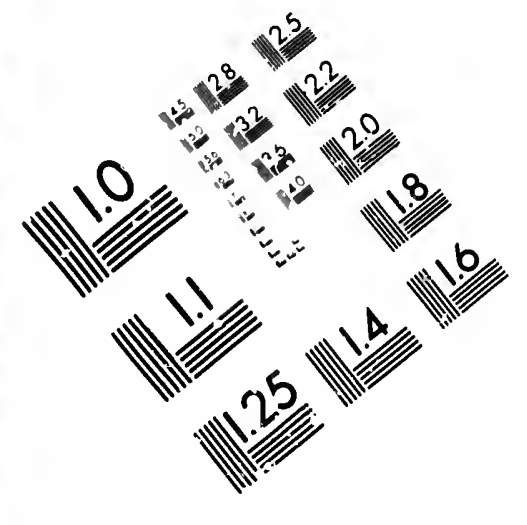

IMAGE EVALUATION

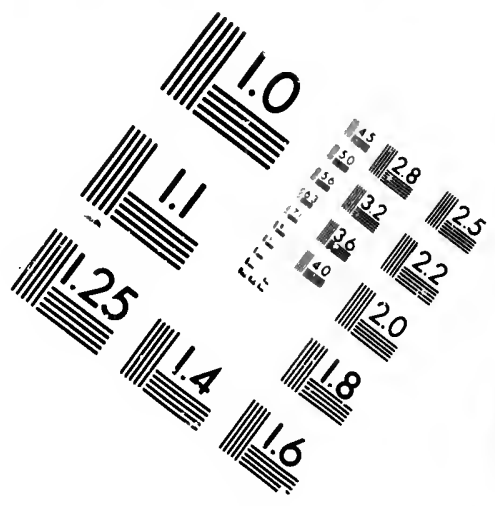

TEST TARGEI (MT-3)
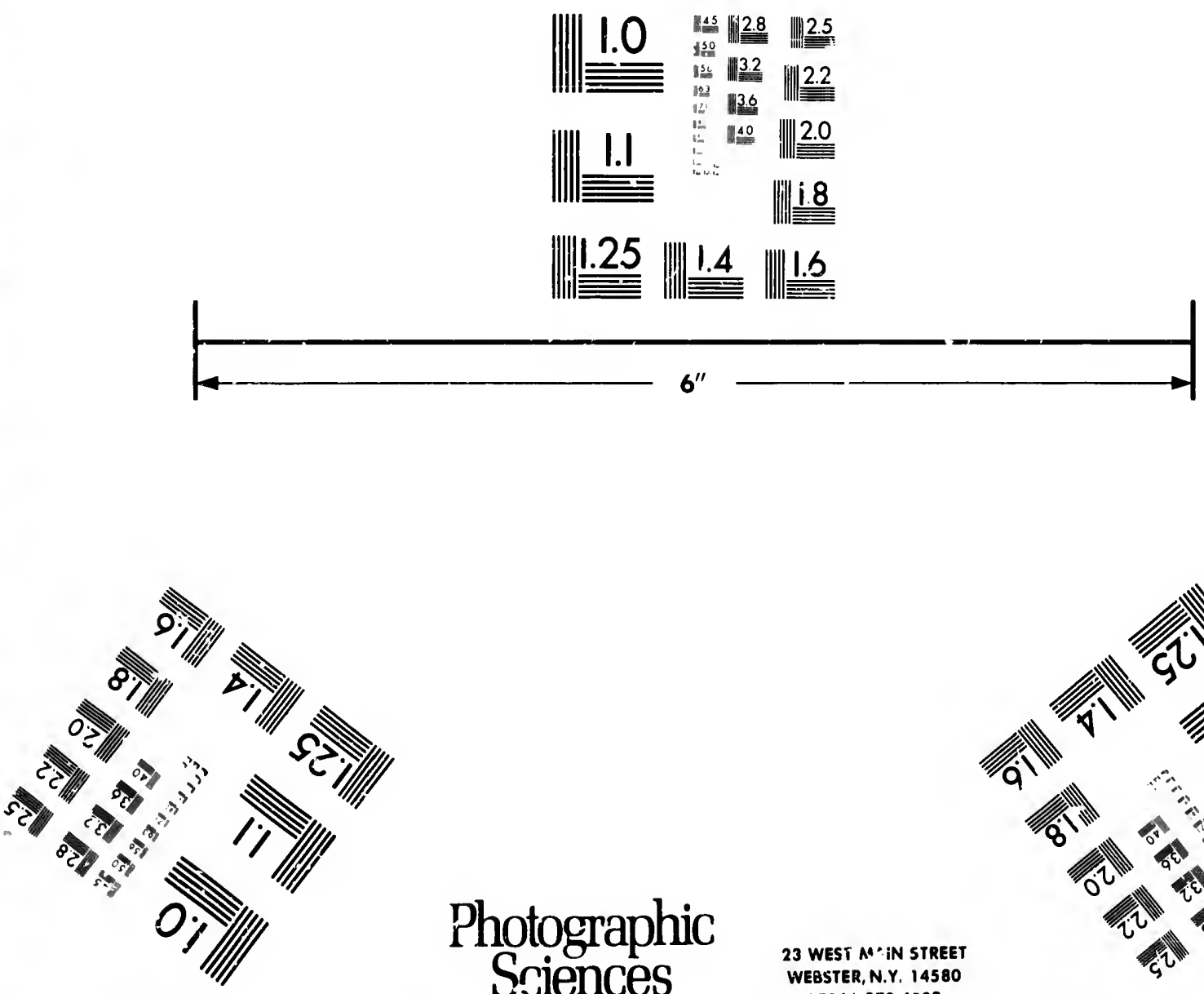

Photographic Sciences Corporation
23 WEST AN' IN STREET

WEBSTER, N.Y. 14580

(716) 872.4503

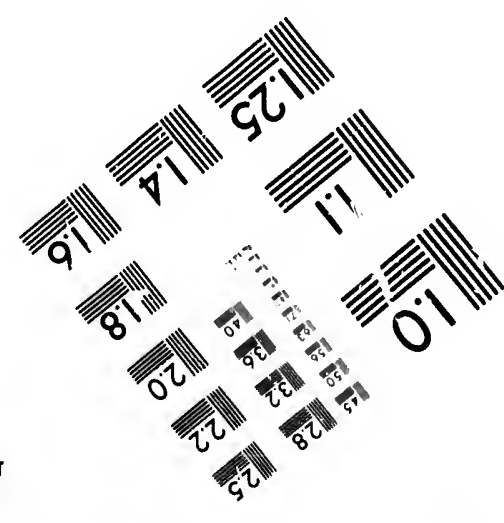




\section{CIHM/ICMH Microfiche Series.}

\section{CIHM/ICMH Collection de microfiches.}


The Institute has attempted to obtain the best original ccpy available for filming. Features of this copy which may be bibliographically unique,

which may elter any of the images in the reproduction, or which may significantly change the usual method of filming, are checked below.

Coloured covers/

Couverture de couleur

Covers damaged/

Couveriure endommagée

Covers restored and/or láminatzd/

Cauverture restaurée et/ou pelliculée

Cover title missing/

Le titre de couverture manque

\section{Coloured maps/}

Cartes géographiques en couleur

Colcured ink (i.e. other than blue or black)/

Encre de couleur (i.e. autre que blewe ou noire)

Coloured plates and/or illustrations/

Planches et/ou illustrations en couleur

Bound with other material/

Relié avec d'autres documents

Tight binding may cause shadows or distortion aiong interior margin/

La reliure serrée peut causer de l'ombre ou de la distortion le long de la marge intérieure

\section{3 lank leaves added during restoration may} appear within the text. Whenever possible, these have been omitted froin filming/

II se peut que certaines pages blanches ajoutées lors d'une restauration apparaissent dans le texte. mais, lorsque cela était possible, ces pages n'ont pas été filmées.

\section{Additional comments:/}

Commentaires supplémentaires:
L'Institut a microfilmé le meilleur exemplaire qu'il lui a été possible de se procurer. Les détails de cet exemplaire qui sont peut-être uniques du point de vue bibliographique, qui peuvent modifier une image reproduite, ou qui peuvent exiger une modification dans la méthode normale de filmage sont indiqués ci-dessous.

\section{Coloured pages/}

Pages de couleur

Pages darnaged/

Pages endommagées

Pages restored and/or laminated/

Pages restaurées et/ou pelliculées

Pages discoloured, stained or foxed/

Pages décolorées, tachetées ou piauées

Pages detached/

Pages détachées

Showthrough/

Transparence

Quality of print varies/

Qualité inégale de l'impression

Includes supplementary material/

Comprend du matériel supplémentaire

Oniy edition available/

Seule édition disponible

Pages wholly or partially obscured by errata slips, tissues, etc., have been refilmed to ensure the besî possible image/ Les pages totalement ou partiellement obscurcies par un feuillet d'errata, une pelure. etc. ont été filmées à noi'veau de façon à obtenir la meilleure image possible.

MAP ON INSIDE BACK COVER HAS BEEN FILMED OPEN AT THE END.

This item is filmed at the reduction ratio checked below/ Ce document est filmé au taux de réduction indiqué ci-dessous.

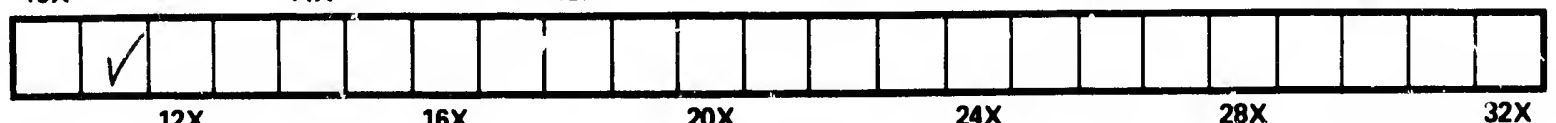


The copy filmed here has been reproduced thanks to the generosity of:

Thomas Fishar Rare Book Library, University of Toronto Library

The images appearing here are the best quality possible considering the condition and legibility of the original copy and in keeping with the filming contract specifications.

Original copies in printed paper covers are filmed beginning with the front cover and ending on the last page with a printed or illustrated impression, or the back cover when appropriate. All other original copies are filmed beginuing on the first page with a printed or illustrated impression, and ending on the last page with a printed or illustrated impression.

The last recorded frame on each microfiche sha!l contain the symbol $\rightarrow$ (meaning "CONTINUED"), or the symbol $\nabla$ (meaning "END"). whichever applies.

Maps, plates, charts, etc., may be filmed at different reduction ratios. Those too large to he entirely included in one exposure are filmed beginning in the upper laft hand corner, left to right and top to bottom, as many frames as required. The following diagrams illustrate the method:
L'exemplaire filmé fut reproduit grâce à la générosité de:

Thomas Fisher Rara Book Library, University of Toronts Library

Les images suivantes ont été reproduites avec le plus grand soin, compte tenu de la condition et de la netteté de l'exemplaire filmé, et en conformité avec les conditions du contrat de filmage.

Les exemplaires originaux dont la couverture on papier est imprimée sont filmés en commençant par le premier plat et en terminant soit par la derniere page qui comporte une empreinte d'impression ou d'illustration, soit par le second plat, selon le cas. Tous les autres exemplaires originaux sont filmés en commençant par la premiere page qui comporte une empreinte d'impression ou d'illustration et en terminant par la derniàre page qui comporte une telle empreinte.

Un des symboles suivants apparaîtra sur la derniere image de chaque microfiche, selon le cas: le symbole $\longrightarrow$ signifie "A SUIVRE". Ie symbole $\nabla$ signifie "FIN".

Les cartes, planches, tableaux, etc.. peuvent être filmés à des taux de réduction différents. Lorsque le document est trop grand pour être reproduit en un seul cliché, il est filmé à partir de l'angle supérieur gauche, de gauche a droite, et de haut en bas, en prenant le nombre d'images nécessaire. Les diagrammes suivants illustrent la méthode.
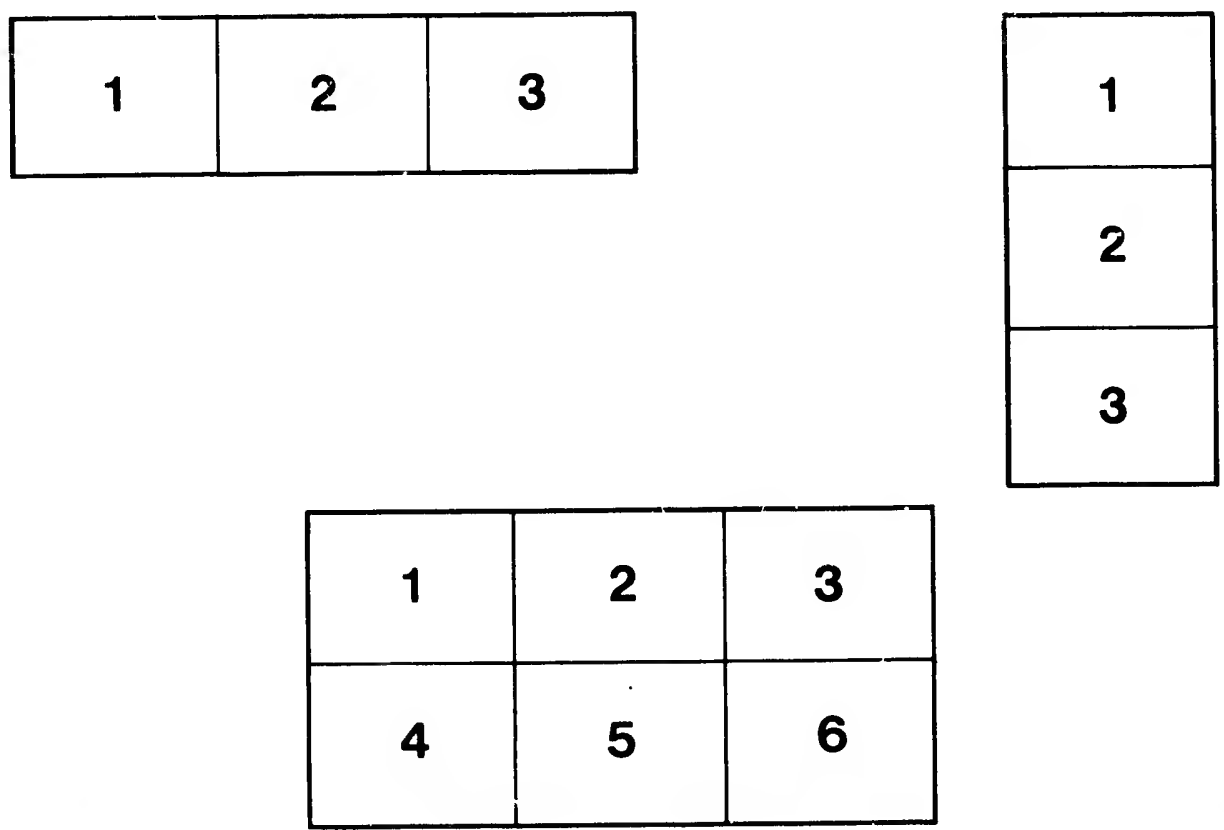
hich
A.

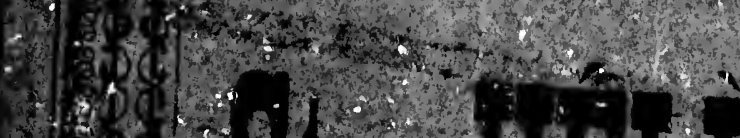
W. 3 (s) H.

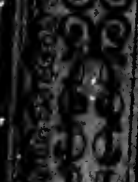
is
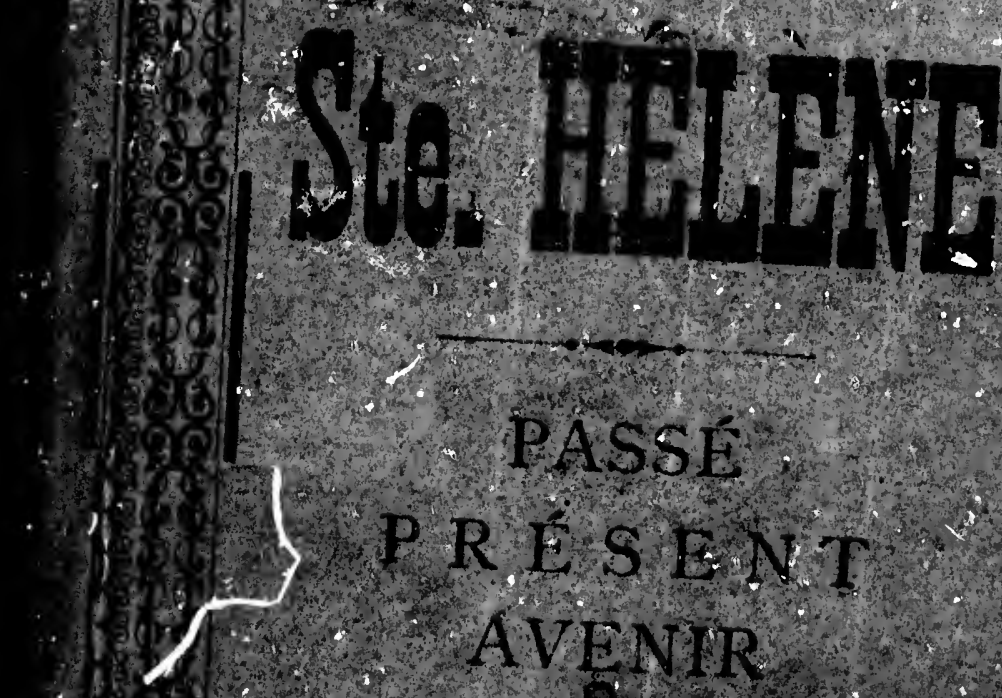

\section{PASSE}

PRESENT

- AVENIR

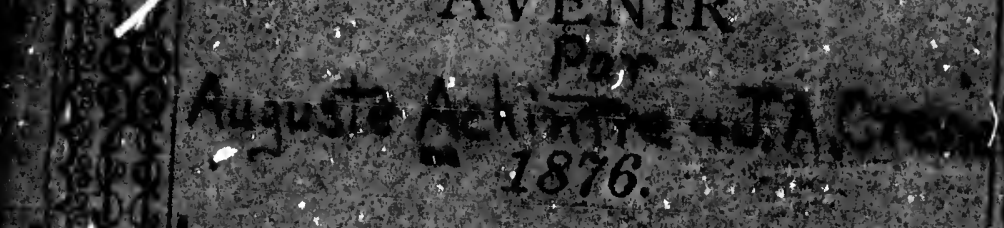

10. (19)

ted

506

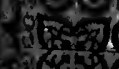

4

I 



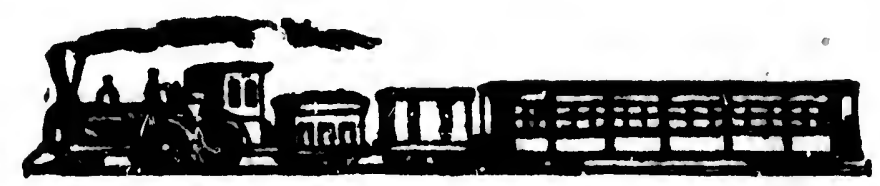

\section{BOSTON \& MONTREAL AIR LINE}

LA ROUTE LA PLUS COURTE PAR LA LIGNE DU VERMONT CENTRAL.

ARRANGEMENTS D'ETE COMMEN-

L'Express de jour quitte Montréal a 9 h. a.m., pour Boston, par Lowell, arrive a Boston a 9.45 p. $m$.

Le train pour Waterloc quitte Montréal a 2.45 h. p. $m$.

L'Express de Nuit quitte Montreal à $3 \mathrm{~h}$. p.m., pour Boston, par Lowell, Lawrence, ou Fitchburg; ausst pour New-York, par Springfield ou Troy, arrivant a Boston a 7.15 a.m., et New-York, par Troy $n .7$ a.m., et par Springfield a 12 p.m.

\section{TRAINS SE DIRIGEANT AU NORD ET A L'OUEST}

I'Express de Jour quitte Boston, par Lowell, a 8 h. a.m., Troy a 8.30 a.m., correspondant avec le dernier Train-Poste, qui laisse New-York a 4 a.m., et arrivant a Montréal a 9.20 p.m.

L'Express de Nuit quitte Boston a 6 p.m. par Lowell et New-York a 3 p.m., par Springfield et par Troy a 4 p.m., arrivant a Montreal a 8.t5 a.m.

Les Wagons Dortoirs Pullman sont at:tachés aux Trains Express de Nuit, marchant entre Montréal et Boston et Montreal et Sprinfield, et les Wagons Dortolr 
de Wagner, entre st. Albans et New-York par Troy.

Les Wagons Salons Pullman se trouvent sur les Trains Express de jour, entre Montréal et Boston.

Pour Billets, prix du Fret, s'adresser a l'Office du Vermont Central, 136, rue St. Jacques.

G. W. HOBART, Adminis. Gen. St. Albans, Vt., 3 Juin 1876.

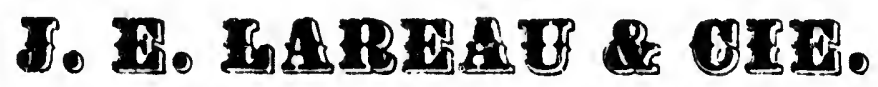
MARCHANDS a COMMISSION

39 et 41. Rue St. Paul (Près du Marche Bonsecours)

MONTREAL.

IEON DEROME

MAROHAND DE

VIANDES DE TOUTE. ESPECE

DE PREMIERE RUALITE

Etal No. 70, Mars'é Bonsecours MONTREAL.

Les viandes sont transportees à domicile.

F. HUTCHISON

VINS, EHCERIES, PROVISIONS, EtG.

72, Rue Notre-Dame, coin de la rue Bonsecours

IVOTVIIREALI. 
rk

nt

n-

a

t.

n.

J

J)

$\therefore$ - 120 -

$\rightarrow$

.

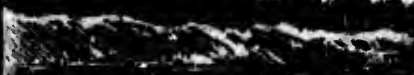

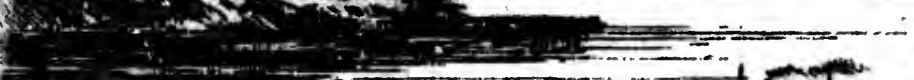

$=$

minosis

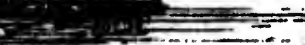

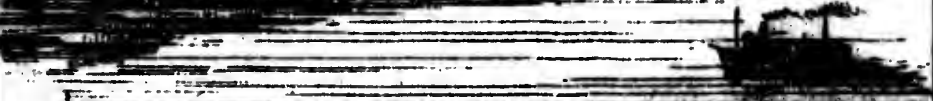

Fis.

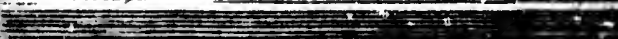
$-1=-10$

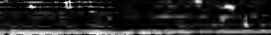
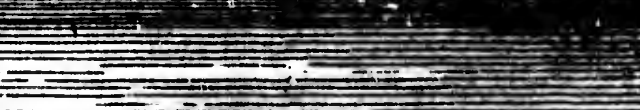

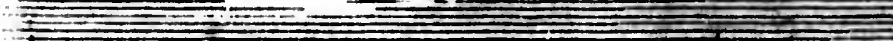

$\because: \div$

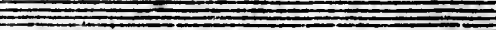

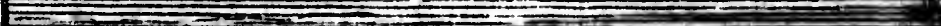

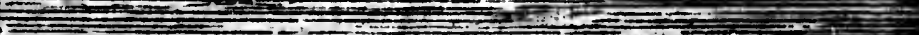

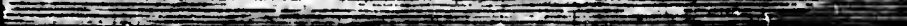

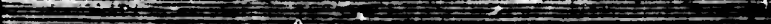

20

$=$

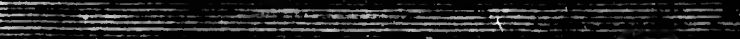




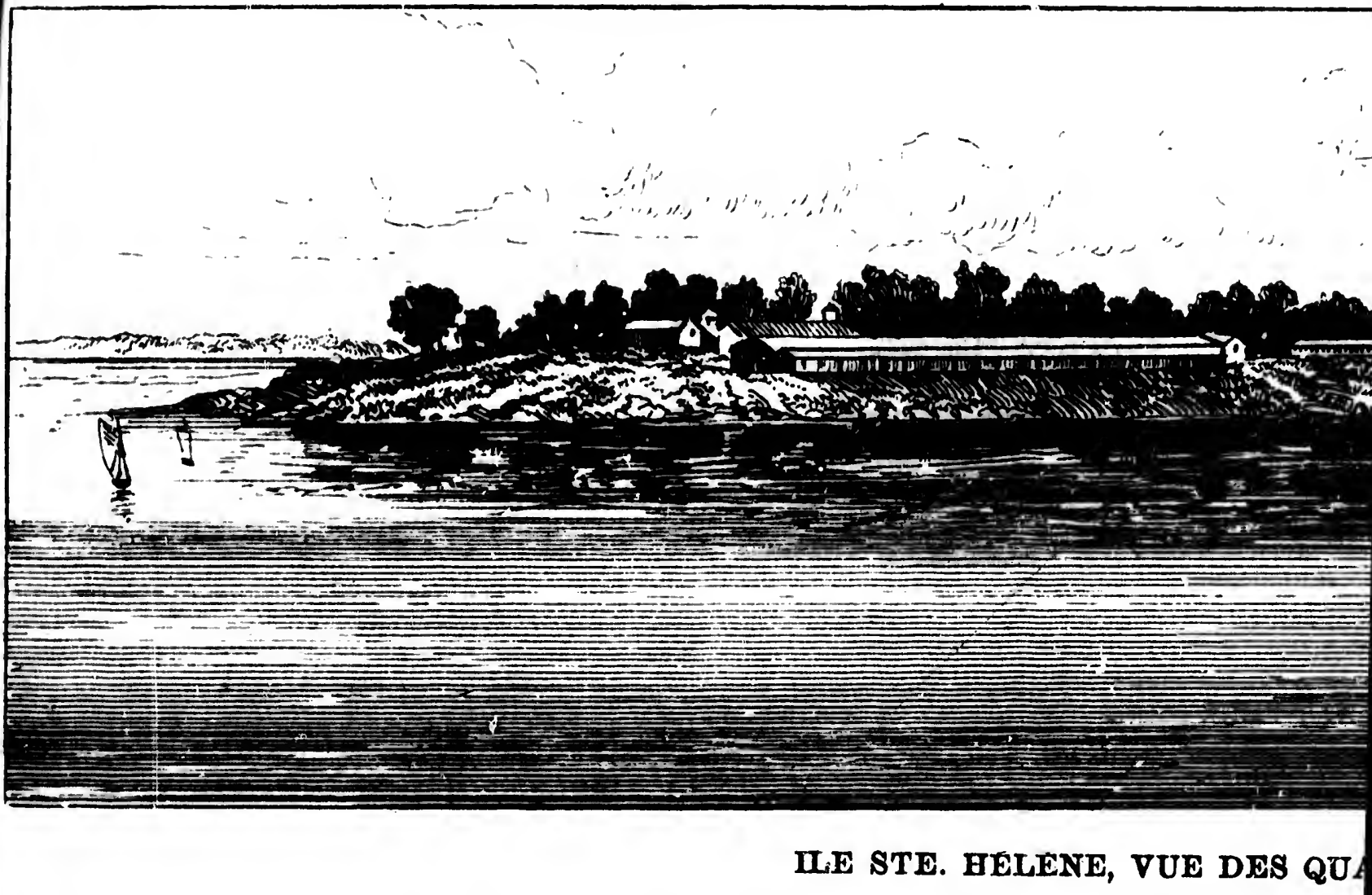




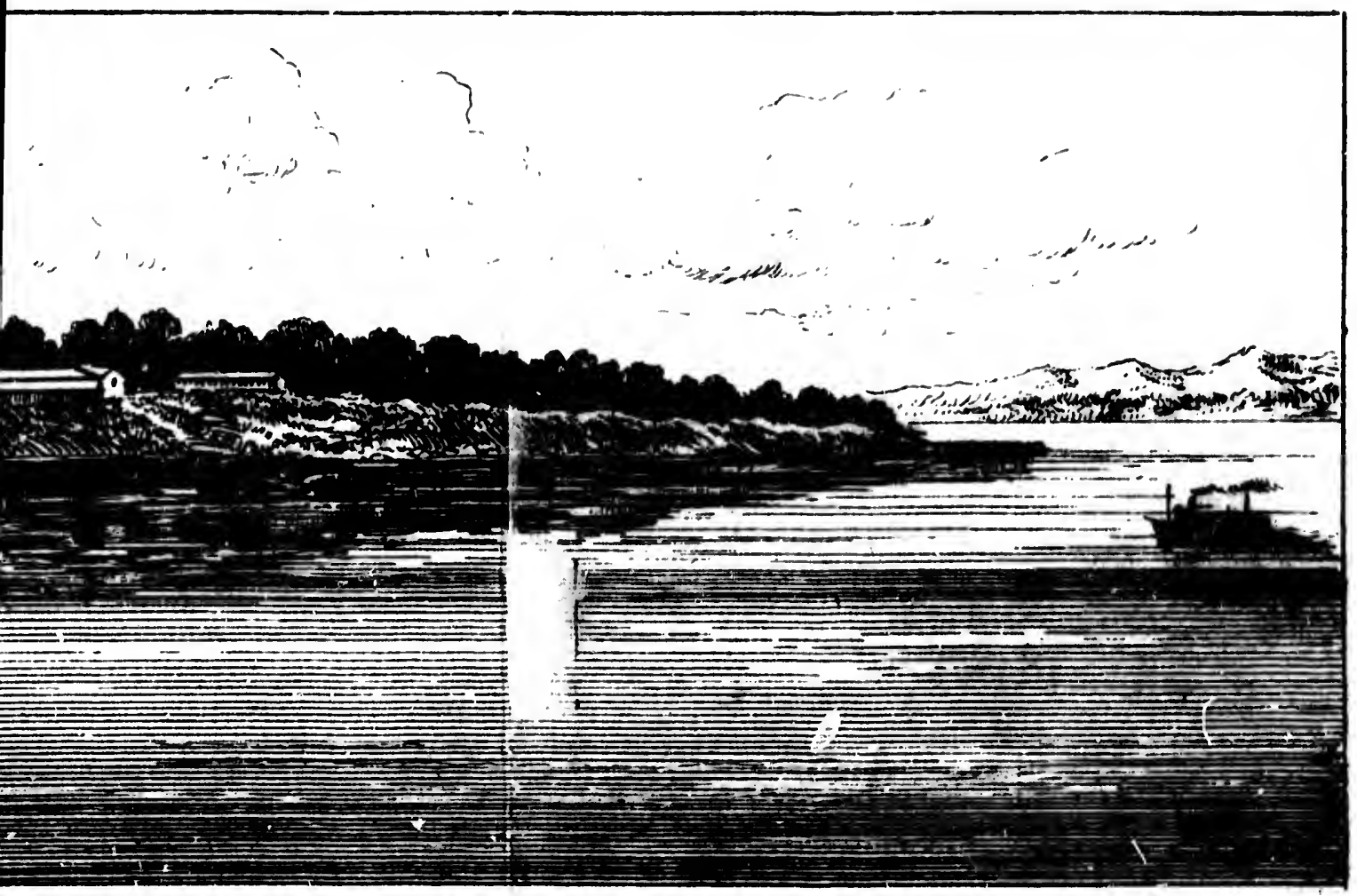

\section{VUE DES QUAIS MOLSON.}




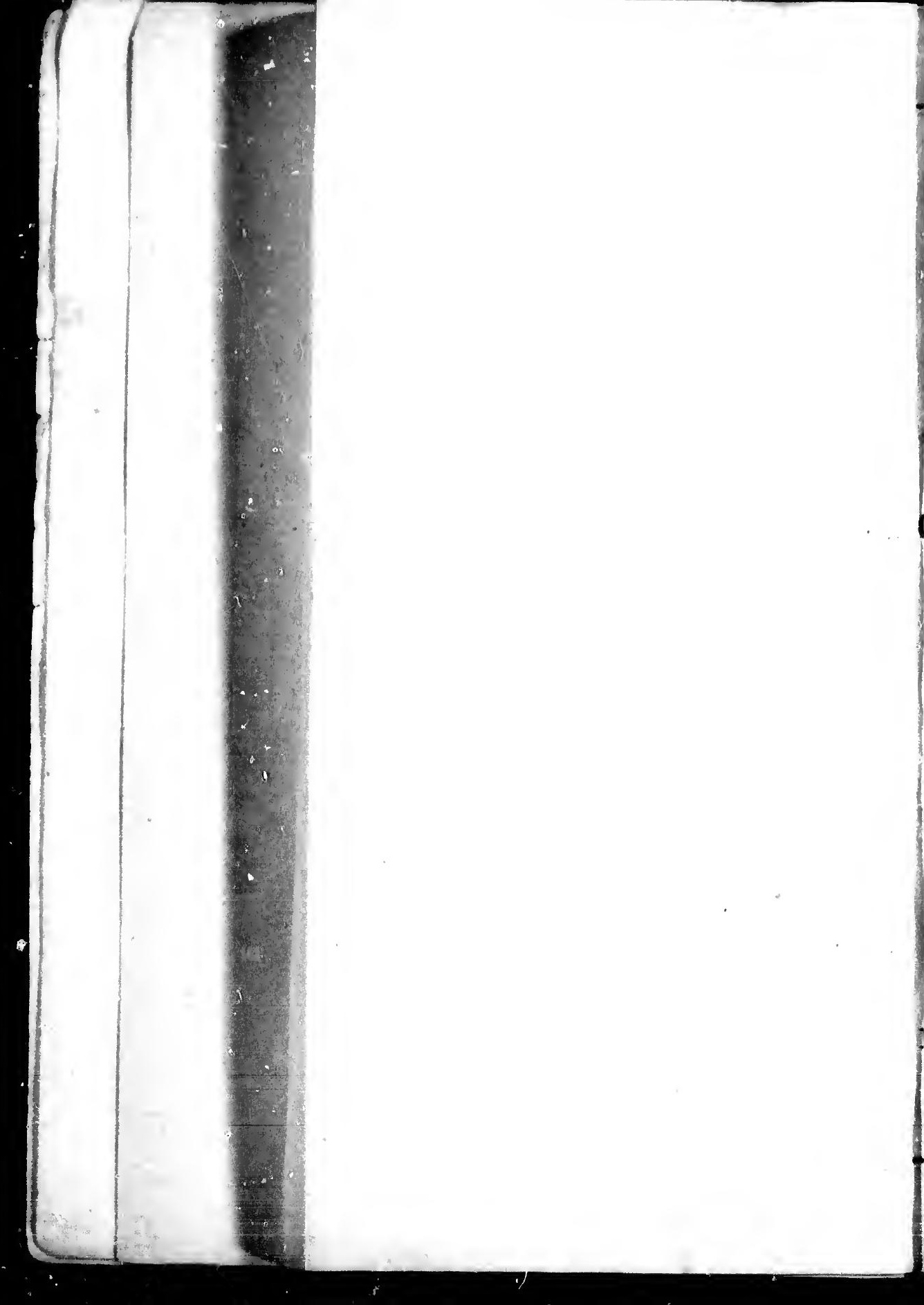


L'ILE STE. HELENE.

P'ASSÉ, PRÉSENT

ET

AVENIR.

Géologie, Paléontologie, Flore et Faune.

Eidition ornée de quatre gravures et d'une carte de l'lle.

PAR (MM.)A. ACHINTRE \& J. A. CREVIER, M.D.

3

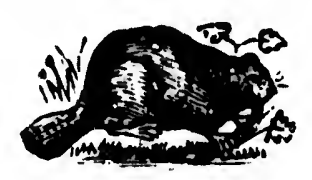

M O NTR A L

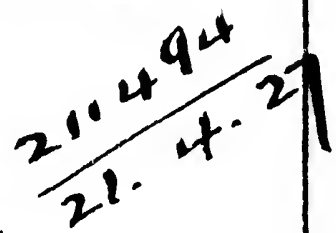

Des Ateliers du Journal LE National

$$
\overline{1876}
$$


Enregistré conformément à l'Acte du P’arlement du Canada, en l'année 1876, par A.uguste Achintre, au Bureau du Ministre d'Agriculture, à Ottawa.

Des Ateliers du journal LE NATron AE, 73, rue St. Jacques, inontréal. 


\section{A L'ILE STE, HÉLÈNE.}

Séduisante narade assise au seuil de l'onde, Tu naquis en ces jours oì Cybèle féconde, Aux caresses du ciel livrant son large sein, D'un hiouvel univers concevait le dessein. Comrae an joyau de prix l'opulente Nature Jeta sszes attraits une verte ceinture; Et, Gepuis, fière, chaste, en ces atours nouveaux, Ty unizes ta beauté dans le cristal des eaux.

\section{II}

Aux rrevìières rumeurs que le juur fait éclore, Quand thorizon s'empourpre aux baisers de l'Aurore, Que sta ehaque brin d'herbe un rubis tremblctant Réfléchic la splendeur de l'azur éclatant, Par un matìr. de Mai queiles grâces sauvages, Quels agrestes parfums exhalent tes rivages! Et comme ivre d'orgueil, à ton réveil jaloux, Le St. Laurent t'étreint de ses bras forts et doux ! 


\section{III}

Vienne la canicule, aimable encharteresse, Vers tes sentiers fleuris tout Montréal s'empresse, A l'heure où du zénith le brutal Messidor Aux blonds épis des blés lance ses fièches d'or. En tes halliers discrets cù chuchote la brise, Sur ta grève picrreuse où le flot vert se brise, A de bruyants pic-nics, aux couples amoureux, Tu verses la fraîcheur de tes massif́s ombreux.

\section{IV}

Mais l'Automne est venue, émérite coquette, Maquiller champs et bois des tons de sa palette: Améthiste, topaze, émeraude, saphir, C'est l'arc-en-ciel mobile au souffle du zéphir. Sous tes bois sans écho, plus d'enfants frais et roses, Plus de joyeux ébats, seuls des rêveurs moroses ; Te; arbres frissonnants, sur tes gazons jaunis, Voient leurs fe:illes tomber: les beaux jours sont fini!s A. Achintre.

Mor.tréal, 15 Mai 1876 . 


\section{HISTOIRE.}

CONSIDERATIONS GENETALES.

Comme ses sœurs aînées, les îles Britanniques dans la Manche; les Acores dans l'Atlantique; l'Archipel Grec dans la Méditerranuée; les Phillipines dans l'Océan Indien; les Sandwich dans le Pacifique; l'ile Ste. Hélène a aussi son Histoire, sa Flore et sa Faune.

Au triple point de vue géologique, zoologique et botanique, c'est un univers minusciale riche de tresors et de mervell. les. Au point de vue géographique, une des millionièmes parties du monde, laquelle possède ses chaínes de montagires, sa ligne de partage des eaux, ses caps, ses golfes, ses détroits, ses plaines, ses vallées, ses lacs et ses rivières, tout comme le plus vaste de nos continents.

Si nulle tribu indigène, nulle peuplade autochtone ne l'habite aujourd'hui, l'on ne peut jurer que certains vestiges ne révèlent un jour l'existence dex habitants primitifs de l'île. 
En attendant cette découverte, ce sol, qui vit tomber sous la fleche d'un ennemi embusqué dans ses taillis le corps de maints braves guerriers, prête maintenant ses pelouses et ses bosquets aux pacifiques promeneurs de la ville; et ce bois dont les échos répétèrent souvent le cri de guerre des féroces Iroquois, ligués contre Montréal enfant, retentit aujourd'hui des eclats de la joie bruyante des pics-nic et des rires sonures des bambins roses et joutlus. Accompagnés de leurs mères ou de leurs nourrices, tout ce monde, petits et grands, s'ébattent de companie et font la dìnette dans l'herbe fraiche et raute.

Au lleu des crânes sanglants qui servirent de coupes pour boire le sang chaud de chefs redouté, des os à deml-calcinés d'un festin de guerre, on ne trouve dans les buissons que les restes et les ustenlites de repas champetres : bouteilles, verres brisís, boîtes cie conserves éventrées, carcasses de poulets, os de gi.got et de jambons.

\section{SON PASSE.}

L'histoire de l'île Ste. Hêlène ne se perd point " dans la nuit des temps," ainsi que 


\section{llisloire.}

celle de certaines villes mystérieuses de l'Egypte ou de la Chaldée; elle est, ar. contraire, contem poraine du berceau de la colonie. En tant que science historique, le fait ranque pecit-être d'originalité, mais il y gagne en certitude, et quel que soit notre désir de poétiser l'orlgine de cette íle, devenue parc municipal, nous ne pouvons remonter plus haut qu'à liı découverte de l'Amérique.

Inutile donc de prevenir le lecteur que l'ile Ste. Hélêne n'eût jamais rien de commun avec celle de Calypso.

Bien loin qu'un Ulysse moderne ait ete retenu li par les charmes d'une Deesse, et ait oublié dans les délices de ce séjour une épouse fidèle, ce fut au con traire à l'amour conjugal que l'île dint son baptême.

Champlain, l'illustre fondateur de la colonie, devint le premier proprietaire de l'ile, qu'il paỹ en beaux et bons deniers, provenant de la dot de sa femme, Hélène Boule.

Par un reconnaissance aussi galante que juste, le nouvel acquéreur ne trouva rien de mieux que de donner à sa propriéte le nom patronymique de sa compagne: de li le nom d'ile Ste. Hélène. Ceci se passait 
dans les premières années du dix-septième siècle, en 1620 , lors du troisième v yage de Champlain su Canada.

Cette Helène Boule, qui avait épousé, it l'âge de treize ans, le Sieur de Champlain, avait vingt-deux ans lorsqu'elle arriva dans la colonie. A la mort de son mari, elle retourna en France et s'éteignit it Meaux, dans un couvent qu'elle avait fonde. Tel fut le sort de celle a qui l'ile Ste. Helène doit son nom.

Plus tard, en 1688, et après des mutations dont la chronique locale ne mentionne aucune trace, l'ile devint partie integrante de la concession faite par le Roi $t$ Charles Lemoine, qui fut en même temps anobli sous le titre de Sieur de Longueil.

Ce fut lui qui construisit sur l'ile une maison avec dépendances qu'on décora du titre de manoir.

Ce Charles Lemoine, homme de talent et d'execution, a ce que disent les recits du temps, etait arrivé dans le pays en qualité d'interprète ; il s'établit a Montréal en 1650, et s'y maria en 1654. Il eut quatorze enfants, dont scpt, du plus haut merite, ont été surnommés les Machabées Canadiens. Voici les noms de ces héros 


\section{Hisioive.}

qu:, a de" titres divers, illustrèrent leu: famille: d'Iberville, de Longueil, Ste. Hélène, de Maricourt, Francois de Bienville, Serigny, Louis de Chiteauguay, Jean-Baptiste de Bienville.

Sainte-Helène, ne en 1659 , celui dont le surnom suffirait, a défaut de prénom de la femme de Champlain, a baptiser gloriensement not.e pitite ile, prit une part active aux expéditions de son frère d'Iberville. La prise des forts Monsipi, Rupert, Kichichouane, divers combats sur mer, ont associé sa renommée à celle de son frere, d'Iberville, dont les exploits a la Baie d'Hudson sont demeures légendaires.

$\mathrm{C}$ z brave Ste. Hélène est le même qui, au siége de Québec par l'amiral Phipps, en 1690, abattit du premier coup de canon tiré de la citadelle, le pavillon du vaisseau amiral. Quelques jours après, Ste. Héléne tombait frappe a mort, dans une sortie poussee jusqu'a la Canardière.

Le titre du deuxième proprićtaire de l'ile se transmit in sa descendance, et finalement au colonel Grant de Blairfindie, qui épousa la dernière Baronne de Longueil.

Celle-ci vivait encore, il y a quelque 
trente ans, et habitait lin une sorte de résidence quasi-seigneuriale dont on n'apercoit plus aujourd'hui, a la partie orientale de l'ile et dominant la vallée St. JeanBaptiste, que les murs en ruines. Les jardins de l'habitation étaient magnifiques, pour le temps, et joulssaient d'ane grande réputation.

Le marl de la noble dame, le Baron Grant, in qui elle survécut, avait construit de son vivant, près de la pointe nord,nommée alors l'Eperon, des moulins que les anciens du pays se rappellent encore.

Il a fallu que de profonds changements se solent opérés dans le lit du fleuve, car le rapide écumeux qui faisait mouvoir les grandes roues hydrauliques, n'existe plus.

A propos de cette baronne de Longueil, derntere du nom, une anecdote.

Malgre ses deux ou trois quartiers de noblesse, la bonne dame, qui avait toujours pratiqué une des vertus les plus chères a la bourgeoisie, l'économie, etait devenue, en vieillissant, quelque peu bizarre. Ainsi pour ne point laisser perdre l'herbe et les baies des arbustes qui couvraient alors l'ilot situe vis-à-vis l'ile Sainte-Hélène, elle y plaça des pores en si 


\section{ilistoile.}

grand nombre que les deux propriétés en furent bientot infestees, et que l'ilot prit a cette époque le ncm, qu'il n'a cesse de porter depuis, d'île aux gorets !

En ville, le cheval de la Baronne fut durant quelque temps aussi célèbre que le Bucéphale d'Alexandre. Volcl comment advint cette réputation. Obéissant a ses ldées d'économie, la dame de Longuell avait attelé a sa voiture aux formes préhistoriques, un vieux cheval d'allures plus que tranquilles, et qui, pendant plus de quinze ans, avait été au service d'un boulanger.

Les gamins d'alors, $n$ seule fin de rire un peu et de faire endiabler la Baronne, ne manquaient jamais en rencontrant l'attelage de le falre arrêter dix ou douze fois dans la même rue. Il leur suffisait pour cela de crier Bread! A ce mot magique, lanimal, fidèle à ses anciennes habitudes, s'arrêtalt court, et ni le fouet, ni les hue! ne l'eussent fait avancer. Madame la Baronne se trouvait obligée cle descendre, et ce n'était qu'une fois remoniée que le quadrupède se remettail en marche. A quelques pas plus loin, les enfants-cet âge est sans pitié-criaient 
de nouveau Bread! et la scène se renouvelait an milieu des éclats de rire des passants et des voisins.

Durant tout le cours du lième slècle, aucun ouvrage fortifié ne fut éleve sur l'ile. Les récits du temps nous apprennent bien que Montreal s'entoura plusieurs fois de murailles et de forts, atin de se défendre contre les attaques des Iroquins, mais il n'est jamais fait mention de points fortifies sur l'île Ste. Hélène.

Dans les archives, cartes, plans, qui ont ete consultés en France jusqu'a ce jour, il ne se trouve rien non plus indiquant même l'existence d'un simple ouvrage de terre.

Le seul document que l'on posséde pour celairer ee polnt obscur de l'histoirr de l'ile, e'est un vieux plan déposé à Ottarar, que l'on regarde comme datant de 1759 ou 1760 , et ou se voit une espece de fortin. Cette redoute situee a la partie méridionale de l'ile, ne pouvait commander que la ville et le hassin en amont.

Comme entre les années 1755 et 1760 , Montréal avait été plusieurs fois menacé de se voir assiege par des forces venant du cóté de la Prairie, peut-être cet ouvrage 


\section{Ilisloire.}

est-il un reste d'anciennes fortifications passagères etablies durant l'une de ces epoques critiques.

Quoi qu'il en soit la version la plus accreditce est celle attribuant ces travaux au chevalier de Levis qui, dans des circonstances à jamais mémorables, passa la plusteurs semaines.

On apperçoit encore les ruines de ces ouvrages à l'extrémité de l'allée de Lévis, sur une terrace où une batterie d'obusiers brille au grand soleil, comme ennuyée de sa solitude et de son inaction.

Notre hypothèse demeure non-seulement la plus vraisemblable, car une batterie établie sur l'île, en face de la baie d'Hochelaga, pouvait causer de séricux dommages a la flotte anglaise qui aurait tenté de remonter le courant, mais elle a pour elle le souvenir d'un des episodes les plus dramatiques qui termina, sur ce modeste îlot, les désastres d'une campagne où la defaite fut, de l'avis de tous, aussi glorieuse que la victoire.

Voici comment les choses se passèrent. Le vainqueur de la batalle de Ste. Foye, le chevalier de Levis, ayant eté force d'abandonner le slége de Québec, a la suite 
de secours arrivés d'Angleterre, venait d'atteindre Montreal avec le reste de ses troupes.

Le surlendemain de son arrivee, trois corps d'armee anglais operaient leur jonction a quelques lieues de Montreal. Devant la superiorite de ces forces, plus de 20,000 hommes, M. de Vaudreuil, le commandant en chef, réunit un conseil de guerre, et après une longue déliberation, on se resolut a capituler, la lutte devenant une suprême folie.

Les termes de la capitulation furent acceptes; moins un pourtant: les honneurs de la guerre pour les troupes francaises.

A ce refus, le chevalier de Levis, saisi d'une noble indignation, ne voulut rien entendre, et sulvi de ses braves compagnons, environ deux mille hommes, se retira sur l'ile Ste. Helene, disposé a faire payer cher au vainqueur ses exigences. En son nom et au nom de sa petite armée, il protesta contre un refus injurieux pour l'honneur militaire.

Les conseils de son chef M. de Vaucireuil réussirent a la fin et le décidèrent a une obéissance qui, dans les circonstances, de- 
verait une malheureuse mals fatale necessité. La reddition des armes devant s'opérer le lendemain, le chevalier de Levis convoqua ses troupes pour une heure assez avancée de la solrée.

C'etait par une nuit humide et froidé de la fin de septembre; de gros nuages gris, fouettes par la bise d'automne, ondulaient comme une houle sur le ciel, dont on apercevalt parfois un pan etoile a travers les dechirures des nuees; de blanches vapeurs commencaient a monter du fleuve. Au loin, vers St. Lambert et Montréal, l'eclat de certaines lueurs piquaient le volle de brume de taches jaunatres: c'étaient les feux des Grands Gardes des camps anglais.

De grandes masses noires, coupees par intervale d'eclairs intermittents, se meuvent dans l'om bre et déroulent leurs longs anneaux dans les fourrés du bois, pour marcher ensuite d'un pas lent et cadencé sur la route principale de l'ile: ce sont les régiments qui déflent par compagnie, et les épées nues des chefs dont la lame brille sous un rayon de lune.

Tout a coup un roulement de tambour, roulement prolongé, retentit dans les ténèbres; un autre lui succède, suivi de 
sons mats, secs et sourds ; chaque coup de baguette ressemble a un sanglot; cela frappe l'oreille mais tombe sur le cœur.

Le dernier peloton vient de se former $a$ la gauche de l'armée. Les troupes sont rangees en ordre de bataille. En avant de leur front, un vaste brasier où flambent des trones d'arbres, éclaire les mâles figures d'un groupe d'officiers, au milieu desquelles se détache pâle et crispé le visage du chevalier de Lévis.

Au mouvement decrit par l'épée du commandant en chef, les tambours de toutes les compagnies éclatent a la fois, comme un coup de tonnerre; puis les roulements diminuent, s'affaiblissent, pour moduler ces gémissements lugubres et sourds au milieu desquels les fifres jettent, semblables a des cris nlaintifs, des notes entrecoupées et stridentes.

A ce moment, trols hommes sortent des profondeurs des rangs et se dirigent vers le brasier; ce sont les porte-etendards ce chacun des regiments. Tous trols tiennent d'une main ferme, mais le front ineliné, la hampe du drapeau dont les plis, déchiquetés par la mitraille, retombent en lambeatux. 


\section{IIistoire.}

A un second signal de l'épée du chevalier de Levis, les officiers abaissent vers le feu, quil fait son ouvre, l'image de la France militaire.

Pendant que s'accomplit cet holocauste de l'honneur, les tambours battent aux champs, les troupes présentent les armes, les officiers saluent de l'epee; on dirait l'éclat d'une parade à St. Germain, sous les regards du roi. Puis, lorsque la dernière fleur de lys eut crépité, lançant vers le clel, sous forme de larmes de feu, une suprême protestation, un cri, un seul, formidable rumeur, joillit a la fols de toutes ces poitrines: Vive la France!! Et les échos du rivage voisin répetèrent: Vive la France!!

Le chevalier de Lóvis venalt de brùler ses drapeaux plutôt que de les rendre a l'ennemi.

Tout etait perdu pour la France au Canada, tout, "fors l'honneur," comme l'avait ecrit jadis de Pavie le plus chevaleresque des Valois.

Vers 1807, la guerre menacant d'éclater entre les Etats-Unis et l'Angleterre, celleci acheta de la famille de Longueil l'ile Ste. Hélène, et y établit des ourrages de dé-. 
18 L'ile Sle. ilikine.

fense, dont dGux blockaus ou redoutes en bois, avec une couverture susceptible de porter de forts canons. Ces constructions, aux murs percés de meurtrières, commandent la baie d'Hochelaga.

Un de ces fortins, qui existe encore sur le mont Wolf, ayant servi de poste d'observation durant la première invasion fénienne, est connu sous le nom de Feniun Post.

A la même époque, on eleva aussi aux lieux ou ils existent encore une caserne, une poudrière, un magasin militaire, des ateljers, quelques cottages destinés aux logements des officiers, le tout a grands frais.

Un peu plus tard, on construisit une prison militaire qui fut détruite par l'incendie en 1848.

Au moment de la catastrophe, qui survint au mois de decembre, alors que le fleuve charriait d'enormes glaçons, un nommé Medar Dufresne, aujourd'hui pensionné du gouvernement, qu'il a servi trente-quatre ans en qualité de convoyeur a l'île, reçut l'ordre de faire traverser le fleuve a quarante prisonniers militaires chassés par l'incendie. 


\section{Hisloire.}

Echapper aux flammes pour tomber au milieu des banquises, c'était vraiment, purger sa détention, quelque méritée qu'elle fût. Le brave homme nous a raconté que, plusieurs fois, prndant cette périileuse traversée, il dât son salut au dévouement des prisonniers qu'il transportait, car les glaces faillirent falre chavirer l'embarcation. Alnsi ce furent les détentis qui sauvèrent leur gardien.

Le surveillant en chef de cette prison était un nomme W. Nigth, que l'on décorait du titre pompeux de Gouverneur.

Son château récuit en cendres, le même personage resta logé dans l'île jusqu'à ces années dernières, en qualité de gardien général des magasins militaires.

A partir de cette prise de possession, l'ille devint une espèce d'apanage de la couronne, de fief militaire; les piqueniques, les parti $u$ s de pêche et de chasse, les promenades au clair de la lune furent interdits; on éleva sous le nom de magasins militaires, de casernes, ces constructions massives sous les voutes desquelles s'entassaient les poudres, le matériel de l'artillerie: affuts, canons, boulets, obus, etc., etc. 
Une petite garnison composee d'un étatmajor fixe et d'un détachement d'un des corps stationnés a Montréal, veilla:t nuit et jour sur les trésors confiés a sa garde.

Chaque année, depuls cette époque et jusqu'en 1870, le régiment anglais en garnison a Montreal, envoyait successivemont chacune de ses compagnies camper dans l'ile. Elles s'exercaient la au tir a la carabine; et, par ce changement d'air et de régime, se refaisaient une vigueur nouvelle.

L'ile Ste. Helène a vu jusqu'à deux régiments étendre les blancs pavillons de leurs tentes sur ses tertres reverdis.

S. A. R. le Prince Arthur, durant son stage d'officier, y a passe quinze jours avec sa compagnie. Une petite :lottlle d'embarcations, appartenant au Commissariat angiais, servait au transport des troupes et des approvisionnements de toute espece. Quant au service des postes, c'est notre chaloupier et sauveteur bien connu de Montréal, Joe Vincent, quj, entrepreneur du contrat, remplissait les fonctions de iacteur quotidien, et celn quelque temps qu'il fit.

A la suite du retrait des troupes anglaises 



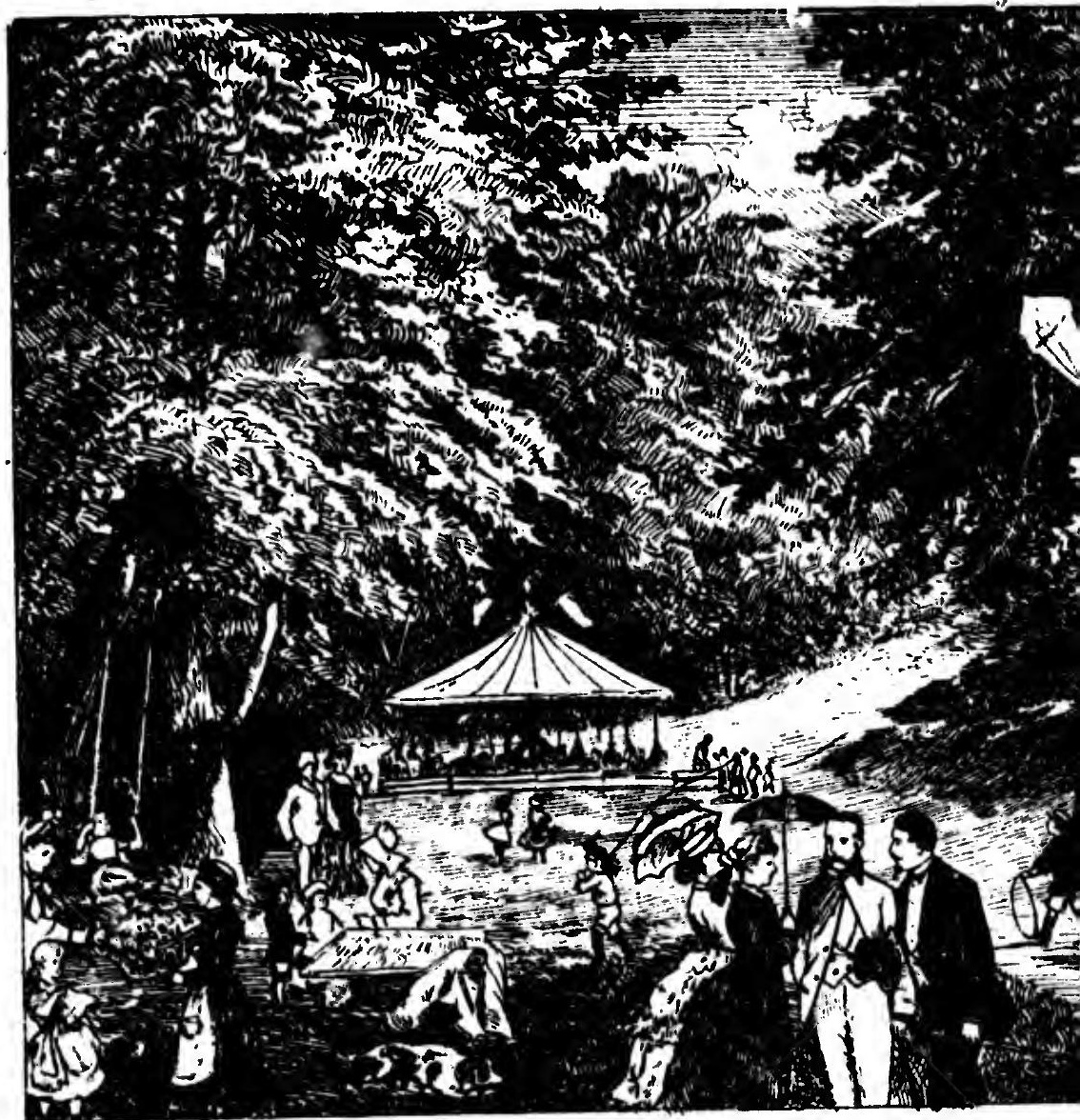




\section{Histoire.}

du Canada, l'ile fit retour au gouvernement canadien et continua a servir de prinuipal dépôt d'armes, etc., pour l'usage de la millce volontalre des districts Nos. 5 et 6 , dont les quartiers-généraux rênis sont établis a Montréal.

A la fln de l'été de 1870, les deux compagnies de dépüt organisées, au printemps, pour le service de l'expedition de la Rivière-Rouge, n'étant plus requises pour cet objet, furent envoyées tentr garnison l'une a Kingston, l'autre a l'île SainteHélene.

L'année suivante, un détachement des artilleurs volontaires de la Batterie "B," de Quebec, prenait possession de la partle de l'ile que le gouvernement militaire de la Puissance s'est réservée, partie qu'entoure une palissade assez haute, et derriere laquelle croissent les plus belles futales du parc.

Le depart des tronpes anglaises du pays lui fit perdre sa physionomle belliqueuse; une partie du matériel fut transportée en Angleterre, l'autre vendue a l'encan; les soldats s'embarquerent, et sauf quelques vénérables canons préposés aux salves des fêtes officielles, ou aux saluts régle- 
mentíires accordés aux personnages, l'ìle n'a plus l'aspect d'un camp ou d'une forteresse, mais celui d'un bois tranquille et frais.

Jalouse de ses prérogatives, et redoutant pour Montréal nous ne savong trop quel slége fantastique dans l'avenir, l'administration militaire fit longtemps la sourde oreille aux demandes que notre conseil municipal ne cessait de lui adresser au sujet de cette localité, qu'il voulait transformer en jardin public. Les negociations aboutirent enfin, et le gouvernement fedéral consentit a donner a la ville l'usufruit de cet immeubie, quitte a réclamer son bien a la première alerte l'unc invasion indo-chinoise.

Espérons que ce désastre, bien que possible, ne se réalisera poini, et que Montréal deviendra, par droit de prescription, proprietaire d'une ile aussi inutile a sa défense stratégique, qu'avantageuse aux plaisirs et à la santé de sa population. 


\section{GÉOLOGIE.}

ORIGINE E'T FORMA'TION UL L'ILE.

si l'ile de Montréal, aux temps prênistoriques, surgit tout d'un coup cies profondeurs de la mer silurienne, a la suite d'un de ces cataclysmes qui ébranlent un continent et en bouleversent les traits, l'ile Ste. Helène, elle, est de plus modeste origine. Snn berceau ne fut point entoure des fiammes bleuâtres, des panaches de fumée, des flots de lave, et des formidables détonations qu'un volcan laisse échapper de ges tlancs convulsionnés.

Beaucoup moins eclatante, son apparution ne fut point instantanée, et sa croissance $n^{\prime} e m p r u n t e$ rien à ces phénomènes des premiers jours du monde. La forme et les matériaux de l'ille ste. Hélène sont dus a la lente accumulation des detritus de toute sorte transportés par les eaux du fieuve, qui, peu à peu, ont formé, à l'aide des débris arrachés aux calcaires de la vallée du st. Laiirent, de quelques blocs transportes de points fort eloignés, du Saguenay, du lac Champlain, ont formé, disons-nous, l'île actuelle. 
Chaque annee et chaque four, notre petite ile augmentait son volume des debris de roches que la glace et, les eaux charrient; de nouvelles couches de vase, de sable, de pierres et de gravols, venant s'ajouter aux premtères, exhaussaient lentement son niveau, etendaient ses contours, et, un beau matin, notre gracieuse adolescente émergea du setn des eaux.

\section{SoN AGE.}

De même que la viellesse se reconnait chez les êtres vivantsa des signes certains, ainsi l'age des terrains s'atteste par d'irrecusables témoignages géologiques.

Entre la formation de l'ile de Montreal et celle, beaucoup plus récente, de l'ile Ste. Helène, les observations de la science comptent un immense periode de temps.

On suppute ces longs intervalles en comptant les siécles, les milliers d'annees parfois qu'a exigees la formation de certaines couches. Dans le cas particulier qui nous occupe, c'est en calculant le temps necessaire a la formation de couches absentes dans l'île Ste. Helène, et présentes dans l'ile de Montreal, que les 


\section{Giologie.}

savants ont pu établir l'acte de natssance des deux sœurs.

Ainsi l'ile de Montréal comprend six couches de terrains, disposes comme les feuillets d'un livre; savolr, en procedant de bas en haut: les formations de Chasy, de Bird's Eye, de Black River, de Trenton, d'Úıica. Cette dernière, la plus jeune de toutes, est celle sur laquelle coule le St. Laurent, et qui forme le soubassement même de l'île Ste. Hélène. Par l'excessive lenteur que chaque couche met a deposer son sediment, on peut approximativement calculer le nombre d'annees qu'a demandees chaque formation.

Le signe et la preuve de l'age respectif des deux iles se montrent dans la partie occidentale de l'île Ste. Helène, $\boldsymbol{n}$ fleur de terre, sous la forme de deux petits bancs de rochers de la formation Helderberg.

Les fragments de cette couche laissent au-dessous d'eux, lorsqu'on veut connaitre les terrains qui la séparent de la coucl:e la plus superficlelle de l'ile de Montreal,six formations differentes ayant une epaisseur de plus de 2,000 pleds. 
En commencant de bas en haut, le nom et l'ordre de ces terrains sont les suivants:

\author{
Hudson-River. \\ Médina. \\ Clinton. \\ Niagara. \\ Guelph. \\ Onondaga.
}

Cette superposition donnerait à l'ile Ste. Helene environ deux cent mille années de bénéfice sur son aînee l'ìle de Montréal. Comme l'on voit, et toute coquetter'se a part, cela vaut la peine d'etre compte.

Les roches calcalres de la formation Helderberg situées su: l'île, contiennent bon nombre danimaux et de plantes fossiles dont les noms, la monographie et la classification, œuvre de notre savant paleontologue canadien, M. Billings, se trouvent ci-apress, au chapitre Faléntologie.

A ce propos, une citation, dont l'oubli accuserait autant notre ignorance que notre défaut de patriotisme:

“A notre pays revient l'honneur d'avoir pu signaler le premier être vivant connu jusqu'à ce jour pour avoir habité le monde, l'Eozoon Canadense, Dauson. Sir IV. Logan avait le premier fait con- 
naître le terrain Laurentien, rcohe métamorphique qui repose immédiatement sur lc granite et oì se trouve l'Eozoon, et M. T. W. Dawson, principal de l'Université Mc.Gill de Montréal, est celui qui le nomma et le décrivit en 1865 , sur des échantillons recueillis au Grand-Calumet et à Grenville. C'est dans la seigneurie de la Petite-Nation, sur le z̧e lot du rang St. Pierre, qu'on a trouvé depuis les échantillons les plus parfaits de ce fossile.

"La découverte du plus ancien terrain stratifié connu, le Laurentien ế celle de l'Eozoon, jetèrent un tel émoi parmi le monde savant, que le célèbre Sir Chs. Lye!l, ne craignit pas d'avancer, à l'égard du dernier, dans la réunion de l'Association Britannique pour l'Avancement de la Science, tenue à Bath en 1864. que c'était sans contredit la plus grande découverte géologique de son temps." (1) :

Ce que l'ile offre aussi de remarquable, ce sont $l \in$, blocs erratiques disséminés 'ans l'intérieur et sur les contours de ses rivages. A voir ces masses posées dans toutes sortes d'attitudes, les unes de couleur sombre, les autres affectant des tons fauves ou gris d'argent, on les prendrait, pour des molosses accroupis, gardlens jadis vigllants, mais aujourd'hui immobiles de l'île, et qu'une divinité Jalouse aurait métamorphosés en rochers.

(1) Naturaliste Canadien, Sept. 1873, (l'Abbé Provancher.) 
Quant a la manière dont ces masses, véritables curlosité gé riogiques, ont etê transportées sur l'ile, ordinalre propre aux périodes anciennes, par le charrol des glaces.

Il existe partout en Canada, comme alleurs du restc, des milliers d'exemples de ce genre de charriage.

Ainsi, pour ne citer qu'un cas, on peut voir, encore aujourd'hui, incruste dans le flanc occidental de la montagned'Yamaska, a une hauteur de plus de cinq cents pieds, un enorme bloc de di rant au-delin de mille pieds 3.

Cette roche erratique provis at d'une montagne de fcrmation identique sit $x e ́ e$ sur les côtes du Labrador. C'est de cette distarce de trois cents lieues que les glaces l'ont charriee a Yamaska.

THR RAIN DE FOR ATION. Nature du terrain.-Cong nerat a pâte, dolomitique férug:ueuse.

Résultat donné par l'analyse chimique du conglomérat:

Carbonate de Chaux...... 58

id. de Magnésie.... 17

id. de Fer

Sable ou silice insoluble dans les acides........ 42 
Espèces des roches contenues dans le conglomérat dolomitique de l'ile:

Grès blanc, (formation Potsdam.)

Grès rouge, (formation Médina.)

Schistes ou ardolses

Schistes noirs, (formation Utica.)

Calcaire, (formation Trenton, Chasy, Hudson River.

Ces divers fragments, arrondis ou angulaires, ont une grosseur val lant entre cinq a six pouces; quelques biocs atte:gnent un volum in 15 a 30 tonnes.

ROCHES METAMORPHIQUES.

Dolerites, Trachytes, Diorites, Quartzite, Leptynite, Pegmatite, Agenite, Augite, Gneis, Porphyre noirà tre et jaunâ tre, 'I rapp, Silex, Gneis grénatique, etc., etc. Cristaux de Feldspath, de Pyroxène, d'Hornblende, Jaspe rouge, noir, etc., etc.

Autres minéraux que l'on trouve dans l'île et sur ses rives:

Quartz vitreux.

id granulaire.

id compacte.

id caverneux.

id hyalin.

Protognie.

Silex noir.

id gris. Albite.

Schiste argileux.

id micacé.

Fitc., etc.
Calocire carbonifêre.

id cloriteux.

id siliceux.

id argileux.

id conchilifère.

id micace.

id talqueux.

Silex jaune.

id corné.

Labradorite.

Schiste siliceux.

id pyriteux. 
30

L'ile Ste. Héline.

FORMATION HEI.DERBERG.

A l'est de l'ile, au pied du rapide, deux bancs de calcaire fossillfères. Iargeur, 10 pieds; longueur, 25 a 30 pieds, coupés dans la direction sud-ouest par deux dykes paralleles de Dolérite.

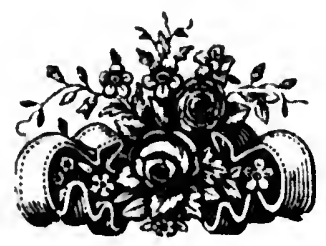




\section{PALÉONTOLOGIE.}

(Science des plantes et des animaux fossiles.)

C'est par la présence des plantes et des animaux fossiles au sein des pler res ou des couches qui forment les diverses ecorces de notre globe, que le géologue, arme de son marteau, de sa pinve et muni d'une loupe, reconnaît et constate la nature des roches et l'espèce des terrains.

La formed'un animal, l'empreinted'une plante, les scories des volcans, les traces de grains de pluie marquées sur la vase plastiqua de rivages, postérieurement recouveris d'autres couches, constituent autant de faits et d'événements qui servent à etablir avec certitude la paleontologie, cette préface de l'histolre de la terre.

Telle espèce de coquillage, telle famille de plantes, servent a reconnaître t,elle ou telle couche sédimentaire; car les formations ignees, qui constituent les assises $d \dot{u}$ globe, n'en renferment aucune.

Les fosslles de l'ile ste. Hélène ne se 
rencontrent que dans les fragments de calcalre de la formation Heldelberg, et dans les quelques blocs érratiques (1) déposés dans l'interieur et sur les grèves de l'ile.

Le cadre de cet opuscule ne nous permettant pas de donner la nomenclatiure lee fosslles contenus dans chaque espèce de terrain, nous renvoyons les personnes qui seralent désireuses de les connaître, aux ouvrages spéciaux de géologie, et plus particulierement, pour ceux traitant de l'ile de Montréal, aux œuvres de feu Sir W. Logan et de M. Blllings.

\section{MOLIUSQUES.}

(Animaux marins, invertébrés, sâns membres articules, a chair molle.)

Mollusques, Brachiopodes.

(Ayant des bras au lieu et place des pieds)

1. Rkynchonella mustistriata.

2. id. Wilsoni.

3. Straphomena punctulifera.

4. Pentamesas galeata.

(1) Rochers isolés d'ordinaire que les glaces ou les ealix ont charriés en certains lieux. 


\section{LITOGRAPHIE! TYPOGRAPHIE ! GRATURE!}

Impressions de toute sorte, depuis la Tete de Compte la plus unie, jusqu'a la Pancarte la plus élégante

A DES PRIX MODERES AU BUREAU DE

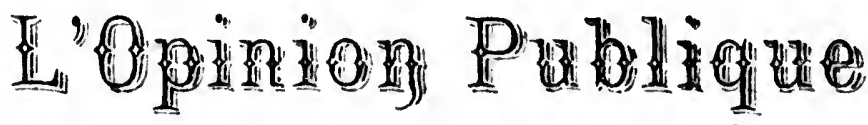
5 \& T, RUE BLEURY, MONTRÉAL.

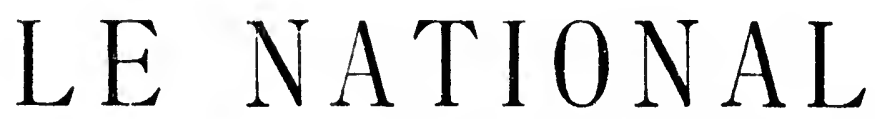

\section{SEUl organe libéral a montréal,}

Circulation 5.000 ; Est reçu dans toutes les paroisses du Canada.

Contient toutes les nouvelles les plus récentes du monde entier.

Abonnement à la Ville, à l'annee, - $\$ 8.00$ “ à la campagne, (port payé) $\$ 6.00$

Le NATIONAL est le seul journal frangais qui publie une Edition Hebdomadaire de 8 pages, au prix de $\$ 2.00$ par année.

73, RUE ST. JACQUES. 


\section{CHEMIN DE FER \\ DU
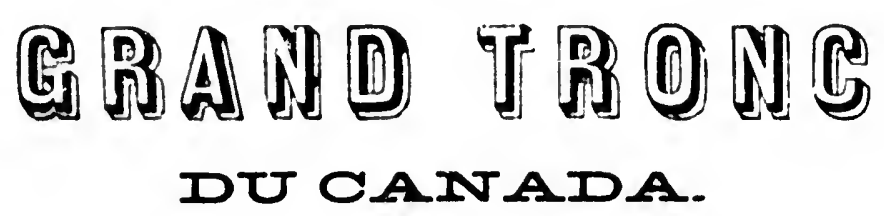

Chemin de Fer du Grand Tronc, Grande Ligne directe entre l'Atlantique et le Pacifique. Fait des arrangements a la convenance des compagnies de touristes pour toutes les parties de ce continent, pour les excursions, petites ou srandes, aux environs de Montréal, et sur le parcours de la ligne du Grand Tronc : Excursions, Bains de Mer, Centenaire; ainsi que pour l'achat des billets d'excursions, en vente aux nombreuses agences de la Compagnie en Canada et dans les Etats-Unis d'Amérique.

Service direct de wagons Pullman sur les lignes de Chicago, Boston, et tous les centres d'excursions.

JOSEPH HICKSON, Administrateur-Géneral.

W. WAINRIGHT,

Agent Général des Passagers. 



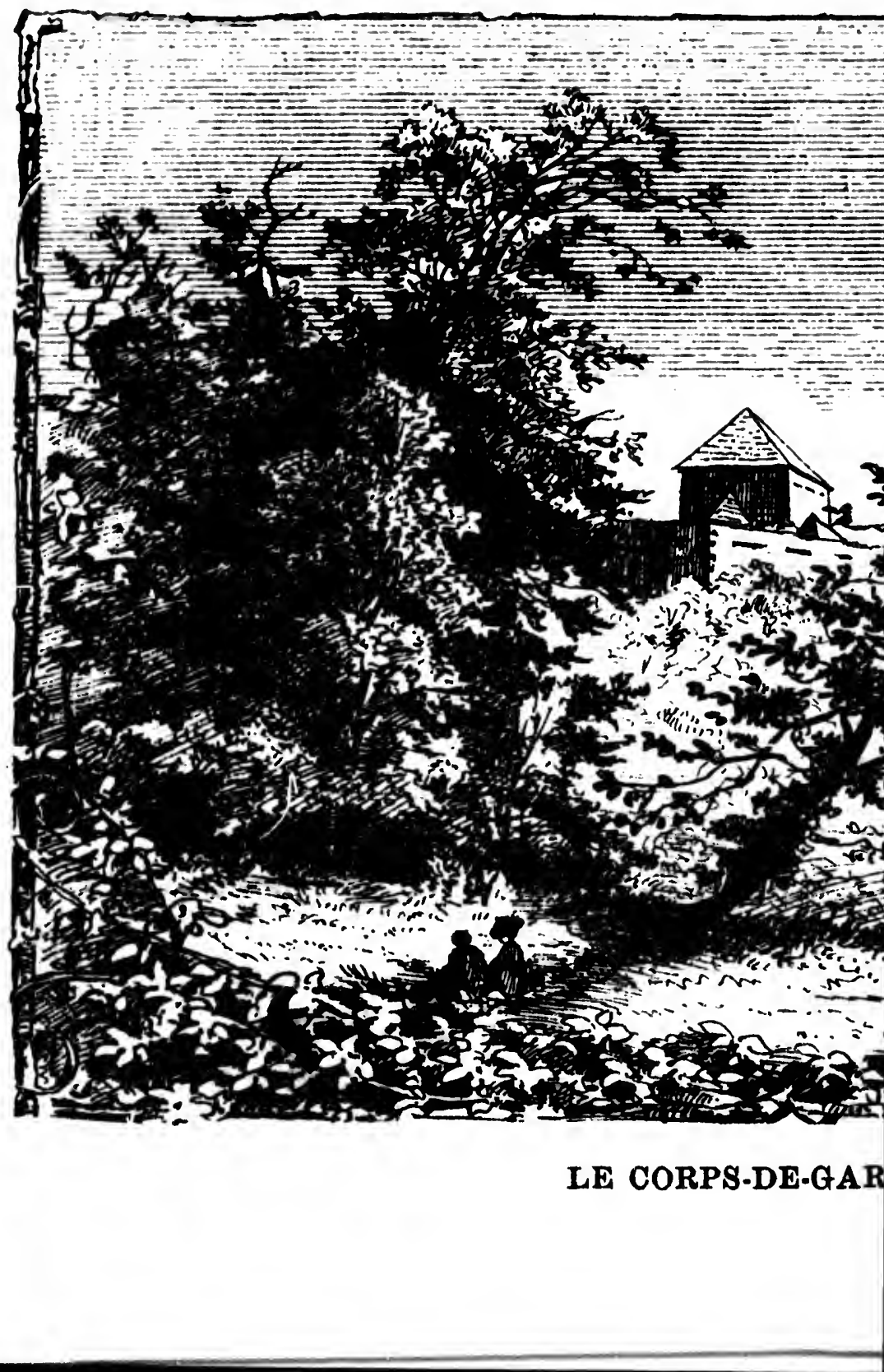




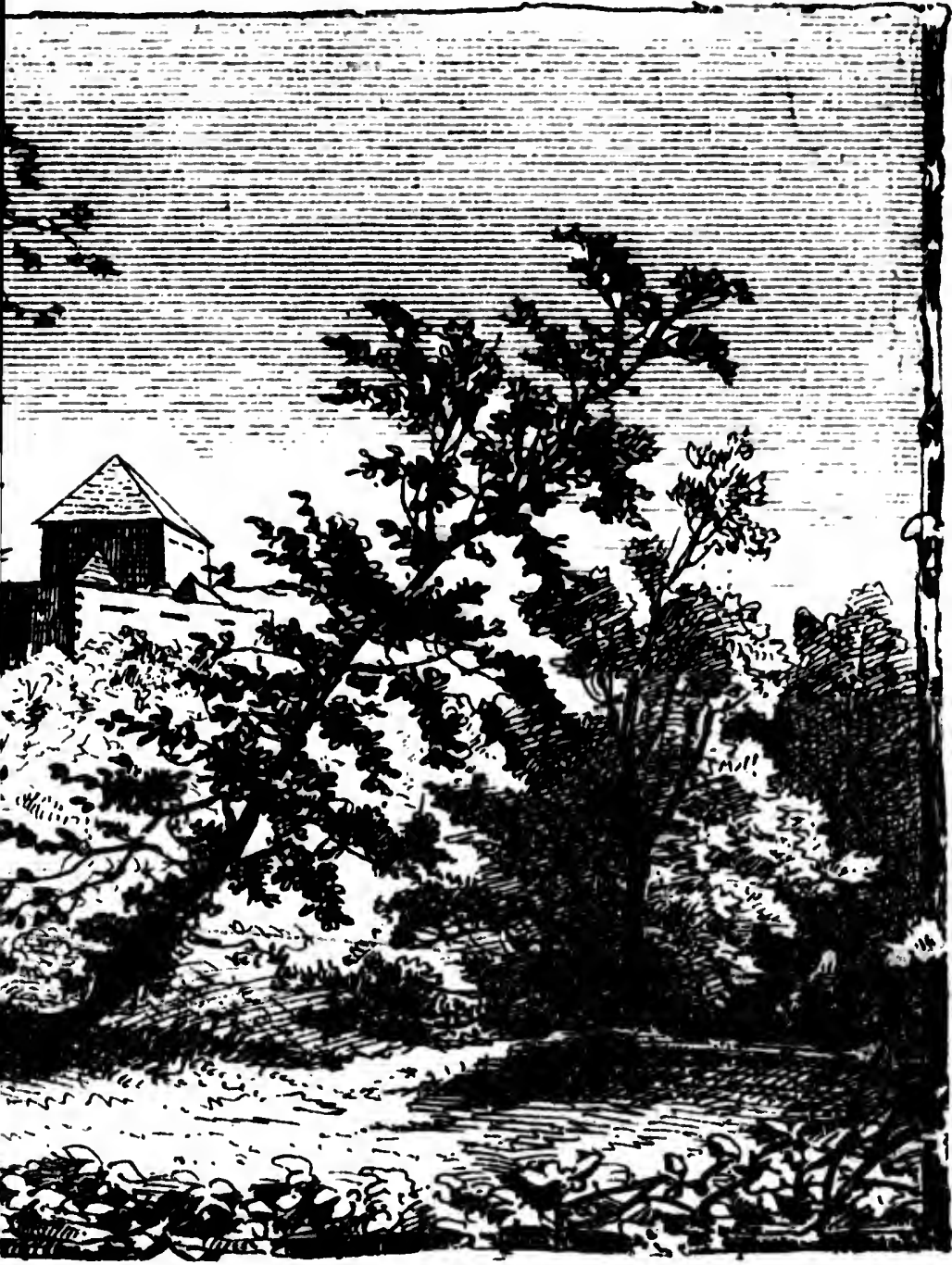

ORPS-DE-GARDE. 


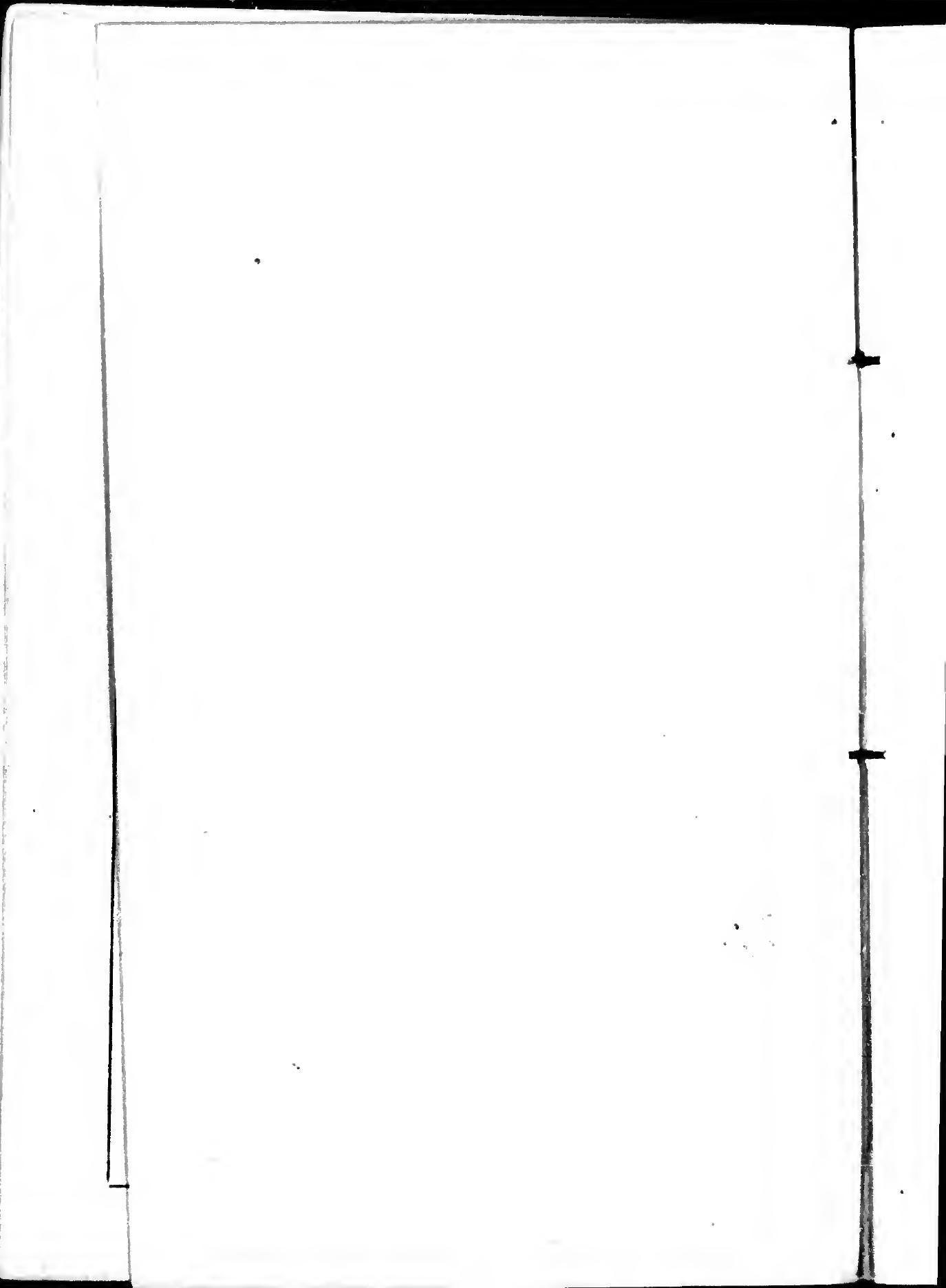




\section{Palromlolongir.}

5. Lingula Artemis.

6. Sy irifera arenosa.

7. Chonetes melonica.

s. Chometes radiata.

9. Atrypa reticularis.

10. Leptoceolia flabilites.

11. Discina grandis.

12. Ortis oblata. Athyris bella. Spirifera peslamellosa.

Mollusques Lamellibranches.

(Ceux dont le corps est muni de plusieurs lamelles ou feuillets; telles sont les huitres, les moules et les coquilles bivalves d'eaux douces.)

13. Anondontapnis ventricasu.

14. Cardium Belli.

Mollusques Gasteropodes.

(Qui ont les pieds sous le ventre; tels sont les colimacons et les limaces.)

15. Helopea Ida.

16. Comularia Mursayji.

Mollusques Céphalopodes.

(Qui ont les pieds places autour de la tête; tel sont les Argonautes, les Poulpes ou araignees de mer.)

17. Orthocerus rigidium. 


\section{Crustacés.}

(Ayant une envelope dure, coriace, testacee; tels sont les hornards, les ecrevisses et les cloportes.

\section{Crustacés Trilobites.}

\section{(A trois lobes.)}

\section{Dalmanites Lyelli.}

Il y a encore une aitre espèce trèscurieuse de ce genre, mais on ne l'a pas encore découverte dans l'île; c'est l'Eurypterus remipes.

\section{Zoophytes.}

\section{(Animanx.-Plantes.)}

Tels sont les coraux et les madrépores. 19. Farosites Gothlandica.

20. Zaphrentis lamellosa.

Parm! les blocs, et les roches calcaires, crratiques de l'île, on rencontre des fossiles appartenant aux différentes formations du terrain silurien du Bas-Canada; tels sont les fossiles des formations calcifères de Chasy, de Black River et Birdseye, de Trenton, d'Utica et de Fudson River. 


\section{LE PRÉSENT.}

Nos connaissances historiques concerna.at l'ile Ste. Hélène remontent a quelques annees, et tiennent $a$ une rencontre singulière que nous fìmes sur ses rives.

C'était en plein mois de janvier, un dimanche, et par une de ces magnifiques journees d'hiver ou, dans le ciel d'un bleu tendre, brille un clair soleil. L'air froid, sec et vif cinglait les visages comme une volee de menu grésil, et les colorait de ces tons frais et roses qui donnent au. promeneurs en cette saison, un air de sante robuste, et particulièrement au teint des femmes ure blancheur et, un eclat si appétissants, qu'on serait iente de mordre a leurs joues comme a la chair ferme et luisante d'une pomme.

Sur les chemins balisés qui, de Montréal ${ }^{6}$ rayonnent vers les villages de la rive droite du Saint-Lairent, les sleighs aux robes trainantes glissaient rapides et légers au milieu d'une foule de piétons et de nombreus patineurs, enveloppes de fourrures on d'épais pardessus de drap; la neige couvrant les campagnes avait les scintille- 
ment d'une poussière de ciristal, et les enormes glacons du fleuve, soudes ensemble, laissaient eclater a leur surface les reffets bleuntres ce leur piof adeur, commes'ils avaient emprisonné un pan d'azur dans leurs arêtes prismatiques, ou laisse filtier a travers leur transparence la lumière d'un ciel submergé.

Signe incontestable d'une température siberiema, deux jets intermittents de vapeur tloconneuse s'echappaient des vors respiratoires des hommes et des che raux, dont les mouvements et la marche sembient, par ces froids aigus, obeir aux effets d'un engin placé dans l'intérieur.

Profitant de la beaute de cette aprèsmidi et de la solidité di pont de glace, lequel, durant trois mois d'ordinaire, relie l'une a l'autre les deux rives du fleuve, votre serviteur, accompagné de deux amis, arriva après une course à l'allure du jour, c'est-a-dire au pas accéléré, a l'extrémité méridionale de l'isle Ste. Hélène.

A cette époque, l'autorité militaire gardait ave un soin jaloux les abords de ce domaine mystérieux, et l'hiver était le seul moment propice pour qui voulait fouler ce sol, gardé non par des hydres 
mais par de simples fusilliers anglais, qui montaient leur faction i l'autre bout de l'île.

Nul sentier, nulle habitation, pas d'abri; des monceaux de neige où l'on enfonre jusqu'a mi-jambe, telle est, en hiver, physionomie de ces lieux; et n'etaient l, rayonnements du givre se renvoyant de. braficace en branche les etincelles dérobés "11 soloil, le croassement diun corbeau perthi la plus hant cime d'un arbre, "n secribati sur un ecueil.

Nous auns di-posions au retour, lorsque sur le bord de l'ilc "n etranger, qui depuis un insiant julatssit écouter notre conversation, uus salua poliment et s'avanca en souriant vers notre groupe.

-Ah! messio as, vous êtes Francais?

-Français ue France, comme on dit ici.

-Moi, pareillement. Arrivé d'hier.

Nous examinames alors notre interlocuteur. C'était un vieillard a cheveux gris, au dos légèrement voûté, mais d'apparence robuste, a la voix ferme, a l'oi! vif, et paraissant encore très-vert.

An! messieurs, on me l'avait bien dit, reprit-il, qu'on l'avait emmené bien loin, bien loin, dans un pays chaud, si chaud 
que les œufs cuisent au soleḷ ; mais je n'ai jamais gobé ca. Comment un homme qui avait vecu toate sa vie dans le feu, pouvaitil craindre la chaleur? Mais, ici, par ce froid-la! je comprends tout. Ah! les brigands! Je ne m étonne plus qu'll soít mort!

Puis devenant plus calme et d'une voix radoucie: seriez-vous assez bon, ajouta-til, de me dire de quel coté se trouve le monument?

-Nous nous regardions stupéfaits. Que! monument mon brave?

-Celui du vieux, parbleu!

Et comme nous hésitions à répondre...

-Ne sommes nous pas a l'île Ste. Hélène?

-Parfaitement.

-Et bien! je vous demande a quel endroit se trouve le tombeau de l'empereur?

Ia foudre tombant a nos pieds ne nous aurait pas frappé d'un étonnement égal a celui que nous éprouvâmes.

Nous essayâmes en vain de lui expliquer que lile dont il parlait etait situee dans l'océnn, sur la côte d'A frique, ce fut peine perdue. Le vieillard soupconneux nous quitta brusquement; et, tandis qu'il choisissait les traces de nos pas afin de marcher plus a l'aise, nous l'entendîmes grom- 


\section{Le Présent.}

meler entre ses dents : ce sont des Anglais qui parlent français ! -

La méprise de cet émigré, sans doute fils de quelque grognard de l'empire, fut la cause qui nous fit rechercher les origines de cet homonyme a'une île blen autrement célèbre.

Jusqu'a ces derniers jours quelques emharcations de plaisance, canots, yachts, montés par un équipage de fantaisie, avaient seuls aborde sur les plages verdoyantes de l'île Ste. Helène. On y portait des provisions, on mettait la nappe sur l'herbe, a l'ombre d'un érable ou d'un orme, et l'on dévorait a belles dents, arrosés de bière mousseuse ou d'un bordeaux généreux, le jambon et le poulet froid, ce menu de rigueur de tout repas champêtre.

Aujourd'hui les excursions sont devenues faciles; deux steamboats confortables le Montarville et le Ste. Hélène, l'un tout flambant neuf, l'autre nouvellement répare, transportent les yageurs a l'île, ou l'on prend terre par un quai solide et commode.

C'est la Compagnie de Navigation de Longueuil, fondée il y a une dizaine d'annees, et dont M. Hurteau est aujourd'hui, le 
Directeur-Gérant, qui obtint, l'an dernier pour une période de einq ans le privilège du transport des touristes a l'ile.

Par ce contrat, et a moins de cas de force majeure, la Compagnie doit commencer son service, le 20 Mai de chaque année, et ne prélever que la somme de 10 cents par passager pour chaque voyage (aller et retour.)

Chacun des vapeurs, capitaine et pilote compris, compte huit hommes d'équipage. Ia traversée de l'ile s'affectue en 7 minutes pour l'aller et 5 minutes pour le retour. Ies commandants de ces vapeurs sont MM. Charles Bourdon pour le Montarville, et Félix Salais pour le Ste. Hélène.

Bien que l'événement $n$ 'ait pas reçu la consecration officielle, $l^{\prime}$ on peut dire, qu'en fait, l'inauguration de l'ile Sainte-Helène, comme parc public, s'est effectuée le 24 juin 1874, anniversaire de la St. Jean-Baptiste et fête nationale des Canadiens-Français.

Il faut avoir parcquru les quais dans lapres-midi du lendemain de ce jour mémorable pour avoir une idée de la foule qui fut transportée a l'ile.

Le comite d'organisation avalt si bien pris ses mesures ; les commissaires, se mul- 


\section{Le Preisent.}

tipliant, car on les voyait partout a la fois, ont déployé une activite telle qu'on a fait face a tout. Malgre les trente mille étranger's ajoutés en un seul jour aux deux tiers de la population de la ville en liesse, pas le moindre accident n'est arrivé, pas un mouchoir de poche $n$ a été soustrail, pas un ivrogne $n$ a eté vu titubant: ni rixe ni dispute. Pour une population aussi mêlée, aussi cosmopolite, ce n'est plus de la vertu, c'est de l'héroïsme. Gloire en soit rendue i Saint-Jean-Baptiste!

Nul doute que si les saints en paradis pouvaient bénéficier de la conduite de leurs clients, le patron des CanadiensFrançais n'eût obtenu de l'avancement.

Trois steamboats pavoisés de drapeaux et doriflammes, $n$ arrêtant que le temps necessaire a l'embarquement et au débarquement de leur cargalson humaine, ont paśsé la journée à convoyer les visiteurs à l'ile. Neuf heures du soir sonnaient lorsque le dernier steamboat, lîchant sa vapeur et etelgnant ses feux, s'amarrait définitivement au quai Bonsecours, à la grande joie de l'équipage exténué.

Sur les quais, des milliers de personnes attendaient fievreusement leur tour d'em- 
barquement. Aussitôt le steamboat accosté, on se préclpitait, on se ruait de tous cútés; quelques-uns accomplissaient de véritables tours d acrobates, escaladant les muralles de bois que les commissaires avaient elevées pour protéger l'opération, naviguant par-dessus les têtes, s'accrochant Icl, se suspendant la ; tandis que le commissalre, la boutonniere ornee de sa rosette, alde du capitaine, des hommes de l'equipage, tous, campes comme des athlètes, $\mathrm{s}^{\circ}$ efforçaient $\mathrm{a}$ coups de poumons, d'épaules et de bras, $a$ contenir cette maree montante et $\boldsymbol{a}$ régulariser le flot. En quelbues secondes le steamboat envahi ressemblait a une fourmilière. A quelque distance de la rive, on n'apercevalt plus du vapeur que les tuyaux des cheminees; ies bastingages, les ponts, le pavillon du pilote même, disparaissalent; on aurait dit une epave flottante couverte de naufragés en vue d'une terre libératrice.

Sur l'île, a l'arrivée et au départ, les mêmes scènes se renouvelaient.

Nous avons vu la dans la foule une famille de cinq personnes enlacees autour de leur chef, comme les serpents autour de Laocoon, séparees tout d'un coup par un 


\section{Le Present.}

remous, et se heller les uns les autres a plus de cent metres de distance.

Pour se rendre au lieu du concert, on etait oblige, tant la presse était grande, de marcher a un pas de procession, a la queue leu leu.

Vers le milleu de l'ile, au fond d une sorte de vallon entouré d'arbres, s'elevait, au milleu d un vaste cercle, l'estrade occupee. par les 600 exécutants des vingt-trois corps de musique, et les sept cents choristes.

M. J. B. Labelle, organiste de NotreDame, armé d'un bâton d'ébène aux bouts garnis d'argent, dirigeait ces volontaires de l'art. Disposés en amphitheatre, des rangees de bancs offraient alix personnes qui ne voulatent perdre ni un mot des paroles, ni une note d'un air, des sieges assez commodes, et cela pour un demidollar.

Entourant l'orchestre, la foule bigarrée: les hommes en habits de fêtes, les femmes en fraîches toilettes d'été, les bambins et les bambines avec leurs cheveux flottants ; tout ce monde bruyant, joyeux,aux visages epanouis, circulant dans les allees ou s'ébattant sur l'herbe, arrêta tout à coup ses cris, ses jeux, sa marche. Le bâton du 
chef d'orchestre venait de frapper sur le bois du pupitre les trois petits coups sees qui servent d'avertissement préparatoire.

Le concert allait commencer.

De ce jour et de ce mornent, 25 juin 1874, late, en tant que parc public, l'inauguration solennelle de l'ile Ste. Hélène. Slx cents choristes, vingt-et-un corps de inusique et une foule de plus de six mille personnes, consacrèrent, non point la prise de possession, mais l'entrée en joulssance du nouveau parc par la ville de Montreal.

Les membres du comité chargés d'organiser ce coneert étaient M.M. I. O. Taillon, Président; G. A. Drolet, Sec.-Trés. ; J. B. Labelle, Dr. Lachapelle, $H$. Bourgoin, Ad. Ouimet. Sur le programme contenant le: morceaux de musique exécutés en ce jour memorable, figurent de vieilles chansons nationales que les vieillards de l'ancienne France se rappellent seuls encore: Vive la Canadienne, A la Claire Fontaine, Par derrière chez mon Père, En Roulant ma Boule, A St. Malo.

L'année précédente, le jour de la fête de St. Jean-Baptiste, 24 juin 1873, une autorisation spéciale du ministre de la Milice, avait permis â l'Union Typographique Jac- 


$$
\text { Le Priseml. }
$$

ques-Curtier, de célébrer son pie-nic annuel sur l'ile. Le Montarville, ayant a son bord les membres du comite de de l'Union, s. H. le Maire Barnard, le Président de la Socicte St. Jean-Baptiste, l'Hon. Juge Coursol, les membres de la Corporation, près de deux mille invités parmi lesquels MM. R. Roy, avocat; I. N. Duvernay, le Dr. Mount,G. A. Drolet, Stevenson, Lovell, I. W.'Tessier, passerent la journee sous les ombrages de l'ile.

Ladministration militaire de la Puissance ne s'est point en effet désaisie de ses titres de prop ieté; elle a simplement concédé a la ville un usufruit temporaire révocable a son bon plaisir, et cela sous les conditions suivantes: .

La Corporation devra tenir sous bonne garde les poudrières et autres constructions militaires; empêcher la destruction des arbres et des clotures, prohiber la vente des boissons alcooliques, et defendre d'allumer des feux; ne point permettre l'admission du public sur l'ile avant huit heures du matin, ni y souffrir de visiteurs une fois le soleil couché. Toute construction, bitisses, murs ou autres ouvrages ne pourront être eriges sur 
l'ile sans l'autorisation du département de la Milice, lequel, en cas de guerre, se réserve le droit de prendre l'ile sans être tenu a aucnne indemnité pour les travaux executés par ia ville. Il demeure entendu que l'usage de l'ile n'a êté donné qu'a la condition expresse d'entourer d'une cloture les constructions militaires y existant actuellement et d'en interdire l'entree au public. Ce'st aussi a la Corporation qu'incombe la charge d'entretenir une police speciale pour veller a l'execution de tous ces réglements.

Ces conditions, soumises au Consell dans le rapport annuel de Son Honneur le Maire Barnard, furent adoptees dans la séance du 9 révrier 1874.

Tous les bâtiments appartenant i l'administration militaire et qui s'élevent dans maints endroits de l'île, figurent sur la carte jointe a cette brochure ; et le lecteur, soit qu'll veulle connaître leur nom ou leur position, n'aura qu'a réferer aux lettres ou aux numeros du sommaire explicatif.

Quant aux mortlers, canons, obusiers, appareil belliqueux qui contraste si etrangement avec les aspects champêtre du 
parc, les uns servent aux saluts officiels, aux exercices du tir ; les autres, démontes, attendent dans un repos pacifique un emploi digne de leur calibre.

Parmi les premlères pièces, ainsi qu'une attentive inspection a pu nous en faire juger, se trouvent 11 canons de 24 sur affuts de fer; 2 canons de 32 sur affuts de bois.

Les secondes, en réserve, comprennent:

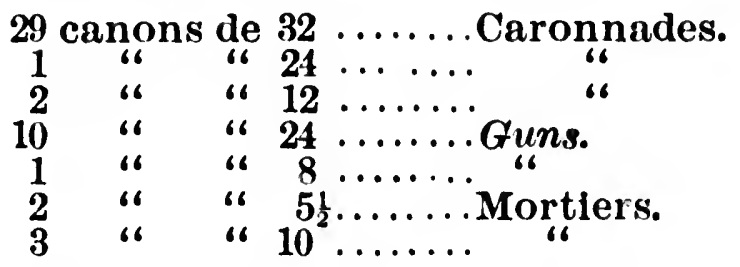

Puisque nous nous occupons du dénombrement des proprietes de l'administration militaire, mentionnons la disparition d'un batiment de trois étages construit en briques et pierre, et dévoré la vellle de Noël, l'année 1875, par un incendie dont on apercevait les lueurs de chaque côte du fleuve. Connu sous le nom de mes, cet edifice, primitivement quartier des officiers, avait ete transformé en caserne. C'est la que logeaint les r olontaires de la Batterie 
18

Lile sle. Hilime.

"B". alors stationnes a l'ile, sous le commandement du capitaine Devine.

Une autre dependance de la mème administration, e'est le petit cimetiè re situé au milieu de l'Allee des crmes, un peu en arrière du Rond-point Dufferin. Dans ce petit enclos d'environ huit cents pieds de superficie, qu'un orme et quelques accacias protégent ciu soleil, dorment huit à dix Sous-officiers et une vingtaine de soldats anglais morts dans l'hôpital militaire de l'île. Quelques enfants et trois ou quatre femmes de militaires laissent aussi lire leurs noms sur la pierre qui les couvre.

Moins un ou deux, tous les noms inserits sur les tombes sont irlandais, et ehacun des regiments qui ont campe sur l'île a laissé là quelqu'un des siens, comme une marque de son passage.

Ise fenillage vert sombre de quelques noyers, les hautes fougères qu croissent entre les tombes toutes noircies et fendillées par le temps, le souvenir de ees jeunes soldats tombes obscurement loin de leur pays, éveillent dans l'âme des promeneurs des pensées graves, une sorte de mélancolie non sans charme et qui, par son contraste méme avec les enchante- 


\section{- COMPAgNiE D'AssuRANCES LA ROYALE CANADIENNE

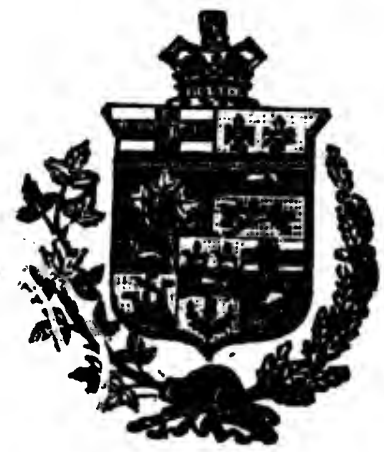

TROISIEME RAPPORT ANNUEL DE LA COMPAGNIE,

Finissant le 31 Decembre 1875.

Capital souscrit ............\$6,000,000 Capital paye en argent $\ldots \ldots \$ 600,000$

ACTIF.-Totalité............\$1,387,999.85 PAs6IF-Comprenant les actes en règlement et non payes ainsi que le total requis pour réassurer les risques en dehors ..................... \$664,790.62 REvenU-Primes reçues....... $\$ 1,368,680.36$ Interet sur Placements.......\$\$57,982.35 Revenu total de l'année...... $\$ 1,426,062.71$ 
Bureau des Directeurs:

JOHN OSTELI, Président.

J. ROSAIRE THIBAUDEAU, Vice-Prés. ANDREW Wilson, M. C. MUliarky, W. F. KAY, ANDREW ROISERTSON, JOSEPH Barsalou, Duncain MCINTYRe, Hugh MACKAY. .

Comprenant en tout mille Agences ou Succursales.

D. L. KIRBY,Son's-Administrateur, Montréal. ARTHUR GAG NON, Secrétaire-Trésorier. CHS. FORTIER,Adm. du Dépt. de la Marine ALFRED PERRY, Administrateur-Général.

\section{IRIMVIR}

Marchand de

\section{Poeles Neufs et de Seconde Mai!!.}

Ainsi que Meubles de toutes sortes, vendus au plus bas prix.

93․ Rue St. Laurent, Montréal.

\section{EDOUARD TRUDEL \\ ENTREPRENEUR DE BATISSES}

Architecte et Expert

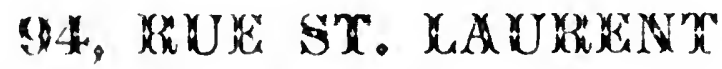

MONTRÉAL. 


$$
\text { Li Pisemt. }
$$

ments de lile en eette saison, vous fait mieux goûter le plaisir de vivre.

Après Dieu qui a dispense sans compter les eaux, les bois, la fraîcheur, la verdure, les oiseaux et les fleurs a l'.le ste. Fúline, le gouvernement fédéral qui nous en a pernis la jouissance, vient, en troisiome lien, a Corporation de Montréal qui, par l'inerniédiaire du comité des pares, ayant clos d'une barrière en bois la zone militaire, a construit dans quatre endroits differents des espèces d'abris, dont les toits peints en rouge tranchent sur le vert cis arbres comme des coquelicos dans les bles; des pompes a mains, filtrant a travers le sol sablonneux de l'ile le breuva;e cher aux inembres des societes de tempérance; de petits pavillons, des plus nécessaires, tout cela pour la simple bagatelle de $\$ 2,690.90$, ainsi dépensées:

Police spériale...... \$547.45.

$T$. Vincent.......... 43.00 louage de chaloupes.

J. B. Galipeau ...... . 535.93 Erection d'abris.

Girard \& Barbeau.... $\$ 2.00$ peinturage.

Charles Garth \& Cie.. 7.75 pompes.

‘. H. Létourneal ... 8.95 dépenses contingentes. 
A. Grenier .

$\$ 1.75$ levier de

E. Chanteloup..... . $\quad 5.00$ insignes pour

Wm. Kesteloot....... 15.00 travaux sur

lîie.

Les recettes formees des revenus des diverses licences accordees ont rapporté a la caisse municipale la somme de $\$ 402.50$

Enfin, M. Sissons, le confiseur-pâtissier, bien connu de la rue St. Pierre, ì qui la ville a concede au taux de $\$ 1800$ par annee le privilége de fournir les rafraîchissements, d'etablir des jeux, des bains, etc.: d'exploiter l'île dans l'intérêt des plaisırs publies, et cela pour une période de cinq ans, a crée pour la saison un établissement auquel il se propose d'ajouter au fur et a mesure des besoins, d'importantes annexes.

Aujourd'hui déja, une élégante construction dò style gothique, élevée $n$ la partie sud-est de l'ile, offre dans son vaste rez-de-chaussée deux grandes salles garnies de tables et de bancs, où des garçons en livrés font un service qui ne laisse rien a desirer.

En face de ce pavillon de petites tables disposées sur la pelouse invitent ceux qui 
aiment le grand air et la libre nature, a prendre leur lunch ou a déguster un sorbet.

En un autre endroit, les amateurs de courses nautiques peuvent choisir au milieu d'une flottille de canots de tout tonnage, et pour un prix modique, l'emba:cation qu'ils souhaitent

A ceux pour qui la pleine cau a plus d'attraits que la cuve d'une baignoire, un etablissement de bains, au nord de l'ile offrira bientôt les facilités d'un exerciee salutaire au milieu des flots immacules de cette partie du bras du fleuve.

Quant à ce qui concerne les rafraichissements de toute sorte, à l'exception des boissons alcooliques rigoureusement defendues, M. Sinons a eu l'excellente idee de construire une glacière assez vaste pour tenir au frais les consommations nécessaires aux besoins de plusieurs milliers de personnes.

Dans le courant de l'été un corps de musique viendra de temps à autre jouer sur l'sle, et cette heureuse inovation ne contribuera pas peu à y attirer les promeneurs.

Dorénavant, et grâce aux améliorations actuelles, aux embellissements que l'ave- 


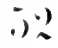

Lile ste. Heline.

nir réserve a l'ile Ste. Hélène, les plaisirs le la campagne ne seront plus le privilége des heureux du jour : des aujourd'hui, les voila di la portée des bourses les plus modestes.

Moyenmant quelques centins l'on se rend a l'ile. I', chacun, suivant son caprice, lit ou reve, marche ou sommeille; l'un déjeûne, l'autre se baigne; ceḷi-ci rame, cet autre gambade; on a pour soi le splendide décor des deux rives du St. Laurent, des domes de verdure pour cielle-lit, d'épais gazons en guise de tapis ; de plus, les chants d'oiseaux, les brises du fleuve et les rustiques senteurs des plantes et des bois,; la solitude ou la foule, le silense ou le bruit, ì volonté; enfin tout ce que les faroris de la fortune vont chercher au loin et à grand prix, et dont le plus souvent les tracas et les soucis les empêchent de jouil.

Avec l'ile Ste. Hélène la campagne est a tous, a la ville et aux faubourgs. Les pauves, pour la belle saison, deviennent égaux aux riches, et chacun de nous, sain d'esprit et de colps, peut, moyennant ses dix centins, se procurer pour une journée les jouissances d'un millionnaire. 


\section{F LORE.}

La flore de l'ìle Ste. Hélène n'offre it proprement parler, rien de remarquable, ni rien qui lui soit spécial.

L'énorme baobab de la zone torride du continent africain, dont le trone atteint parfois 10 ) pieds te circonference, non plus; que le pin gigantesque des sierras de Catlifornie, lequel s'élève à 200 pieds de hauteur, n'étendent, l'un, ses rameaux, l'autre ses cones et ses pyramides de verdure au milieu des essences canadiennes.

Ses espèces aborescentes ainsi que ses plantes se trouvent dans tous les lieux de la province; et si nous nommons ici des individus appartenant ì quelques familles, $\therefore$ "est à cause de leur abondance relative ans l'ile et parce que chaque promeneur en ies reconnaissant, pourra, grace a cette nomenclature, leur appliquer la denomination scientifique, les noms français et anglais, et prendre ainsi, sans fatigue, une leçon de botanique it la fois instructive ot amusante. 
FAMILIE DES ULMACEES.

Du celtique Elm, Orme.

Noms:

Français.

Anglais.

Latin.

Orme.

Elm.

Ulmus.

(Deux espèces.)

L'orme rouge. Red Elm. Ulmus rubra. L'Orme blanc. White Ulmus AmeElm. ricana.

FAM : ACERINEES.

De Acus, pointe.

L'Erable a Sugar Maple. Acer Sacchasucre. rinum.

La Plaine. Swamp Ma- Acer rubrune. ple.

Bois barre. Striped Ma- Acer striaple. tum.

FAM : LILIACEES.

(De l'illium, lys.)

Bois blanc, Bass-wood. Lilia Cana(Tilleul.) densis. 


$$
\text { Flore. }
$$

FAM : CUPULIFiERES.

(De Cupula, diminutif de cupa, coupe.)

Le Hetre. Beech.

Le Charme. Hornbean.

Le Coudrier, Hagel.

( Noisetier.)

Chène blanc. White Oak.

Chìne rouge, Red Oak.

a gland

amer.
Fagus Sylvatica.

Carpinus

Americana. Carylus A mericana.

Quercus alba. Q. rubra.

FAMI : BETULACEES.

(De Betula, Bouleau.)

Le Bouleau Canc Birch. Betula papyhlanr. racea.

L'A une rouge Alder.

Alnus rubra. commun.

FAM： OLEINEES.

(De Olea, Olivier.)

Le Frène White Ash. blanc.

Le Lilas com- Lllæ. mun.

Fraxinus Americana. Syringa vulgaris.

FAM : JUGLANDEES.

(De Juglans, Noyer.)

Le Noyer cendré.

White Wal- Juglans cinenut.

( Nomer tendre.) Hir.kory rea. Le Noyer dur. Bitternut. ra. 
HAM : SA I.ICINEES.

(De Salispus, Saule.)

I t. Siaule humble. (Chatoms.)

Ic Saule jaune.
Inow Bush

Willow.

Yellow Wil- Salix vitellow.

Salix humilis.

Le Tremble. White Poplar. Populus treLe Peuplier River Poplar. pida. du Canada. (Cotton Tree.) Populus Ca(Ie Liarel.) nadensis.

Le Peuplier Large Poplar. Populus grania grandes didenta. dents.

FAM. A MYGDALEES.

(De Amyydulé, amende.)

Le Prunier Red Plum. rouge.

Le Prunier Common domestique. Plum.

Prunus Americana.

Prunus domestica.

Le Prunier sauvage.

Cerisier de virginie.

Cerisier a rrappes.

Cerisier noir, a cerises d'automne.

Willd Bulla- Prunus insitice Tree. tia.

Choke

Cherry.

Cerasus Virginlana. Cerasus scrotina.

Cerasus Canadensis.

Petites Mis- Birds Cherry. Cerasus Penrises. sylvanica. 


\section{lilorer.}

FAM. POMACERS.

[De Pomum, fruit.]

Le Pommier Common Malus contcommun. Apple Tree. munis.

Petites Poires June Berry. Amelanchia ou Amélanchier du Canada.

$\begin{array}{ccc}\begin{array}{c}\text { Pomettier } \\ \text { rouge, Au- } \\ \text { bépine. }\end{array} & \begin{array}{c}\text { Crimson } \\ \text { fruited } \\ \text { thorn. }\end{array} & \begin{array}{c}\text { Cratœgus } \\ \text { Coccinea. }\end{array} \\ & \end{array}$

Sencllier Cock-sprir. Cratogus ergot de coq. crusgalli.

FAMT. CAPRIFOI, I AEES.

[De Capro, chèvre-feuilles.]

Sureau blanc. Common Elcler.

Sambucus Canadensis.

Viorne nue. White Thod. Virbunum [Alises.] nudum.

Bois d'Ori- Hobble Bush. Virbunum gnal.

Lantana.

Fam. Anachrdiactes

(De Ana, Cardia, en forme de cour.)

Vinaigrier ou Staghorn Su- Rhus typhiSumac de Virginie. mach. na. 


\section{L'ile Ste. Hélène.}

\section{FAM.' TIYYMELEES.}

[De Thymelées Daphnce, la nymphedufteure Pénée, qui fut changée en Iaurier.]

Bois de plomb Leather-wood. Dirca-paou bois-cuir. lustris.

\section{ARBUSTES FRUITIERS DF L'ILE.}

FAM. RosaceEs. .

[De Rodon, ou Rosa, Rose.]

Rose sapvage. Swamp rose. Rosa carollniana.

Môres nolres. High black- Rubus villoRonces notres. berry. sus.

Catherinettes, Low black- Rubus canaMúrettes. berry. densis.

Frainboises Will'd red Rubus Penrouges. Rasberry. sylvanicus.

Framboises communes.

Framboises Garden Ras- Rubus Idodesjardins. berry.

Fam. Grossulariegs.

[Groseiller.]

Grosellier ou Prickly Goo- Rlbes cynoRonce de Chine. seberry. basti.

Gadellier rou- Common red Ribesia ruge. Gadelle currant. brum. commune. 


$$
\text { Flore. }
$$

Gadellicr noir. Hack cur- Ribesia niCassis rant. grum.

Fay. Legumineuses.

[De Legumen, gousse.]

Acacia ou Ro- Locust tree. Robinia pseubinier, faux Acacia.

Phuque As- Wild Pea. Astragalus altragaline. do Acadia.

Gesse des Ma- Beach Pea. Lathyrus parais. lustris.

Desmodie du Bush Tre- Desmosdium Canada. toil. Canadense.

Fan. Vaccrnites.

[De Vaccha, vache, plante aux vaches.] Bluet A1relle.

Vaccinum Canada BlueAtrelle de Vaccinum Common low Pensylva- Pensylvani- Blueberry. nie. cum.

Atocas. Can- Oxycoccus Small Cranneberge ou palustris. berry. Coussinet.

Petit The des Gaultheria Creeping Bois.

hispidula. Snowberry.

Fam. Ericacees.

[De Erica, br .yère.]

'The de méri- Wintergreen. Gautheria sier. procumbus. 
60

$$
\text { LIIe Sie. Ilélime. }
$$

Fay. Borraginges.

[De Borrango, Bourlache.]

langue de Hound's Ton-Cynoglossum chien. $\mathrm{Cy}$ - gue: officinale. noglosse.

Langue de Ox tongue. Anchusa offibeuf. Bu- einalis. glosse.

rierbeaux Officinal Lithosperperles. Gre- Gromwell. num offici. mil.'Thides nale. chatmps.

FAM. SCROFULARIEES.

[Plante au Scrofule.]

Bouilion

bl nc. Bonhomme,Molène.

Grande Scro- Figwort. Scrofularia fulaire.

Herbe du

Siege.
Common Verbascum

Mullein. alatum.

lanceolata.

\section{Fan. Polygonesis.}

[Do polys, plusieur's, gonu, genoux.]

Patience Red veined Rumexsanrouge. Doek. guinesis.

Petite oseille. Shefy Sorrel. Rumex acetoOseille des sella. champs. 
Poivre d'eau- Water Pep- Polygonum ('urage.

Herbe a co- Knot grass. chon. Traipunotatum. nasse.

FAM. OMBETLYHERES

[Te nmbella, parasol.]
Panais sau-
vage.
Wild Par-
sinep.
Prstinaca
sativa.

Cerfeuil

sauvage.

Thapsie cor- Twisted

u vu rilial sia.

Hone IVort.

110llće.

FAM COMPOSEES.

[Fleurs composées.]

Verge din. Goldenrod. Solidago lanceolata.

Cumomine Cornchomo-Anthemis apdescharmps. mile. vensis.

Herbe de Mugwort. Artemisia St. Jean. vulgaris.

Armoise.

Herbe a dinde Mrllfoil Yar- Arehillea

ols miller row,

millofolium. feuilles.

Immortelle. Fraglant Li- (rnaphalium feevrrlast- polycephaing. lium. 
FAM. IRIDEES.

[De Iris, arc-en-ciel.]

rlajeux ou Blue Flag. Iris versicoris. lor.

FAM. ARAIIACEES.

[De Aralie, nom Canadien.]

Salsepareille Wild Sarsa- Aralia nudiou Chaspa- parilla. caulis. leille.

Anis sauvage, Spikenard Aralia raceAnis des bois. Pettymormosa. rel.

FAM. LABI前ES.

[De Labium, lèvie.]

Menthe. Spearmint. Menthar vilidis.

Menthe du Horsement. Mentha CaCanada. nadensis.

FAM. CORNEES.

[De Cornus, cornouiller.]

Quatre temps.Dog Wood. Cornus Canadensis.

[FAM. PIANTAGINEES.

[De Planta, plante des pieds.]

Plantin i grandes feuilles.

Plantago inajox.

Bidwort. 
FAM. ASCLEPIADEES.

[De Asclepics, Esculape.]
Cotonnier.
Herbe $\mathfrak{a}$
Common
Asclepias ouate. cornutl.

FAM. TYPHACEES.

[De Typhas, marais.]

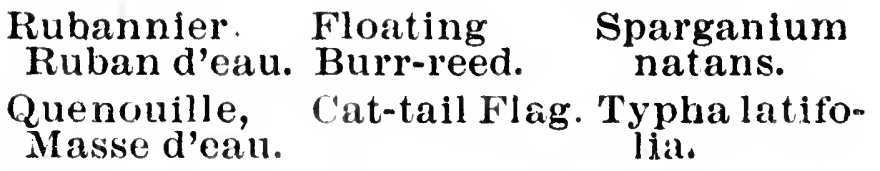

Fam. Alismacees.

[Du celtique Alis, eau.]

Sagittaire. Arrow head. Sagittaria Fleche d'eau. sagittofolla.

Fay. Equisetacees.

[De Equus, cheval et seta, crin.]

Queue de che- Wood Horse- Equisetum val. Prèle tail. sylvaticum. des bois.

FaM. MOUSSES

[De Musfe.]

Gymnostome Moss, froth, Gymmostoperisforme peristormis. mun perisformis. 
64

Lile ste. Hilime.

FAN. Lich̃eNs.

[De Leichen, dartre.]

Parmelie. Smal shield. Parmelia Acharius.

Cladonie Red edgetetter. Cladonia ecarlate. rubra.

Il reste dans lile au moins rols fois autant d'espèces ì decrire.

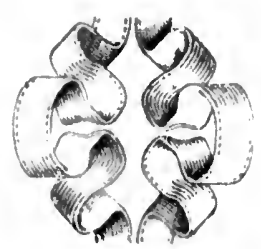




\section{6 \\ rRAV卫RS巴}

ENTRE

MONTRÉAL ET L'ILE STE, HÉLÈNE JUSQU'A AVIS CONTRAIRE.

Lte service se fera autant que possible comme suit :-

DU QUAI JACQUES-CARTIER-9 $\frac{1}{2}, 10 \frac{1}{2}, 11 \frac{1}{2}$ heures A. M., et $12.30,1 \frac{1}{2}, 2 \frac{1}{2}, 3 \frac{1}{2}, 4 \frac{1}{2}, 5 \frac{1}{2}$ et $6 \frac{1}{2}$ heures P. M.

DE L'Ile-10, 11 heures A. M., Midi, 1, 2, $3,4,5,6$ et 7 heures $P$. M.

LE DIMA NCHE-DU Quai Jacques-Cartier: $9 \frac{1}{2}$ heures A. M., $12.30,1 \frac{1}{2}, 2 \frac{1}{2}, 3 \frac{1}{2}, 4 \frac{1}{2}, 5 \frac{1}{2}$, et $6 \frac{1}{2}$ heures P. M. DE l'Ile: $9^{3}$ heures A. M., $1,2,3,4,5,6$ et 7 heures P. M.

Passage (aller et retour), $10 \mathrm{ct}$. Enfants au-dessous de 10 ans, 3 cts.; an-dessous de 3 ans, gratis.

"SIROP DES ENFANTS" DU

DR, J,-EMERY CODERRE: "SIROP EXPECTORANT"DU

DR, J,-EMERY CODERRE, "ELIXIR TONIQUE" DI

DR, J,-EMERY CODERRE,

En vente chez les principanx Pharna ciens. 


\title{
AUGUSTE COUILLARD
}

\author{
MARCHAND DE
}

\section{Ferronneries, Peintures, Vitres, \&c.} 233 \& 235, RUE ST. PAUL (Porte coisine de C.-O. Beauchemin \& Valois.) MONTREAL.

On trouvera a cet etablissement, a trèsbas prix, un assortiment des plus complets de'fournitures de maisons, ustensiles de cuisine et poêles de toutes sortes.

De plus. une grande quantité de SCIES de moulin de toutes grandeurs et de tous prix, garanties de premières qualite.

Les menuisiors et charperitiers de la ville comme de la campanne, feront bien de visiter cet etablissement avant d'acheter allleurs, et les marchands qui l'encourageront y trouveront leur profit.

\section{JOSEPH VINCENT \\ EMBACATIONS DE PLAISANGE}

DE TOUTES SORTES

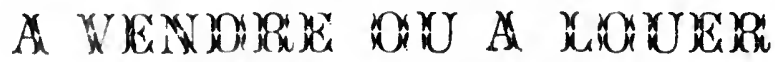

PRIX MODERES

Quai Jacques-Cartier, Montréal.

\section{AU RESTAURANT OU GRAND VATEL}

\section{DAME V, GHIDONE}

93, RUE ST. JACQUES MONTREAL. 


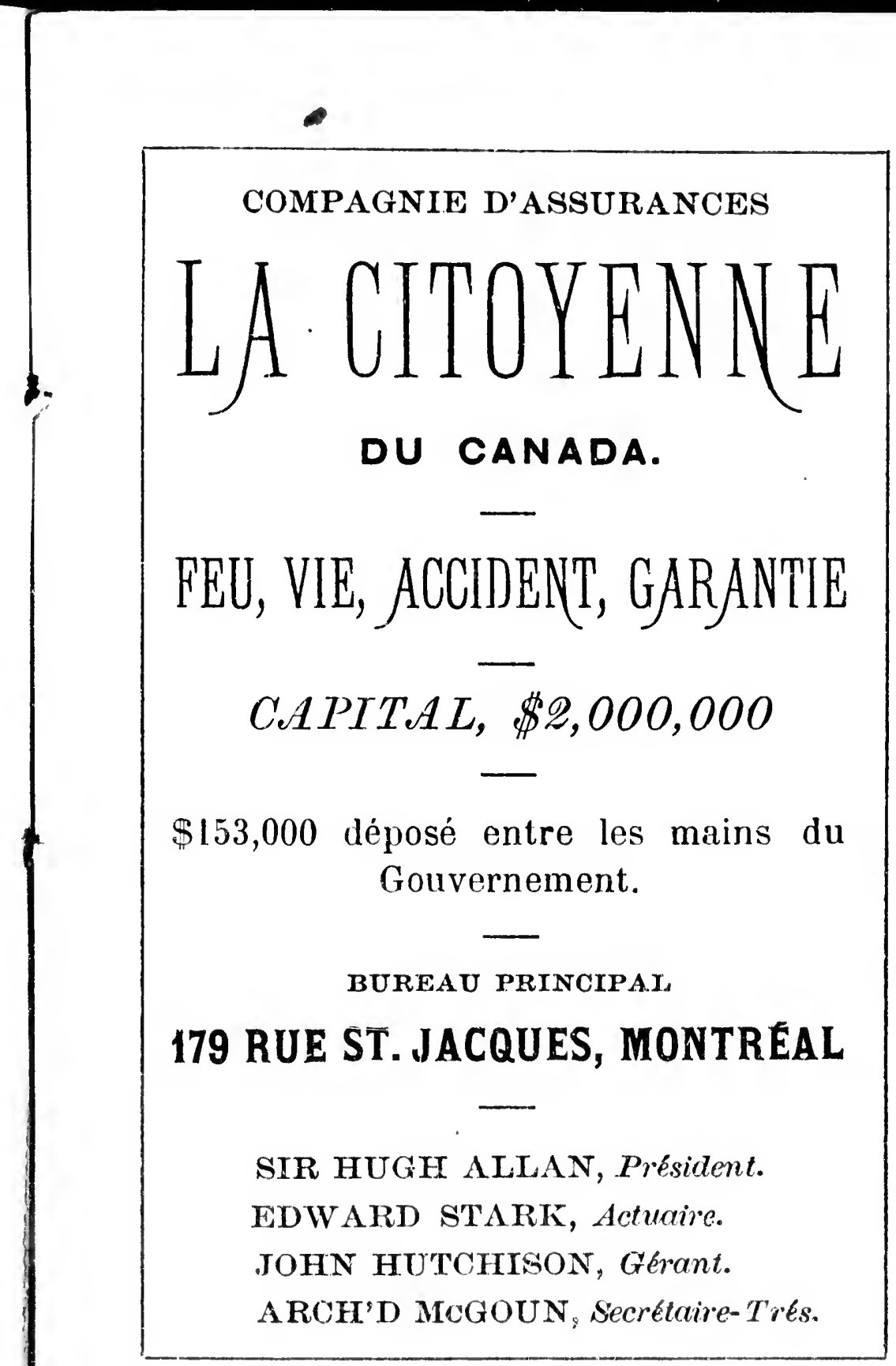




\section{F. F. TRESTLER, M.D.}

$\mathbf{E T}$

STEPHEN GLOBENSKY, L:C,D, DENTISTES

192, RUE NOTRE DAME, MONTREAL.

MM. Trestler \& Globensky, administrent le Chloroforme et le Gaz Hilariant.

BEAUVAIS \& PERRAULT IMPORTATEURS

MARCHANDS DE NOUVEAUTES ENSEIGNE DE LA BOULE D'OR

129, RUE NOTRE DAME, MONTREAL.

P.S.-Spécialité en Marchandises de Deuil.

\section{G. CLIEMENT}

MAGASIN DE

Tabac, de Iruits et Rafraichissements Coin des rues St. Denis et Craig MONTREAL.

REAUDRY \& DUFRFANE, Successeurs $B$ de L. P. Boivin, Florlogers et Bijoutiers, coin des rues Ivotre, Dame ct St. Vincent, Montreal.

Inportateurs de Montres, Pendules et Bijouterie, Argenterie, Coutellerie, Bronzes, Marchandises de Fantaisie, Vases à Fleul's. \&c.. \&c. Objets plaqués en Or et en Argent avec élégance et promptitude. 


$$
1
$$




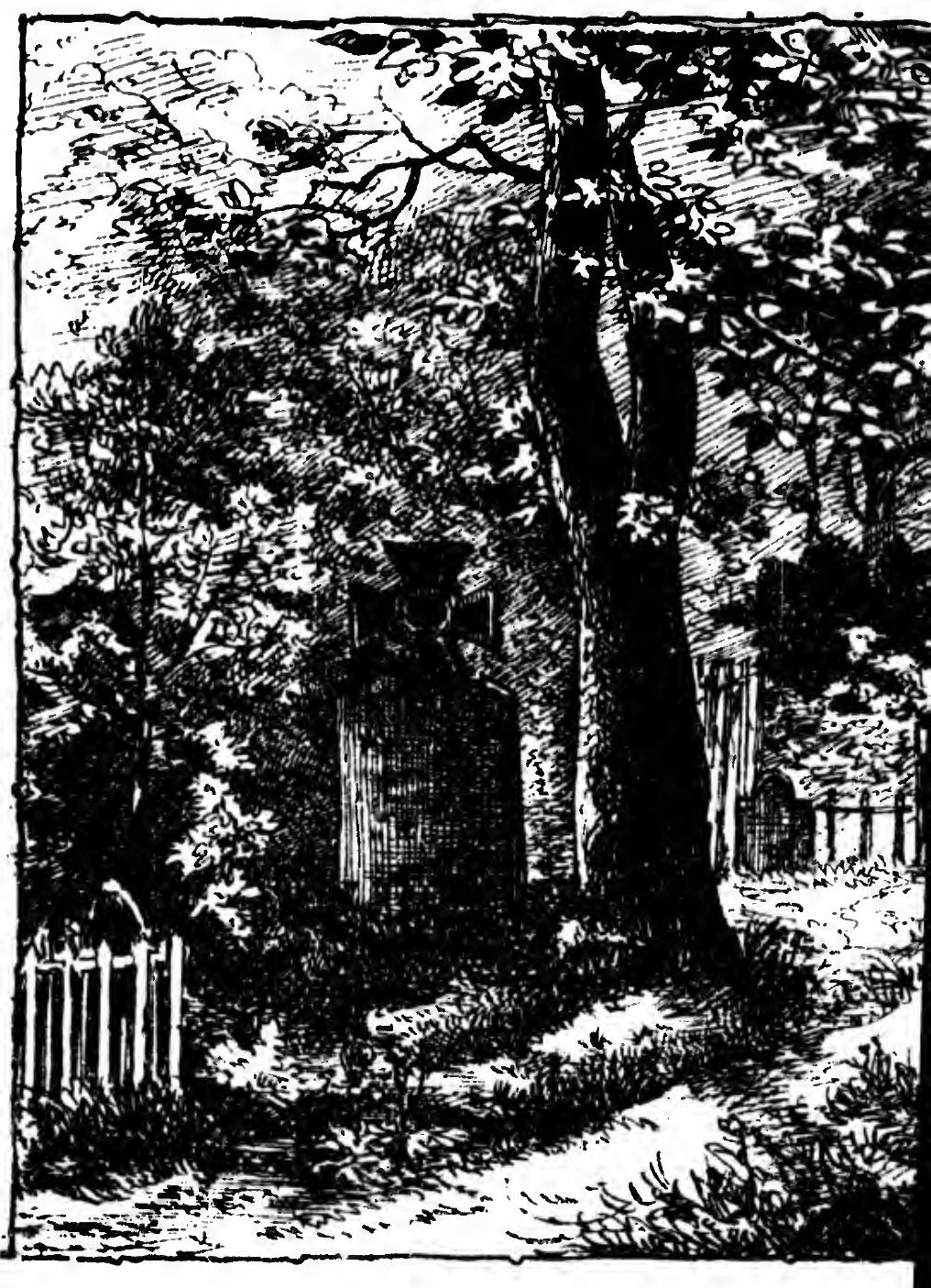

LE CIMETIERE MUL 
:0,

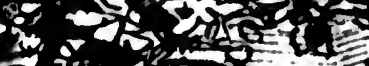

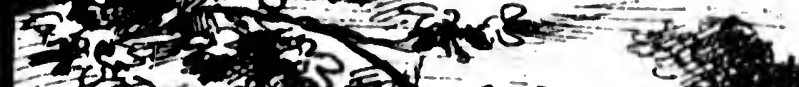

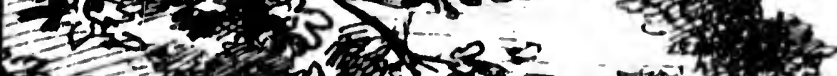

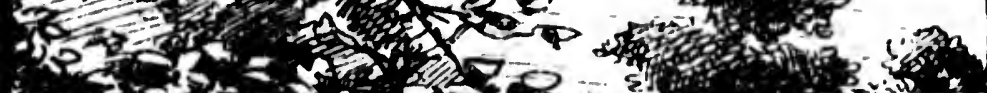

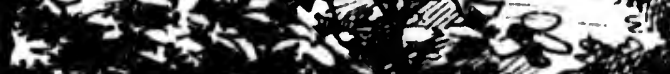
$3-x{ }^{4}$

-

(a) (1)

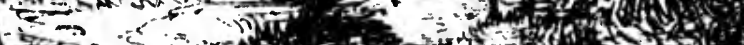

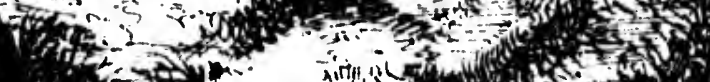
Xa

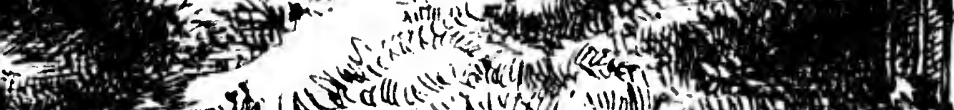

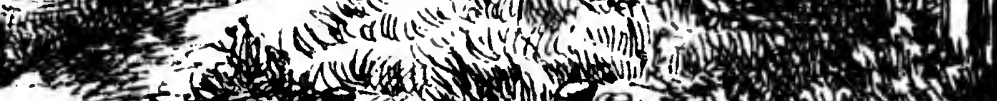

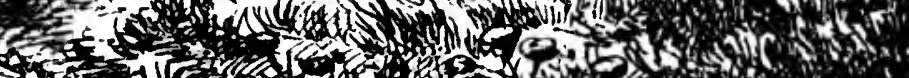
5 50 (1) ator

CETIERE MILITAIRE. 


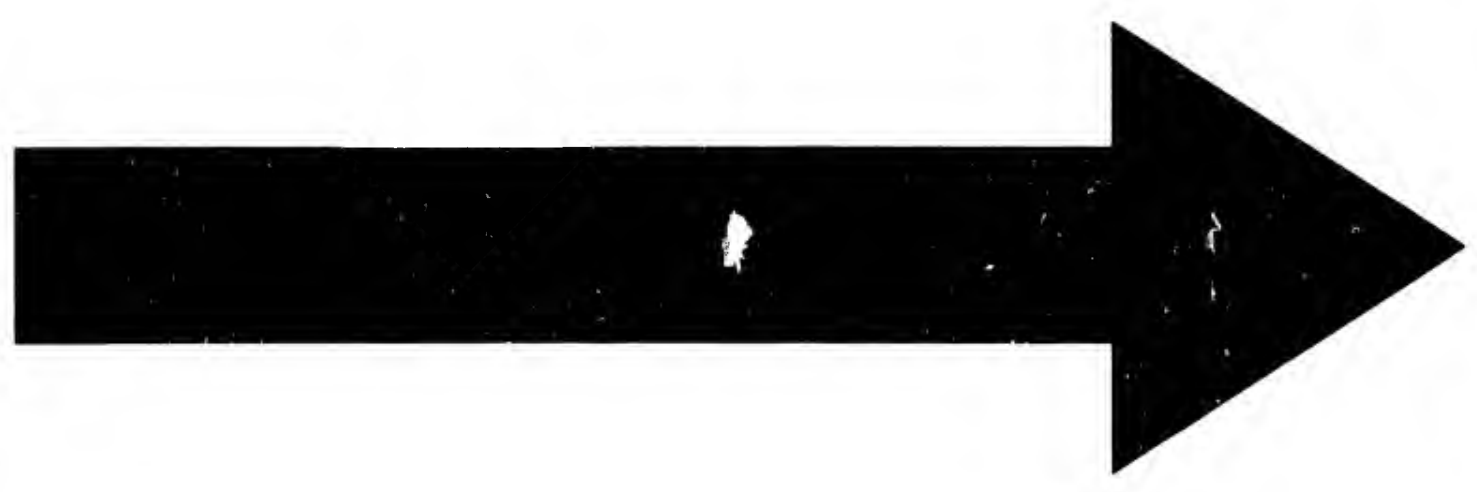




\section{IMAGE E'vALUATION \\ TES 'ं TARGET (MT-3)}
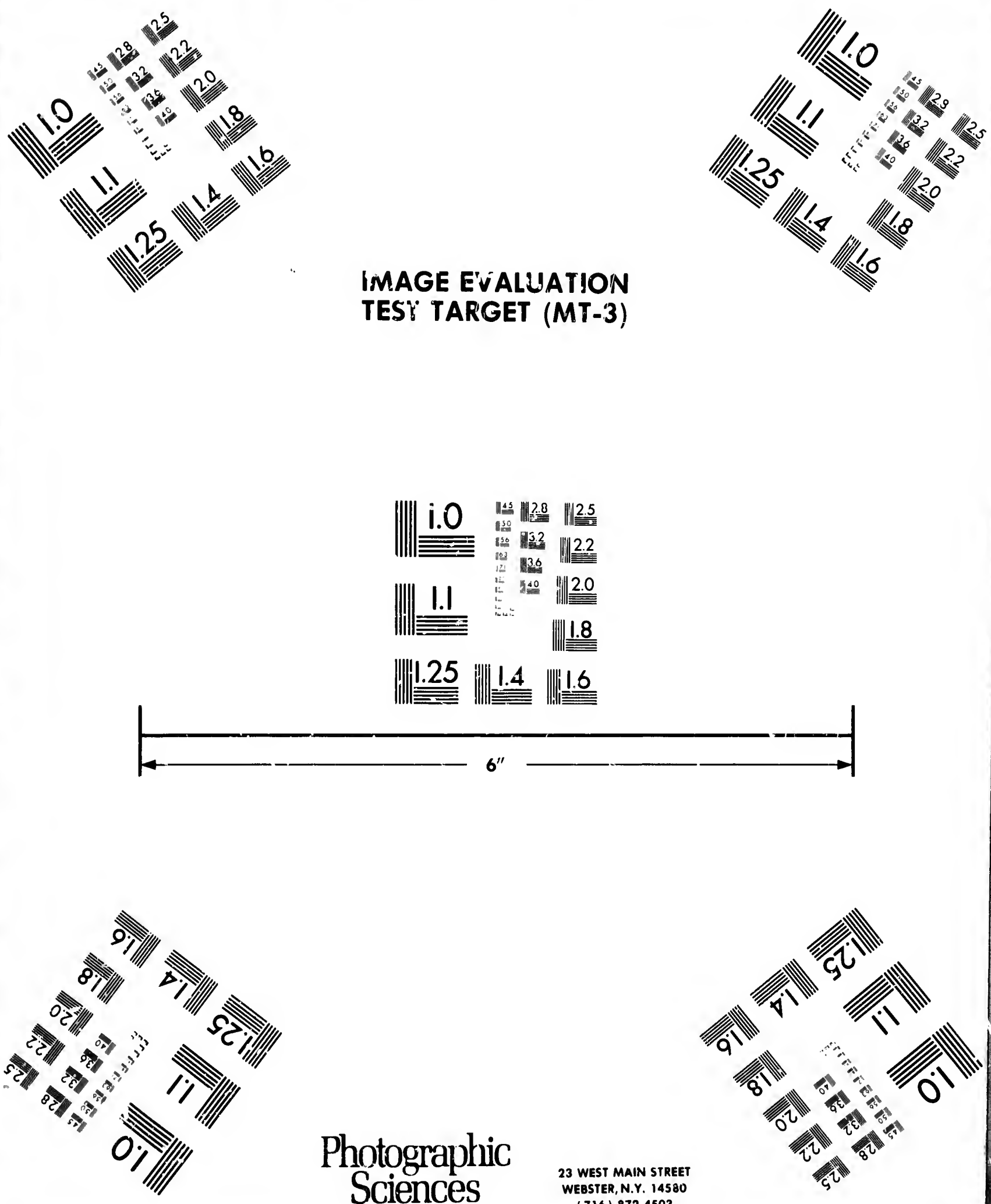

Photographic Sciences

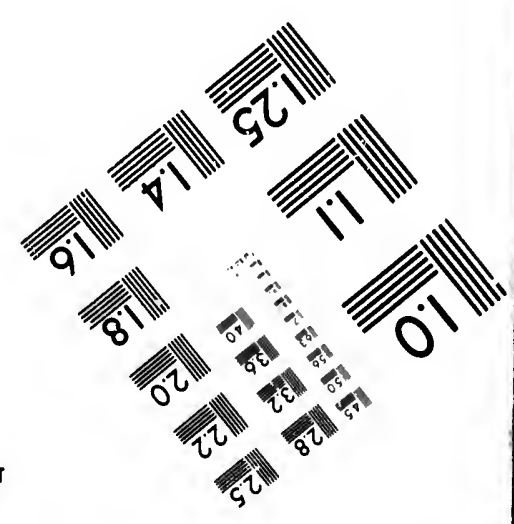





\section{GÉOGRAPHIE,}

En prenant poü base le méridien de Greenwich, l'Ile Ste. Hélène est située par $45^{\circ}$ de latitude nord, et par $73^{\circ}$ de latitude ouest. Ses antipodes se trouvent dans le grand ocean, $\dot{A}$ environ 250 lieue a l'ouest de l'Australie, à la hauteur de la terre de Van Diemen. De telle façon que, lorsque les flineurs de Montreal s'en vont, vers le midi, par un soleil eclatant, goûter la fraicheur des ombrages du parc municipal, nos bons frères du continent australien, regagnent leur domicile a la lueur des réverbères et vont se mettre s.u lit. A travers la masse terrestre, et suivant une ligne verticale, leurs pieds touchent a nos pieds, et la tête de chacun s'élève dans une direction diamétralement opposée; c'està-dire que les uns par rapport aux autres ont la tête en bas, ou en haut, cela dépend du point de vue.

La position de l'Ile Ste. Helène onurt du sud au nord; sa superficie comprend 141 arpents; son contour, 48; sa longueur 19 et sa largeur moyenne 10 arpents. 
Son point le plus culminant se trouve a 1.j3 pieds au-dessus du nivean du fleuve.*

\section{IONTAGNES.}

Blen que les arrêtes des montagnes qui hérissent l'île Site. Hélène, soient fortement accentuees, et se detachent en relief sur son sol légèrement ondule, nous préviendrons le lecteur qu'd leur sommet la colonne barométrique subit péu de variation. Flles n'ofirent a leurs pieds ni les riantes vallees des Alpes, ni sur leurs plateaux les pîturages odorants des sierras de Californie; pas plus qu'elles ne renferment, dans leurs gorges, ces fleuves solidifies qu'on appelle des glaciers.

Comne les Montagnes Rocheuses, elles ne séparent point deux océans; ainsi que les Alleghany, leurs contre-forts ne marquent point l'embouchure de fleuves puissants tels que le Mississippi et le St. Laurent.

Quant, a ce qui concerne l'élévation de leurs pics, nous avouerons humblement que le Chimborazo, au Pérou, le

* Toutes les hauteurs sont prises à partir du niveau du St Iaurent. 


\section{Grographie.}

Chamolari, dans l'Himalaya, 2⿰,000 pieds, humilient quelque peu par leur hauteur, les pitons les plus vertigineux de l'ile Ste. Hélène. A l'instar des Andes, elles ont aussi leurs neiges, qui, sans tire eternelles, les couvrent de la tête aux pleds pendant einq mois. En outre, sans laisser échapper de leurs flanes des fleuves tels que l'A mazone et l'Uraguay, elles nourrissent deux rivières.

CIIAIN FS DE MONTAGNFS.

L'Ile en renferme deux princhipales. La première et la plus considérable s'élève dans la partie centrale et orientale de l'ile, et comprend quatre mon tagnes principales: .

La plus élevie de ce groupe est le

Mont Ẽuulé-153 pieds.

Au suck-est du premier se trouve le

Mont Champlain-135 pieds.

Au sud-est du précédent le mont

vaudreuil-125 pieds.

A u nord-est le mont

St. Sulpice-140 pieds. 
68

$$
\text { l'ile ste. Heilène. }
$$

La seconde chaine se compose de deux montagnes seulement, situées ì la partie extrême nord de l'îls, près des casern ${ }^{\circ}$.

I e Mont Montcalm-125 pieds.

Le Mont Nelson-105 pieds.

\section{IACS.}

I'Ile en compte deux, situés chacun a une de ses extrémités. Aucun ne présente l'étendue ni les îles nombreuses du lac Supéileur. Un géant altéré les boirait d'une haleine, et le ginéral Tom Fouce serait le seul homme ti perdre pied dans le plus profond des deux.

De même que le lac Titicaca, au Pérou, ils pourraient être situés comme lui a une altitude de 11,745 pieds, mais c'est in peine s'ils dépassent de quelques pouces le niveau du tleuve.

Bien que les rainettes abondent sur leur's rives, que les tetards et $d$ 's myriades de vairons nagent dans leurs eaux, on ne saurait trouver la les précieuses laictances du sterlet et de l'esturgeon du lac Ladoga, avec lesquelles on prépare en Russie le fameux caviar. 


\section{Géngraphie.}

Les deux lacs sont :

Is Lac Artinur.

Le Lac Frontenac.

Le premier, placé au sud de l'lle, a 100 pieds du fleuve, d'une longueur de 160 pieds et et d'une largeur de 55 pieds.

Le second, au nord-est de l'Ile, a 100 pieds du fleuve, long de 150 pieds, iarge de 80 pieds.

A la louange du lac Frontenae, nous devons dire, qu'obéissant a un légitime orgueil, il joue un rôle semblable a celui de son collègue de terre ferme, le lac Champlain, et que, comme celui-ci, sous le le nom de Richelieu, déverse dans le St. Laurent le trop plein de ses eaux, le lac Frontenac porte egalement nu fleuve, sous le nom de rivière Bienville, l'excédant de ses ondes.

Quant au lac Arthur, c'est ur.e sorte de mer intérieure qui, comme la Mer Morte, mais avec le sel en moins, n'a aucune communication.

RIVIERES.

Deux cours d'eau traversent l'Ile et en arrosent ia partie septentrionale : 
La Rivière Bienville.

La Rivière Hiberville.

La Bienville prend sa source dans les monts Boule et Montcalm. et apres un cours de plusieurs centièmes de mille, se jette dans le lac Frontenac.

L'Hiberville sort du lac ci-dessus nom mé, et l'humble tributaire du St. Laurent, va se perdre dans le fieuve, a la tête des Rapides, au nord-est de l'île. Son cours a près d'un huitième de mille.

Comme quantité ou excellence, leurs eaux cgalent celles des plus grands fleuves du monde; comme quantité ou volume, c'est quelque peu différent. Sous ce rapport, veritables rivières d'Espagne, elles peuvent se reclamer du Mançanarès, que les géographes supposent couler à Madrid. Ainsi que celui-ci, elles seraient reconnalssantes aux personnes qui, durant les chaleurs, leur feraient l'aumône de quelques verres d'eau.

Une particularite les distingue cependant, leur int mitence: elles coulent deux fois l'année, au printemps et en automne. Durant l'hiver, elles font des économies pour les premiers beaux jours ; peudant l'été, époque de leur morte saison, 


\section{Gern!raphie.}

leurs flots partis en vacances permettent aux fourmis de traverser leur iit a pied sec.

\section{ILES.}

Un archipel et quatre îles de diverses grandeurs entourent l'île Ste. Hélène, comme des satellites leur solell. Ce sont:

L'Archipel des îles St. Lambert, au sud-est. L'Ile Ronde, au sud-ouest.

L'Ile aux Gorets, au sud-est.

L'Ile aux Fraises,

L'Ile Moffat ou Lapierre, au sud-sud-est.

Si l'archipel des Moluques a ses épices, les Chinchas leur guano; si Java possede la panthère noire, les îles f'idji leurs anthropophages, les nôtres n'oifrent rlen de semblable. Seulement, au printemps, des nuees de canards et de sarcelles s'abattent sur ces îlots, a la grande joie des indigènes de St.Lambert, qui ne manquent point d'en faire leur régal.

Cet archipel, formé de quelques rochers et de gros cailloux, sortes de mottes de ter re recouver tes d'une herbe courteet d'un vert cru, demeure presque inaccessible, tant il est entouré de récifs et de bas- 
fonds. Des baigneurs et des pecheurs aventureux se hasardent parfois a aborder sur ces bords peu frinuentes.

Quant aux iles Ronde, aux Fraises, Moffat, les noms qu'elles portent, designant ia forme de la première, les produits de Ia denxirme et le nom du proprictaire de la derniore, sont assez caracteristiques pour dispenser de toute autre explication.

L'île aux Gorets, appelee improprement aux Moutons, a reçu son titre lors des premiers pores que la Baronne de Longueuil jugea devoir y placer.

\section{DETroITs.}

Les détrolts sont au nombre de deux : le détroit Bonsecours, entre l'île aux Fraises, et la grève aux Ecrevisses; le détrolt d' Hochelaga, entre l'île Ronde et les casernes ; ils ont peu de largeur. Celui de Bonsecours ne ressemble en rien a son confrère des Dardanelles, d'ou le navigateur apercoit, en le franchissant, d'un côté les rivages de l'Europe, de l'autre la côte d'Asie.

Quant au détroit d'Hochelaga, bien que moins iarge que l'Hellespont, il n'aurait 


\section{Giographie.}

point encore vu se renouveler la prouesse de ce jeune grec d'Abydos, Léandre, qui, chaque soir, traversait le detroit a ls nage, pour aller passer quelques instants avec son amante, Héro, de postique memoire.

On assure, cenendant, qu'i l'époque ou des regiments anglais de la garnison de Montréal campaient dans l'île, plusieurs excellents nageurs dejouaient, aux premières ombres, la surveillance des sentinelles, et, traversant le detroit, s'en allaient attérir a Hoche'aga, après avoir fait une halte sur l'île Ronde.

Le lendemain, dess l'aube, nos galllards retournaient dans un canot de louage, aborder sur l'île, d'ou ils se glissaient ensuite dans la chambrée.

C'est ainsi que ces braves fils de Mars se servalent de Neptune pour aller compter fleurette a la belle-sœur de ce dernier.

Inutile d'ajouter qu'on ne rencontre point dans ces détroits les banquises qui encombrent la navigation de Belle-Isle, ou les brouillards de la Manche; et qu'aucune branche du Gulf stream ne tempere le climat de leurs iles, comme ceia a lieu pour celles du canal ou detroit de Bahama 
PROMON'TOIRES, CAMS, POINTES.

Promontoiredes Roches, sud-sud-est. Hauteur, 25 pieds.

Pointe des Récifs, sud-sud-est.

Pointe Albert, sud-sud-est.

Promontoive du Tonnerre, est-nord-ouest.

Pointe Coursol, est-nord-est.

Cap du Rapide. est-nord-est.

Pointe aux Caillour, onest-nord-ouest.

Promontoire Logan, est-nord-est.

Si les caps et les promontoires de l'île Ste. Hélène sont nombreux, lls n'ont rien d'extraordinaire. Nul ne jouit d'une celebrite quelconque.

A l'exception du promontoire du Tonnerre, auquel un arbie au tronc tordu et brule par la foudre donno son nom, on chercherait vainement autour de l'ille des ruines semblables a la colonade de ce temple qui, jadis dédié a Minerve, s'élève, au sud-est de l'A ttique, si. le cap Sunlum, et sous le portique duquel Platon venait disputer avec ses disciples.

On y trouveralt encore moins un promontolre égalant la célébrité de celui de Leucade, d'où les amov reux desespérés, à l'exemple d'Artemise t de Sapho, se pré- 


\section{(iéngraphlir.}

cipitaint sur les écuells ot y trouvaient la mo1t; sans compter les survivants i l'expéri nee qui retournaient $\lambda$ jamais guériz de ce mal d'amour dont chacun de nous a souffert ou souffrira.

Rien non plus des tempetes du cap Horn ou du cap de Bonne-Espirance. Seulement, a l'est de l'ile, au pied du rapide ecumeux dont la rosée cristalline retombant sur les rives y porte une délicieuse fraicheur, s'élève le cap Logan, audessus de la formation Heiderberg.

\section{GOLF :S, BAIES ET CRIQUES.}

Les côtes de l'ìle ne présentent pas une echancrure à iaquelle, en nous servant mème du langage le plus hyperbolique, nous pourrions donner le nom de golfe.

Aucune d'elles ne peut lutter avec la beauté splendide de la bale de Naples, qui a son volcan, le Vesuve et les charmantes îles d'Ischia et de Procida; celle si pittoresque de Constantinople; et nulle n'offre la sûreté de la haie de San Francisco.

Les petites baies ou criques qui dentellent les rivages de l'ile Ste. Hélène, suffiraient à peine à abriter le navire du 
commodore Natts. Quant un cunot vient a y jeter l'ancre, sun arcière reste exposé a tous les caprices du Hot. Aussi, pour éviter l'inconvénient de voir l'embarcation entrainće, les matelots amateurs la tirent tout simplement i terre. Cette dernière façon est encore le plus sûr des mouillages.

Baic Papineau, nord-nord-ouest. Baie Morin, nord-nord-ouest.

Baie Lafontaine, nord-ouest.

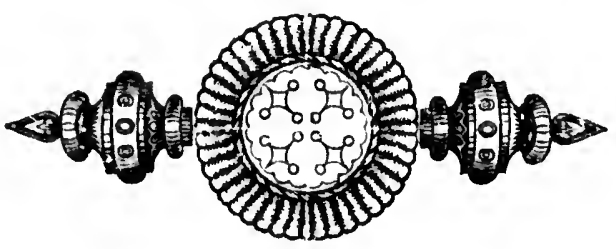




\section{FAUNE.}

S'il nous iallait cataloguer d'une façon méthodique les espèces, les genres, les familles, les individus, qui composent la Faune de notre ile, un gros volume suffirait $\lambda$ peine a cette tâche.

En énumérant les quelques espèces cidessous, nous n'avons eu qu'un but, celui de domner un sommaire fort incomplet des êtres qui constituent les habitants de ce petit monde; essayant de faire naitre ainsi le goût de l'histoire naturelle chez quelques uns, et d'occuper les loisirs studieux de quelques autres.

Il nous suffira de dire qu'en comprenant les espèces vivant dans les eaux qui entourent l'île, les oiseaux qui, traversant les airs, pauvent se reposer dans ce pied à terre verdoyant, l'on arrive au chiffre respectable de 4,391 espèces. Si l'on ajoute à ce noubr 3600 plantes, 200 fossiles et cent minéraux, on atteint le nombre de 5,859 objects d'histoire naturelle.

C'est là, comme on voit, un champ assez vaste pour les touristes amateurs de cette science. 
78 L'ile ste. Hiline.

Volci comment les diffirentes espèces du règne animal se trouvent reparties sur l'le, en commençant par les espèces les plus nembreuses, savoir: 3,500 inseztes; 600 infusoires ou zoophytes microscopiques ; 200 oiseaux ; 50 mollusques; 35 poissons ; 12 mammifères ; 8 reptiles et 8 crustacés.

\section{MAMMIF ËRES.}

[Animaux portant des mammelles.]

Noms :

Français. Anglais. Latix.

L'Ecureuil Red Squirrel. Sciurus carorouge. liensis.

Le Suisse. Ground Squirrel.

Le Rat com- Common mun. Rat.

La Souris Common commune. Mouse. Tamia qua-. drueitata. Mus decumanus.

Mus musculus.

Le Mulot des; Field Mouse. Mus acrarius. champs.

Autrefois, on rencontrait sur l'sle l'Ecureuil volant, le Rat musqué, le Lièvre, le Sifleux ou Marnotte du Canada. 


\section{Fanme.}

Carnassiers INSECTIORES.

La petite

Taupe grise.

La Chauve- Bat. souris.

Mole of cooper.

Sorex cooperi

Vespertilis noct:vagans.

\section{Carnassiers Digitigrades.}

[Qui marchent sur l'extrémité des doigts.]

La Marte du Fisher Mar- Mustela CaCanada. tin.

Le Vison. Mink.

La Belette. Weasc I.

La Bête-Fu- Shunk. ante ou

Putois. nadensis.

Cette dernière classe a complètement disparu de l'ille.

\section{Les OiskauX.}

Rapaces.

La Buse ou Marsh

Busard des Hawk.

Marais.

Le Hibou blanc.
Putorius vison.

Putorius herminea.

Mephitis

Americana. 
80

$$
\text { L'ile Sle. Hilime. }
$$

\section{Grimpeurs.}

Le pic ou pi- Hairy Wood- Pieus villosus que-bois pecker. chevelu.

Le Grand Pi- Pileated vert noir.

Woodpecker.

Hylatomus pileatus.

\section{Passereaux.}

I'Oiseau Ruby throat- Trochilus Mouche. ed Humming-bird.

Le mangeur Night Hawk. Caprimulgus de Maringouins, l'Engoulevent ou Popetue.

Le Martin Belted King- Ceryle Pecheur.

L'Oiseau bleu ou Traquet.

Le Recollet Cherry Bird. Ampelis ou Mangeur de Cerises. Le Jaseur du Cedre.

Alcyon, Alcedo Alcyon.

Blue Bird. Sialia Sialis. 


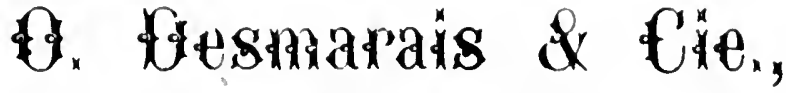 PHOTOCRAPHE,}

No. 18, Rue St. Laurent, Montréal.

BRANCHE A LA VILLE ST. HENRI.

Vues Stéréoscopiques des principaux Edifices de la ville, superienris à tous ce qui a ete fait; toujours en mains, et aussi toutes sortes de Photographies de première classe.

\section{A VENDRE CHEZ}

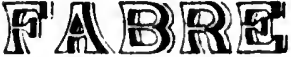

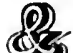

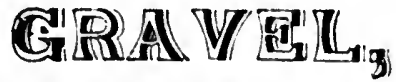

219, RUE NOTRE-DAME, MONTREAL,

Plans et Livres de Renvoi de la Cito et de la Paroisse de Montreal et des Comtés d'Hochelaga et Jacques-Cartier, reliés ou non reliees.

\section{"A CEUX QUI TOUSSENT."}

Employez la PATE DE GoMms D'EPINE'TTE du Docteur Chevaller, 25 cts. la boîte.

LAVIOLETTE \& NEISON, CHIMISTES, 215, Rue Notre-Dame, Montreal.

\section{GEORGE LEMIRE PHOTOGBAPHE.}

68, JACQUes-Cartier, Montreal,

Faisant des Photographies do tous genres, ct de premiêre classe. 


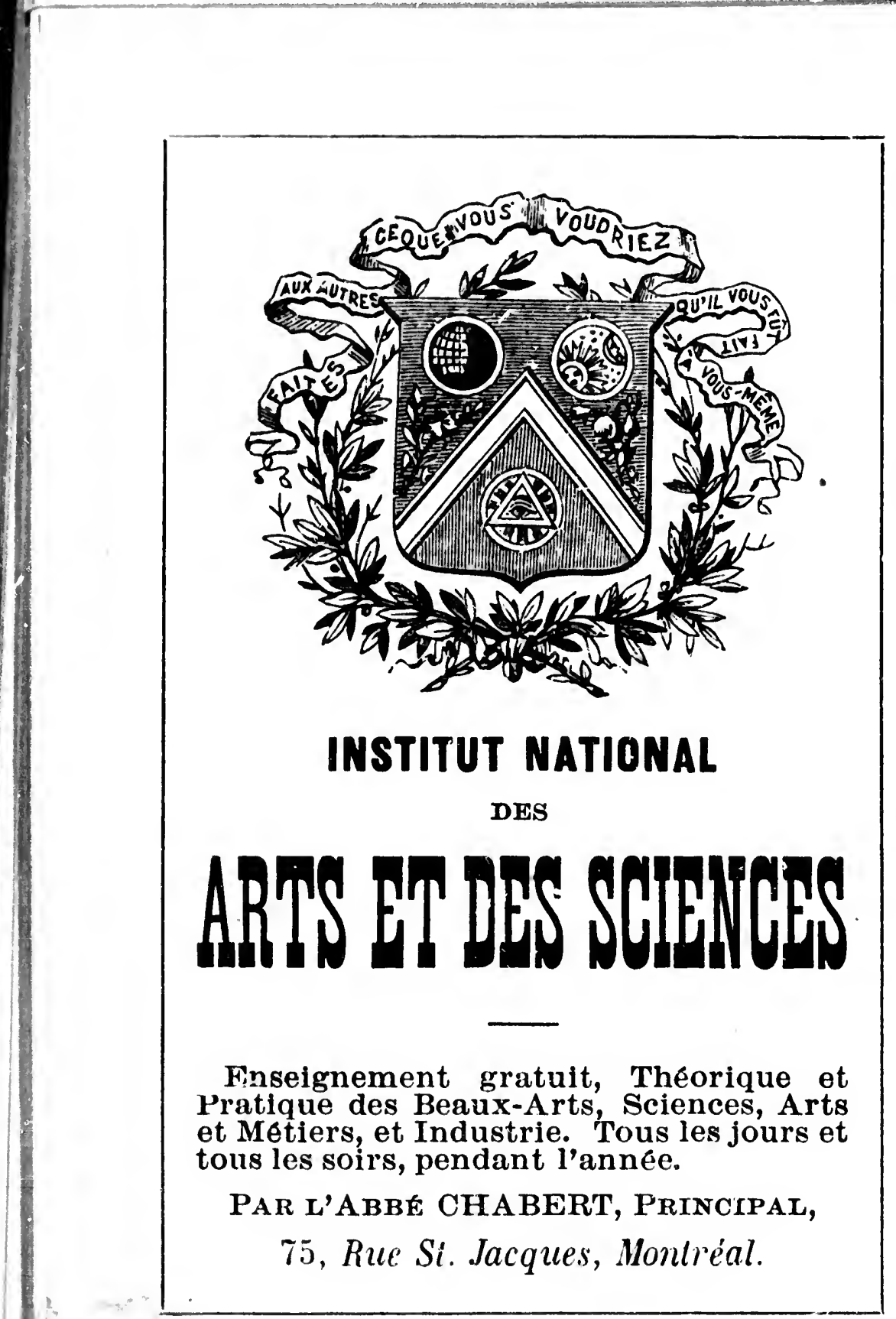




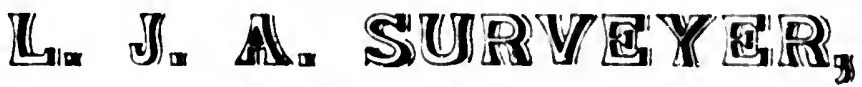
MARCHAND DE

Ferronnerie, Poêles, Corniches, Bains, Couchettes en Fer, Coutellerie et Articles Electro-Plaqués.

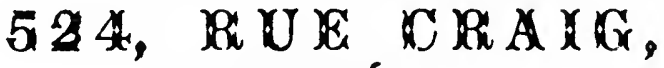
MONTREAL.

Ar. $\mathbb{K}_{\mathrm{x}}$ Aansereau \& $\mathbb{F}_{x}$ 474, RUE STE. CATHERINE,

MONTREAL.

\section{DR. NE.POLEON ROBILLARD MÉDECIN,}

S'occupant spécialement d'accouchements.

98, Rue Visitation, Montréal.

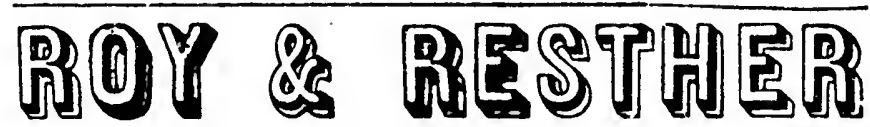

ARCHITECTES,

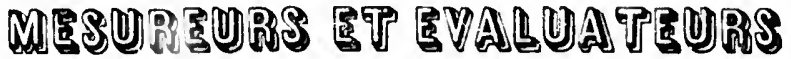

BUREAU : 63, RUE 8T. JAGQUE8

RESTHER, Résidence: 807 , Rue Ste. Catherine, ROY,

" 72\%, Rue St. André,

MONTREAL.

MM. ROY \& RESTHER se chargeront de tout arbitrage, evaluation ou mesurage de travaux de construction, et fournira aussi les quantités aux entrepreneurs. 
Ventillateur Bréveté

\section{GEO. ' YON,}

Ferblantier et Plombier,

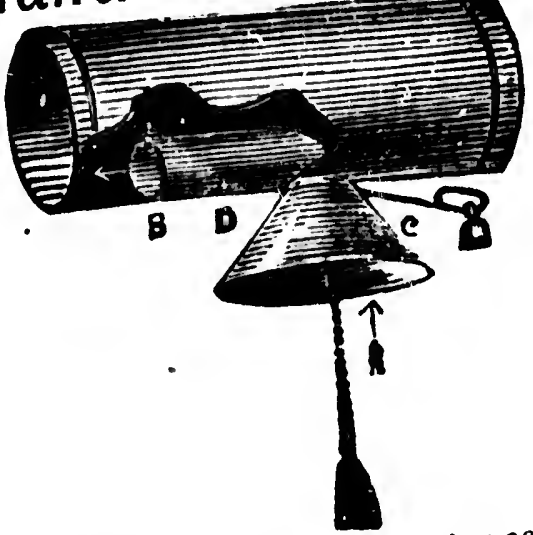
Approuvé par les hommes de science et de l'art,
à la porté de toutes les bourses.

ITSTE DE PEIX.

Aspirateur pour tuyaux de poëles, suffisant pour aérer les pièces ou passent les tuyaux Systeme complet dubes métalliques consistant en plafonds, pour poses dans les de 4 ou 5 pieces appartements de ordinaires a

- dans les maisons Montréal ........̈les de cuisine $\$ 4.00$ Aspirateur pour poèr poëles de pas- $\$ 3.00$ sage............. 


\section{fillule.}

La Fauvette Water IVag- Turd's aquahochetail. ticus. quetre.

L'Oiseau Jaune ou Fanvet te Yellow War- Dendroica jaune.

Le Goglu ou Rice Bird. Dolichonyx Mangeur de riz.

L'Etourneau Caw Bird. Molothrus ordinaire.

L'Etourneau swamp aux ailes rouge, les oryzivorus.

Carouge commandeur.

La Corneille. Common Crow.

Corvus Americanus.

Outre ces espèces, on trouve celles des Echassiers, des Palmipèdes, etc., ete.

REPTIIES.

Ophidiens ou Serpents.

$\$ 1.60$

a $\$ 55$

$\$ 4.00$

$\$ 3.00$

[De Ophidion, petit serpent.]

[Aucune des especes n'est venimeuse.]

Le Serpen, Milk Snake. Ophibolus Aspic. eximius.

LaCouleuvre Stripped Coluber Sircommune.

Snake. talls.

La couleuvre Grass Snake. Coluber ververte. nalis. RENT. 
82

L'ile Sle. Hélìne.

Batraciens.

[Reptiles quadrupèdes a peau nue, doigts distincts, sans ongles.]

La Grenoulle haléclne, ou grenoulle tachetce de noir.

Lagrenoulle Wood Frog. Rana sylvades bols.

La grenouille Bull Frog. mugissante ou Wawar-

Leopard Frog.

Rana halecina. tica.

Rana mugiens. ron.

Rainette ver- Tree Toad. Hyla versicosicolore.

Le Crapaud Toad. Americain ou Crapaud galleux.

Salamandre it dos rouge.

Le Menobranche lateral ou Lézard d'eaudouce. lor.

Bufo Americanus.

Salamandra Salamand- cinerea. er.

Proteus of Triton lateraLakes. lis.

PoIsisons.

[Ce sont ceux-mêmes du fleuve SaintLaurent:] 
Les rivieres de l'ile, et pour cause, ne renferment aucun poisson. Quant aux lacs, leurs eaux n'abritent que quelques vêrons ou epinoches, du genre cyprin.

\section{Mollugques Acephates.}

Mulete ou Right River Unio rectus.

Moule Mussel. droite.

Mulete com- Complete Unio complete. Mussel. planatus.

Mulete ven- Big beliied true. Mussel.

Mulete en cœur. Shape heart U. Ventricosus.

rsicoaeri-

Anodontes ou Moules d'etang. Anondonte de Lewis.

Mulète per- Pearl Mussel. Unio Margalière. ritana.

Mulète mar- Margined ginee. Mussel.

Unio Marginata.

\section{LES ZOOPHYTES INFUSOIRES}

Sont des animaux-plintes, presque tous microscopiques. Les eaux stagnantes de l'ile en renferment plus de 600 espèces. 


\section{Crustaces.}

[ Animaux couverts d'écailles, ou d'une enveloppe dure, flexible ot divisée.]

L'ecrevisse Fresh Water Astacus Bord'eau douce. crawfish. tani. Isa petite Cre- Little Prawn. Grammarus vette. minor.

Il faut y ajouter plusieurs espèces de Cloportes. Woodlouse Oniscus, or Sowbug.

qui sont Indéterminés.

\section{IJES INSFCTES, BEETIES.}

[Animaux divises on segments.]

COL.FOPTERES.

Insectes a alles couvertes de fourreaux solides et coriaces.

Le Frappe May Bug. Lachnasterna d'abord ou fusca.

Hanneton.

Crives yeux Capricorn Monohamus. ou Longi- Beetles. cornes.

Barbeaux a Crusader cár-Necrophorus. charognes, rion beetles.

La mite ou Eater bacon Dermestes petit castor, beetles. lardarius. ou Dermestes. 
Casse tète ou Spring Beet- Elater, vol sautereau. les. Corymbites. Elatirides.

Mouches à feu Lighning ou Lampire. Beetles.

Photynus, vel Photuris.

Betes dorees Tiger beetles. Cicindella oll Cicin. delles.

i punctata.

betes a bon Gilded Dandy. Chrysomeln Dieu ou

('hrysomeles.

Pucerons jau- Yellow bugs. Diabrotica nes ou Mou- vittata. ches jaunes, ou Galéruques.

Les Coccinel- Lady bugs. Coccinella. les ou Pet1tes vaches.

ORTHOPTERES.

[Insectes a ailes pliees en eventail, etuis mous.]

Sauterelles. Grasshoppers. Ódipoda. Criquet noir. Black criket. Gryllus

mus.

\section{Criquet} blanc.

Barbean de Cuisine ou Blatte.

Coquerelle German cock-German ou Blatte germanique.
Domestic criket.

Comr:on cockroach. campustus. Gryllus domesticus. Stylopiga orientalis. Periphana. 


\section{$86 \quad$ L'île Sle. Hélène.}

HEMIPTERES.

[Dont les ai]es sont u moitié revêtues a'étuis coriaces.]

Punaises des The Squash- Pentatoma, bois ou Pen- bugs. tatomides.

Arma.

NEVROPTERES.

[A mâchoires, et à 4 ailes reticulées ec transparentes.]

Les Demoi- Uragon fly.] Libellula, vel selles ou

Libellules.

Les Mannes Caddice flies. Frigana. ou Friganes.

Les Ephémè- Shad flies. Ephemera. res.

HYMENOPTERES.

[A mâchoires, et pourvus de 4 ailes veinées.]

Fourmis. ' Ants.

Abeilles, Bees.

Bourdons, Drones.

Guêpes.
Wasps.
Formica.

A jis mellifera.

Bombus

Vespa, Jehneumon.

DIPTÉRES.

[A deux ailes nues.]

Barbeaux a cheval ou Horse flies,

Gastrus equi. Oestres. Bot flies. 


\section{Faune.}

Ver du dos Cow flies. des vaches ou Oestres beuf.

Mouches a Meat fly. Calliphora vers. vomitaria.

Brulots ou Burning flies. Simulium. Ṡimules.

Les Ièves-culs Mosquitos Culex pipiens ou Culbu- larva.

Hypoderma bovis. teux, larves des Maringouins.

Moustiques, est le nom que l'on donne a tous les autres diptères de petite taille.

\section{Apriteres}

[Sans ailes: les poux, la punaise des lits.] Pou de terre. Spring tails Podura. lice.

Pou rouge Red louse. Strombium. strombe.

Betes a mille Gallyworms. Julus venuspattes, Jules tus.

Scolopendre, The centipe- Iithobius bêtes à 100 des. Américanus. pattes.

Poux des bois, Moose louse. Ixodes albiPou du chepictus. vreuil et du liêvre. 
88

\section{L’ile Ste. Héline.}

L.EPIDOPTERES.

[A quacre ailes écallicuses et colorées.]

Le grand Pa-Ceeropia pillon gris Moth. brunâre.

Attacus ceciopia.

Grand Papil- Polyphema Attacus Polylon jaunitre. Moth. phema.

Papillon jau-The Philodice. Colias Philorie soufre, ailes bordées

de noir.

Papillon brun The Morning Vanessa anchocolat, ai- Cloak. tiope. les bordées de jaune.

Papillon blane du choux.

Papillon de la 'The Tent Clisiocampa chenille des Caterpillars. Americana. pommiers, et des cerislers.

'Tous les petits papillous de tuit, qu'on rppelle vulgalrement Petits Anges, appartiennent a la nombreuse classe des Noctua ou Noctuelles; telles sont a ussi toutes les teignés qui attaquent les céréales et les etoffes. 
Mollusques.

[Qui ont le corps mou: Colimacons, etc.] LAS GASTERGPedes.

[Qui ont les pieds sous l'estomac.]

Escargots Lana Snails. Helix abolaHélíces. bris.

Escargots. Variable land Helix altervariables.

Escargots concaves.

Paludine. snalls. nata.

Concave land Hellx consnatls. cava.

River snails. Paludina desisa.

Paludine in- Upright river Paludina tègre. snails. integra.

Limné sta- Spiral fresh Limnea stagnante. A mbrette. water snails. gnalis. A mber snalls. Succinea.

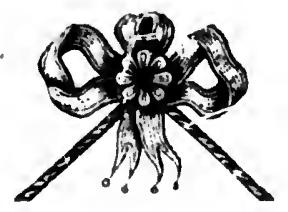




\section{L'AVENIR.}

Qu'adviendra-t-il de cette île Ste. Helène qui, posée sur les eaux du fleuve comme une corbellle de verdure et de fleurs, invite aux jours caniculaires toute la population de Montréal a aller respirer la fraîcheur de ses ombrages, a gonter le tranquille repos de ses bosquets, ou a s'etendre, paresseuse, sur le velours de ses pelouses?

Sa destinée future cépend de nos édiles, du souci qu'lls prendront de la santé et des distractions publiques.

Outre ses nombreux squares, le quartier Centre de Montréal a son Jardin Viger; l'Ouest aura bientôt le Parc Mont Royal; n'est-il point juste, puisque la Nature a traité le quartier Est en bonne fee par le don qu'elle lui fit de l'île Ste. Hélène, que le flleul profite des largesses dę sa marraine?

En tout temps et en tous pays, les jardins et las parcs ont servi a embellir la demeure des particuliers, l'enceinte des villes ou leurs environs; ce fut la premiere conquête de la terre par le travail et le génie de l'homme. 


\section{L'Avenir.}

Si, dans l'antiquitá, les jardins du sage Alcinous, du pieux Laërte, du philosophe et guerrier Xénophon, furent de simples vergers, la Grèce eut plus tard ses bois sacres; la Syrie, de superbe jardins a Antioche, puis ceux de Semiramis a Babylone; l'Egypte, les siens ornés de pilones, d'obélisques et de colonnades de palais; la Perse, ses déicieux Paradis. Les Arabes creèrent en leur genre de véritables merveilles, en Sicile, a Palerme; en Espagne, l'Alhambra; les Astèques et les Toltèques, les jardins flottants de Mexico; les modernes, Boboli, a Florence; · les Jardins du Belvedere et du Quirinal, a Rome; le Luxembourg à Paris, etc., etc.

Situee entre deux bras du fleuve St. Laurent, dont le double courant entretient sur ses bords une perpétuelle fraîcheur, l'île Ste. Hêlène, hien que d'une superficie peu considerable, offie, grâce $\lambda$ son site exceptionnel, aux arbres magnifiques de l'interieur, aux decoupures de ses côtes et aux courbes de ses sentiers, tout ce que l'art d'un Le Nôtre ou d'un Kent réussissaient à créer à force de combinaisons savantes et d'argent.

L'eau et le feuillage, ces deux grands 
$9 \cdot$

L'lle Sle'. Héline.

coloristes des parcs et des jardins, sont li, tout prêts, n'attendant pour nous charmer que les ordres d'un homme de goût.

Quant aux perspectives, les ondulations du sol de l'ile se prêtent on ne peut mieux it des effets pittoresques et peu coûteux.

Quelques éclaircies habilement ménagées, des semis de sapins sur ses collines, un rideau de trembles ou de bouleaux aux robes argentées sur les bords de la grève; une saulaie aux rameaux penchants sur l'enu moirée des lacs; de ei de la, un vétéran de la corêt dominant un tertre solitaire, et répandant autour de son tronc vigoureux l'ombre de sa puissante ramure: tout cela sont des creations fachles qui ajouteraient in ce parc naturel autant de traits charmants et nouveaux.

Ce seraii folie que de songer à métamorphoser notre 1 le Ste. Hélène en parc artificiel ou en jardin paysager, et de vouloir réunir en un aussi petit espace, les bois, les eaux. les rochers et les batiments qui entrent d'ordinaire dans les plans des jardins modernes.

Comme jardins classiques, nous pouvons citer, en France, les Parcs de Versailles, du grand Trianon, de Marly, de Chantilly, 


\section{Lisenir.}

de Sceaux, etc.; en Italie, la Villa Panfili, a Rome; le Parc de Turin; en Angleterre, ceux de Greenwich, de St. James; en Espagne, l'Acazar à Séville; le Prado et le Buen Retiro, a Madrid; les passeios a Lisrónne; l'Alaméda, a Gibraltar; mais le plan de ces jardins classiques ou mauresques ne saurait en rien convenir a notre ile. Un jardinier chinois pourrait seul transformer notre rocher fleuri en une de ces merveilles comme il s'en voit tant dans l'Empire du Milieu; et encore notre ile, pensons-nous, n'y gagnerait qu'en originalite bizarre et ce serait tout.

Si l'Angleterre s'énorguelllit a juste titre des jardins publics de Finsburg, Victoria, Battersea, Kensington, Green Park et Hyde Park ; Berlin a son / hiergarten et Sans-Souci ; Vienne son Prater et Schœenbrunn ; Drescle, son Grosse-Gurten : Cassel, Wilhemshohe ; St. Pétersbourg, TzarskoSélo; Paris, les Bois de Boulogne et de Vincennes; Montréal aura bientôt son Parc Mont-Royal aux splendides horizons, aux merveilleux points de vue, et cette île Ste. Hélène aux frais gazons, aux brises constantes, qui se mire comme une coquette dans les eaux de son grand fleuve. 
Nous n'avons point donné la nomenclature cl-dessus pour etablir une comparaison entre un de ces parcs et notre ile modeste, nous avons voulu montrer seulement comblen les grandes villes, en entretenant a leurs frais d'aussi beaux jardins, font cuvre de morallte, de science et de civilisation.

Quelques travaux peu dispendieux, un soupçon d'imagination et de gout, suffiraient pour donner a l'ile une physionomie plus variee; mais l'on devrait avoir soin de conserver religieusement les traits rustiques de ce charmant séjour.

D'abord, il s'agirait d'agrandir le domaine de l'ile Ste. Hélène en y rattachant, comme des fiefs a leur apanage, l'île Ronde, et le petit archipel de St. Lambert, ainsi que les iles aux Fraises et Motfat.

Un pont suspendu jeté entre les îles Ronde et Ste. Hélene serait une construction des plus elegantes, et ajouterait une dépendance de plus sur laquelle on pourrait elever soit une tour, soit une terrasse couverte, garnie d'arbustes, de plantes grimpantes; construction que l'on enleverait à la fin de chaque automne, et dont les ma- 


\section{L'Avenir.}

tériaux se remiseraient dans les magasins de l'île.

Qui empêcherait d'avoir la-le lieu convient a merveille-un ballon captif, dans la nacelle duquel les amateurs pourraient. moyennant un prix modique, se donner les émotions d'une ascension aérostatique!

Quelques ponts de bois jettés sur les îlots St. Lambert feraient de l'archipel une sorte de terre ferme oü de petites chaloupes $\boldsymbol{n}$ vapeur viendraient déposer les explorateurs.

Un pavillon-buvette sur chacune des îles aux Fraises et Moffat, animerait le paysage; quelques jeux : cible, tir aux pigeons ou tout autre, pourraient aussi s'y etablir.

Ceci fait, un chemin carrossable autour de l'île où cavaliers et voitures circuleraient sans encombre, ne serait point fort couteux et ajouterait un grand agrément a la promenade.

Sur les hauteurs qui, du côté de la baie d'Hochelaga, dominent le fleuve et son magnifique horizon, ne serait-il pas possible d'établir une longue et large terrasse, la-

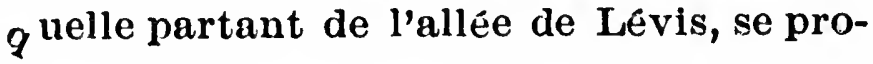


96 L'ile Ste. Hiline.

longeralt en contotirnant la pointe do l'.lejusqu'al l'ancien escalier munlcipal ?

Par un ouvrage semblable, l'on obtiendrait une magnificue promenade, unique au monde, et la vue d'un superbe panorama.

Des chemins tournants, pour faciliter l'ascension des monts Montcalm, Boule et St. Sulpice, sur les flancs desquels on menagerait une cascatelle, une chnte ecumeuse, relèveraient de beaucoup le charme de ces lieux.

Agrandir les lacs Arthur et Frontenac, amener de l'eau dans les deux rivières, et leur creuser un lit sirneux sur lequel on jetterait un ou deux ponts rustiques, donneraient un aspect pittoresque au paysage.

A vec le courant du fleuve, une simple roue hydraulique plongeant dans le $S t$. Laurent suffirait, a peu de frais, a l'approvisionnement d'eau de toute l'île.

Une fontaine monumentale au rond point Dufferin, ne gâterait rien, et un jet d'eau dans la vallée St. Jean-Baptiste, ou seraient cultives quelques parterres, ne deparerait point ce site.

Un monument élevé à la mémoire du chevalier de Levis ne seirit, certes, pas 


\section{L'Avenir.}

plus déplacé sur l'ile, que ne l'est dans le superbe jardin de Stowe, en Angleterre, l'obelisque de trente metres de haut que surmonte ia statue du general Wolíe, le rival heureux de Montcalm.

Et, plus tard, quel endroit plus convenable, quels batiments mleux aménages, que les casernes de l'ile pour avoir la une ménagerle, une soite de jardin zoologique.

Le sort de l'ìle Ste. Helène, ou plutot le changement des princlpaux traits de sa physionomie, dépend beaucoup des travaux que nécessitera l'agrandissement du port de Montreal.

Comme on le sait, cette derniere ville aspire a devenir une metropole commerelale, a rivaliser avec New-York, et meme a dépasser l'importance de cellè-ci en falt de commerce de transit.

Ba situation exceptionnelle sur le $\mathbf{S t}$. Laurent, quil la rapproche a la fois par ses canaux et ses lacs des régions agricoles de l'Ouest, de l'Europe par l'A tlantique ; cette position géographique avantageuse, legitime les désirs et les efforts de Montréal.

De cet objectif a atteindre sont nes deux projets, dont l'exécution simultanee ou successive modifierait notre parc. 
Le premier, par ordre d'importance pour notre ile, est celul de M. T. A Vernon, ingénieur, qui, consulté par la commission du havre sur le mellleur moyen a prendre pour donner a Montréal un port digne de son avenir, a propose de changer le lit du fleuve et de le falre passer entre l'ile ste. Helène et la rive de St. Lambert.

Par cette interversion, le coté nord du fleuve deviendrait un vaste bassin, renfermé entre deux jetées, l'une allant de l'extrémité de la Pointe St. Charles, a la pointe sud de l'île Ste. Hélène, l'autre partant de la pointe nord de l'île pour atieindre le quai dOchelaga. Cette baie artifictelle aurait une superficle de $\mathbf{5 , 0 0 0}$ acres, et une profondeur moyenne de 30 a 40 pieds. Les etées servant de voie de transport, aurafent 200 pieds de largeur, et porteraient une double vole ferrée. Un pont réunissant l'ile a la rive sud, complèterait ce gigantesque plan.

S1 jamais ce projet grandlose se realise, l'ile ste. Hélène, enfermée entre ses iongs quais de pierre, deviendra un simple squarre où quelque société de tempérance elèvera la fontaine de rigueur, 


$$
\text { L'Arenir. }
$$

munie des goblets en etain qu'une chaine métallique retient attachés ù la vasque.

Ie second projet consisterait dans l'établissement d'un pont réunissant les deux rives du theuve, lequel pont se servirait de la surface de l'ile comnie d'un pilier colossal.

Destiné a relier les chemins de la rive nord $i$ la rive sud, ce pont dont le projet $a$ eté soumis à un comité du Parlement, a la dernière session, aurait 7.300 pieds pour la partie construite au-dessus du fleuve seulement.

Cette entreprise connuc sous le nom du pont Victoria-Albert, ne gâ terait point trop l'aspect de l'ile, car il ne ferait quis la traverser dans sa largeur, et le passage des trains, l'arrivee des pietons, des cavaliers et des voitures, venant de chaque côte du fleuve, serait un spectacle qui ajouterait in lîle un attrait nouveau.

Un troisieme projet, mais qui ne toucherait qu'aux abords et non a l'île Ste. Hélène, c'est celui de M. Slippel, ingénieur. Ce dernier propose la canalisation du fleuve depuis l'embouchure du canal Lachine actuel jusqu'a Hochelaga, point ou deux vastes écluses permet- 
traient aux navires de franchir le courant sans encombre et de rentrer dans le port actuel transforme en vaste bassin. Ce même canal se proiongerait au-dessous du pied du courant dans l'interieur des terres dans la direction de la rue de Sherbrooke. A vec ce projet, notre ile Ste. Helène resterait telle qu'elle est; rien ne viendrait mutiler ses massifs ou troubler sa douce tranquillite. Il n'y aurait qu'un panorama vivant et animé sur la face nord, et personne ne s'en plaindrait.

Nous nous sommes bornes ic $a$ indiquer les améliorations dont ce parc est susceptible, sans vouloir, en aucune facon, faire prendre nos suggestions fantaisistes pour des conseils, trop heureux si des changements, dans le sens indique, nous obligent bientôt a transporter au chapitre le Présent, ce qui se trouve aujourd'hui mentionne au chapitre l'Avenir. 


\section{MEMBRES DU COMITE}

UF

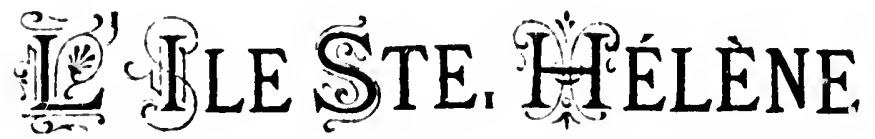

Ths. WILson, Echevin, Président. MM. MaSHANE.

CLENDINNENG.

MACLAREN.

RIVARD.

LORANGER.

DUHAMEL.

C'est à l'activite, aux soins, a la surveillance du President M. Ths. Wilson, que l'île doit les bancs nombreux placés en maints endroits, et les travaux d'amelioration executés sur les chemins et les rives du Parc. 


\section{TABLE DES MATIÈRES.}

page

Poksie-A l'Ile Ste. Hélène........... 3

HISTOIRE........................ 5

Considerations Générales.......... 5

Son Passé....................... 6

GEOLOGIE..................... 23

Palfontologie .................. 31

Le Present. ...................... 35

FLORE......................... 53

GEOGRAPHIE................... 65

FAUNE....................... 77

L'A VENIR .................... 90

MrMBRes DU COMITE DE 'IIE STE.

Herine..................... 101 


\section{COMPAGNIE DE NAVIGATION RICHELIEU ET ONTARIO

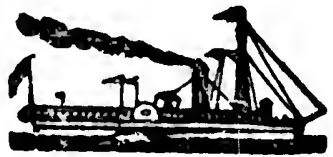

Steamer de la Malle Royale entre Quebec, Montréal, Kingston, Toronto, Hamilton et les ports intermediaires.

Le vapeur QUÉBEC, capt, ت. B. Labelle, et le vapeur MonTreal, capt. $\hbar$. Nelson, partent tous les jours (dimanch es exceptes) pour Québec, à 7 heures.

Les vapeurs de Montreal a tramilton, falsent correspc. $\cdot{ }^{3}$ unce a Toronto avec les vapeurs pour les Chutes Niagara et Buffalo, et avec les chemins de fer pour l'ouest.

Le Corsican, Capt. D. Sinclair; le SPARTAN, Capt. M. W. Balley; le Corinthran, Capt. P. Farreli ; le PAssport, Capt. Wm. Sherwood ; le Algerian, Capt. J. Trowell, partent tous les jours (Dimanches exceptes) du Bassin du Canal, a 9 heures A. M. et de Lachine a l'arrivee du train qui part de la gare Bonaventure a midi.

Le Str. BOHEMIAN, Capt. J. Rankin, pour Cornwall tous les Mardis et Vendredis i 12.50 p.m., du Bassin du Cangl et de Lachine après l'arrivée du traín de 3 heures.

Le Str. TroIs-RIVIERES, Cap,. Joseph Duval, part pour Trois-Rivieres tous les Mardis et Vendredis, a 9 A.M., correspondant à Sol'el avec la Mouche à Feu pour St. Francois et la rivière Yamaska,

Le Str. BeRTHIER, Capt. L. H. Roy, part pour Berthier tous les Mardis, Jeudis et Samedis, a 2 heures P. M. 
Le Str. Cha m BLy, Capt. Frs. Lamoureux part pour Chambly tous les Mardis et Vendredis, i 2 heures P.M.

Le Str. Terpeibonne, Capt. E. Laforce, part tous les jours (Dimanches exceptés) pour l'Assomption, i 4 heures P. M.

Bureau pour les billets et les cabines au No. 133, Rue St. Jacques. Bureau pour le fret au Bassin du Canal et au Quai Richelieu, au pied de la Place Jacques-Cartier.

Bureat: Général : No. 228, Rue St. Paul, Montreal.

ALEX. MILLOY,

Agent du Traffic.

J. B. LAMERE,

Agent Général.

\section{REFORME TRËS IMPOTANTE!}

15020, PROFIT NET, OFFERT AU COMMERCE!

1o. Echantillons expédies sur demande. PLUS DE COMMIS VOYAGEURS !

Profit pour l'acheteur, 5 p.c.

20. Le fabriyuant, n'etant plus influencé par les voyageurs, évite les credits douteux et les pertes qu'ıls entraînent............... 5 "

3o. Le fabriquant, en suivant le même système pour ses nchats, et par une grande économie d'administration, épargne..... 5 5

Le soussigne peut donc offrir a ses pratiques sans affecter ses profits : 15 p. c.

$$
\text { G. BOIVII, }
$$

38, 40 et 42 PLACE JACQUES-CARTIEP. 


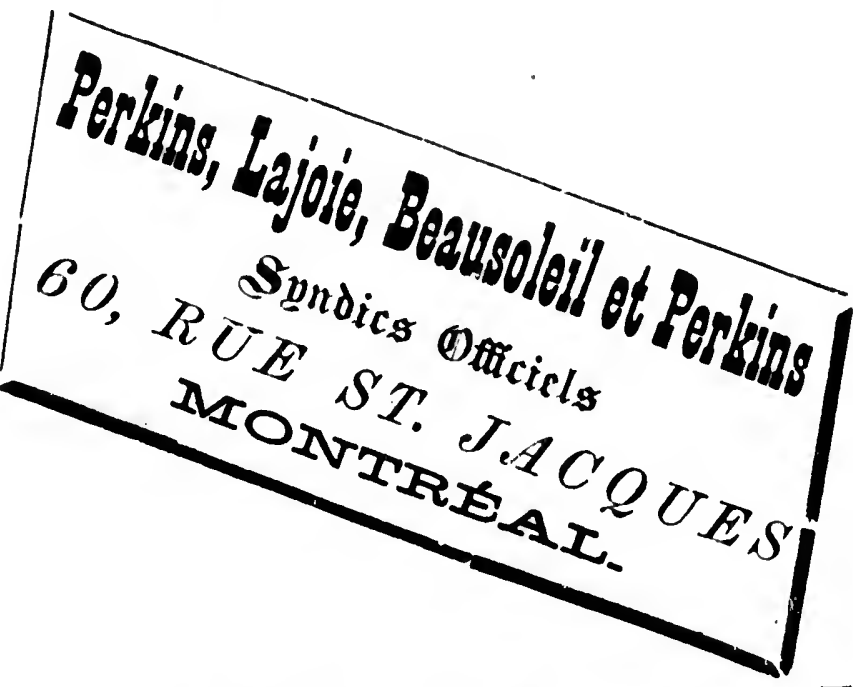

\section{J. O. GUH,MOTTE}

N0.74 \& 76, RUE NOTRE-DAME COIN DE LA RUE BONSECOURS

$\$ 20,000$ rie toutes Marchandises assorties et Hardes Faites pour etre vendues au prix coutant et au-dessous.

HABILLEMENT FAIT EN 12 HEURES.

\section{G. IEPAGE IMPORTATEUR DE}

Ferronneries, Poêles de Cuisine, double et a charbon, Refrigerateurs, Pompes, Appareils de Pêche, Etc., Etc, 67, PUE NOTRE-ïAME, 3e Porte Est de la rue St, Denis A I'ENSEIGNE DU MARTEAU MONTREAL. 


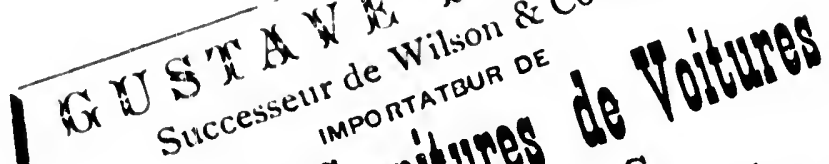

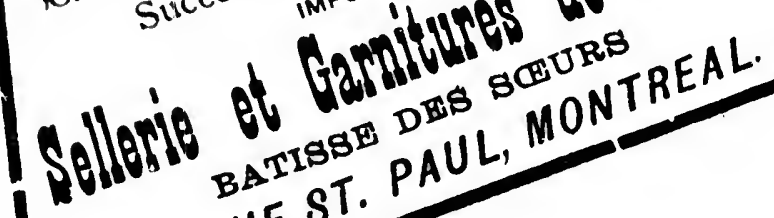
379. RUE ST.

\section{A. IOPOACE}

Marchand en Gros de

fuir, Peaux, fuiles, fle. ET

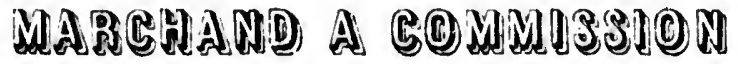

No. 505, RUE ST. PAUL MONTREAL. 


\section{ASSURANGE MUTUELE DE LA CME CONTRE LE FEU}

\section{NO. 9, COTE ST. IA AMBERT MONTREAT.}

La plus prospère sur ce continent. N'assure pas en dehors de la Cité.

N'assure pas de Stock ou Marchandises. N'a pas d'Agents Solliciteurs.

Valeur des Proprietes Assurees \$6,000,000. Capital en Hy pothèques, $\$ 500,000$.

Toujours en Banque, quatre fois le montant de la plus forte annee de pertes subies depuis 16 ans.

Directeurs pour l'annee courante: JEAN BTE. BEAUDRY, Ecr., President. R. A. R. HUBERT, Ecr., Vice-Président. ANDRE LAPIERRE, Ecr.

NAZAIRE VILLENEUVE, Ecr.

CHARLES GARTH, Ecr.

ZEP. CHAPELEAU, Ecr.

OWEN MCGARVEY, Ecr.

GUILLAUME BOIVIN, Ecr.

JOSEPH COMTE, Ecr.

ALFRED DUMOUCHEL, Ecr., Sec.-Trés. WILLIA M WATTS, Ass. PIERRE GIGUERE, Inspecteur. 


\section{MAISON ST, DENIS}

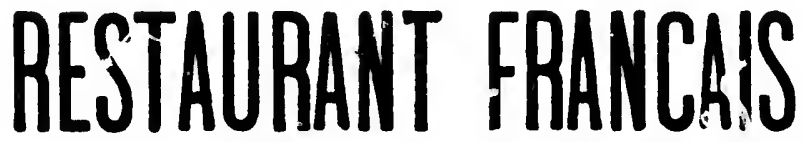

Ed. FORTIN, Propriétaire.

42, Rue Bonsecours

Cet etablissement deja si avantageusement connu du public vient d'être agrandi et fraichement decore. Saile a Manger, Cabinets Particuliers, Salle de Lecture, Salon de Coiffure, on trouve lâ, toutes les délicatesse de la cuisine parisienne et le confort des maisons de première classe.

Vins et Liqueurs de choix, des meilleures marques.

Lunchs, Dejeaners et Diners servis a toute heure.

Attention toute speciale accordée aux diners privés et aux réunions d'amis.

Lunch de 11 A.M., a 2 P.M.. Pr1x 30 cts.

Le Dimanche, le Restaurant est ouvert depuis miàl jusqu'a 8 hrs, P.M. 


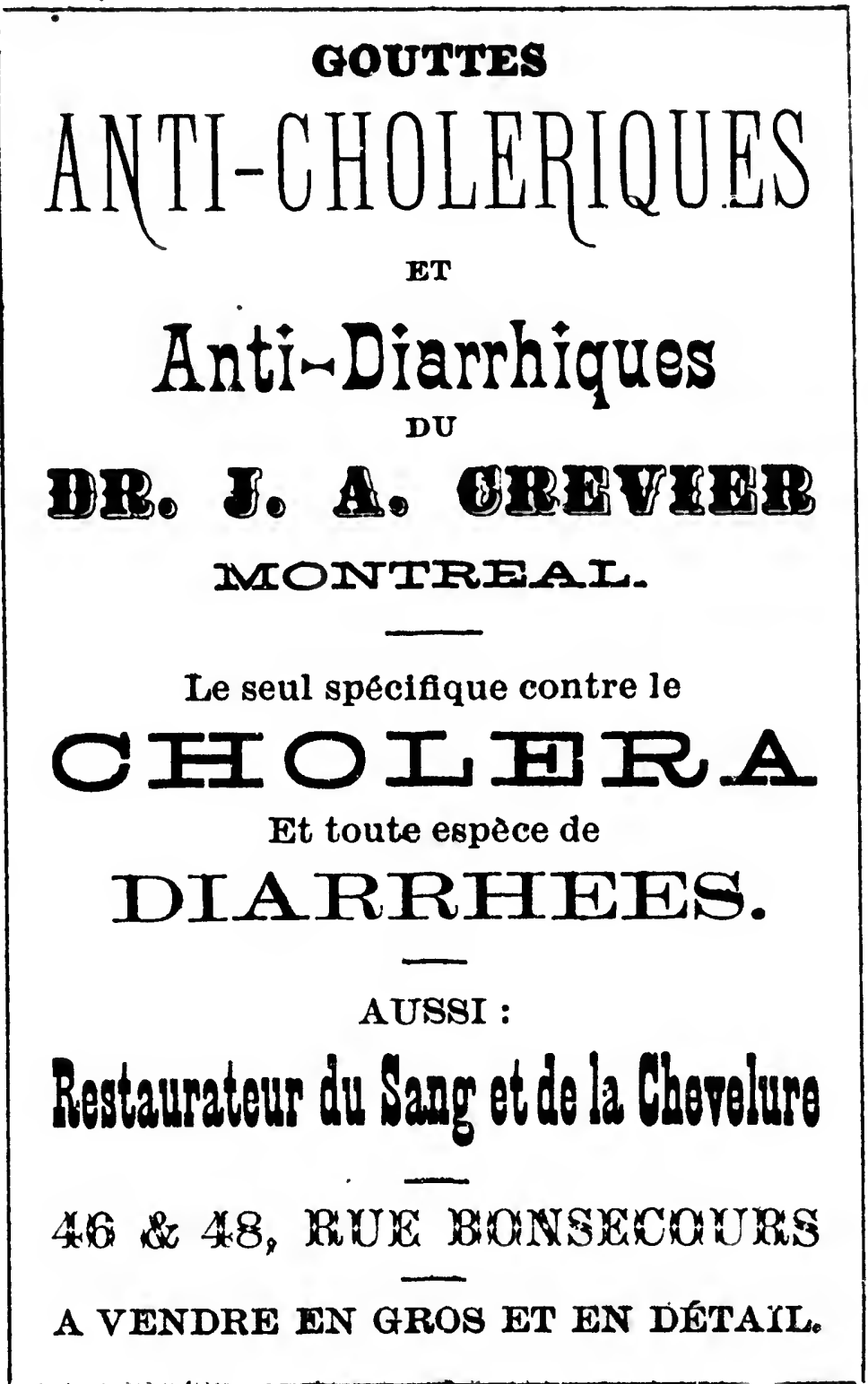




\section{DE BEAUFORT \& TASSÉ Importateurs et \\ MARCHANDS EN GROS}

DE VING, LIQUEURS, AUSSI "BITTERS DU CENTENAIRE" ET VIN DE FER ET QUININE.

33 \& 35, Rue St. Gabriel, Montrial.

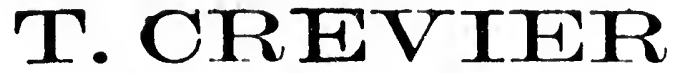

MANUFACTURIER DE

POELES, FOURNAISES A AIR CHAUD, MATERIAUX EN FONTE POUR

BATISSES, FERBLANTERIE,

REFRIGERATEURS, \&c.,

NO. 639, RUE CRAIG, MONTREAL.

\section{BOISSON D'EXE. \\ RUSENHEIM \& JONAS.}

Rien de délicieux, de rafraichissant comme cette " Poudre pour Limonade." Chaque maison doit en avoir. Point de vrai pic-nic sans elle. Dans les rénions d'enfants ou les soirées l'on ne peut se passer de cette Limonade agreable et saine.

AMABLE ARCHAMBAULT ET

CLEOPHIAS EDOUARD LECLERC, NOTAIRES PUBLICS, 53, RUE ST. JAGQUES, MONTREAL. 


\section{J. FORGET}

\section{Courtier}

\section{(MEMBRE DE LA BOURSE)}

Se charge de toutes transactions concernant l'Echange, Actions de Banques, Compagnies Diverses et autres opérations financières.

EDIFICE DE LA BANQUE D'ECHANGE 10.4, Rue St. François-Xavier MONTREAL.

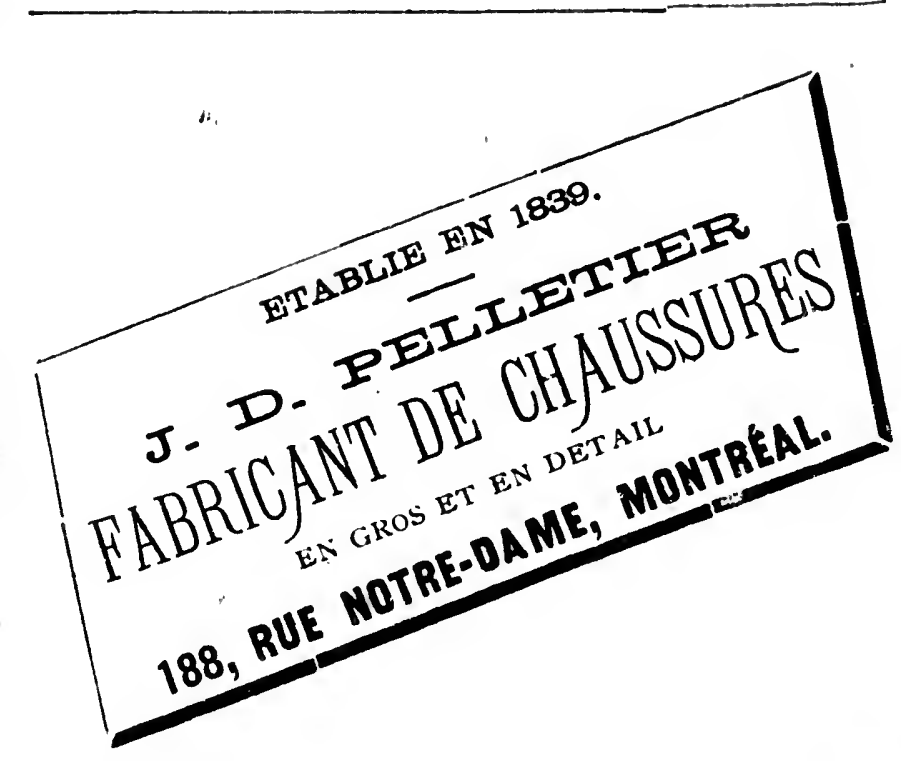




\section{JEAN CASSIDY \& CIE.,} IMPORTATEURS DE

POBCELAIIE, RAEMEE, PBBRERHE,

$$
\text { ๒ ว., Е'TC. }
$$

NOS. 339 \& 841 , RUE ST. PAUL MONTREAL.

P

Thibeaudeau, proros, fie. Importateurs et

Marchands en Gros

$$
\text { NOUVEAUTES }
$$

382, St. Paul et 271 Rue des Commissaires 


\section{CIE.}

BRERIE

PAUL

(a)

\section{LA COMPAGNIE DE}

Compagnie Nationale, aimee du public, assure

Dans des conditions excep. tionnelles les résidences

particulières,

LES FONDS DE MARCHANDISES (Gros ou détail.)

Capital autorisé, - - $\$ 5,000,000$

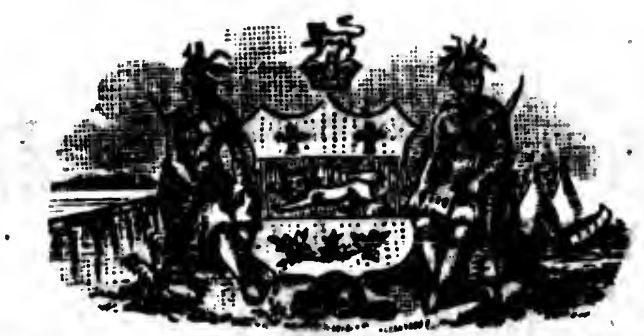

Burean Principal : Québec,

GEO. J. PYKE, Gérant.

Succursale de Montréal

\section{3, PLACE D'ARMES C. D. PerRault, agent.}




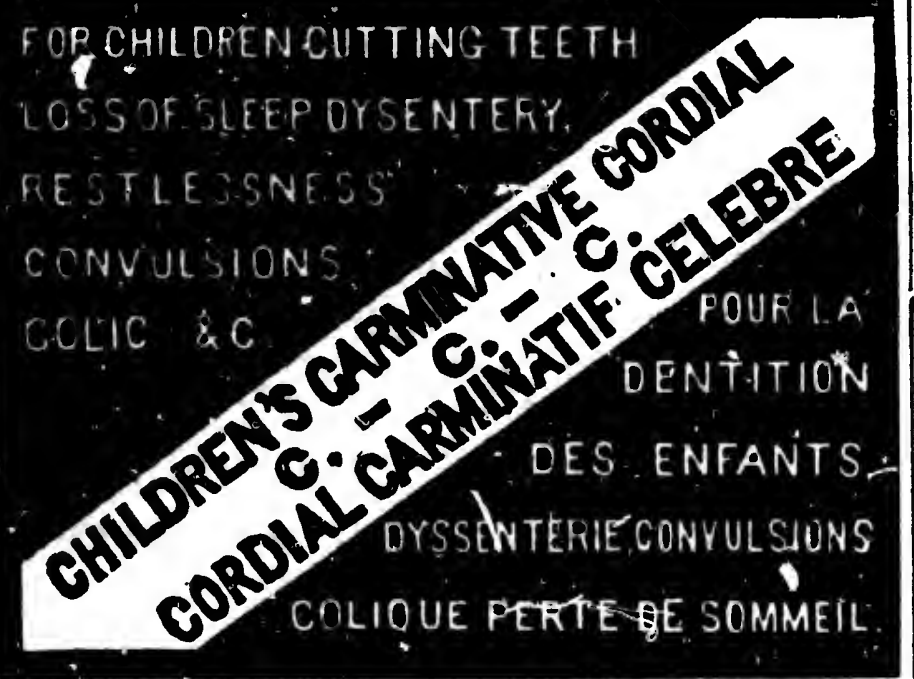

A VENTRE CHEZ

DEVINS \& BOLTON, Pharmaciens, Vis-d-vis le Palais de Juistice, Montréal. APPKOVED OY THE MEDICAL FACULTY - Worir pastiutes.

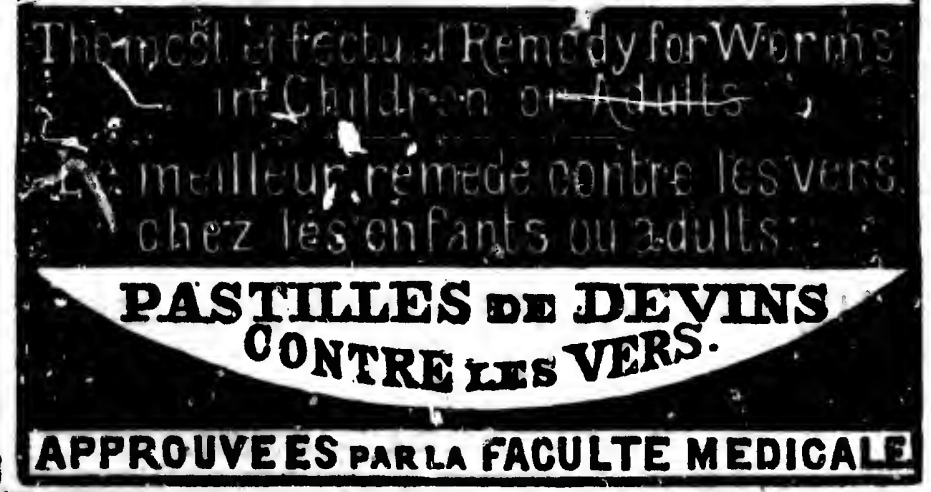
Wrapetarim 



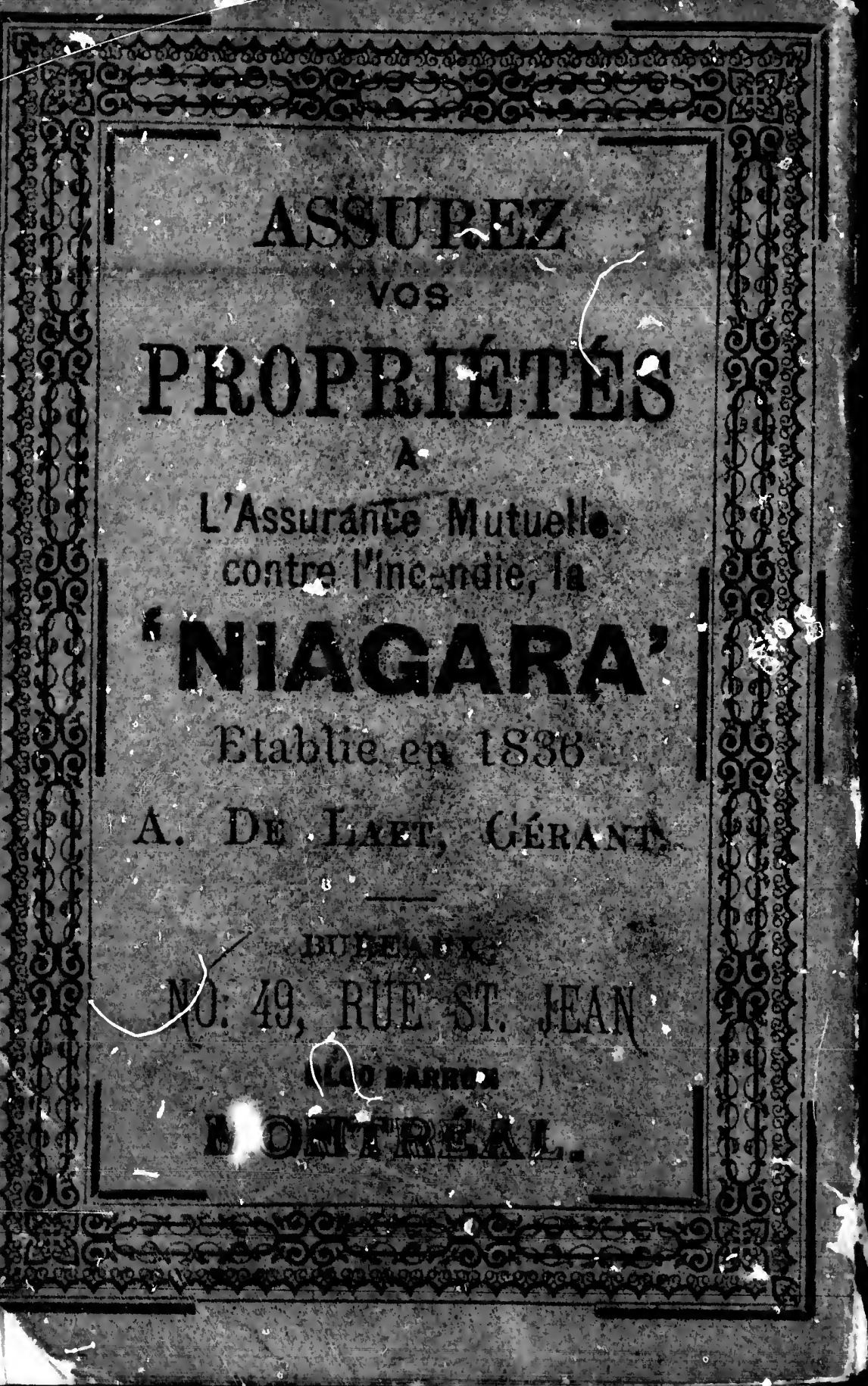




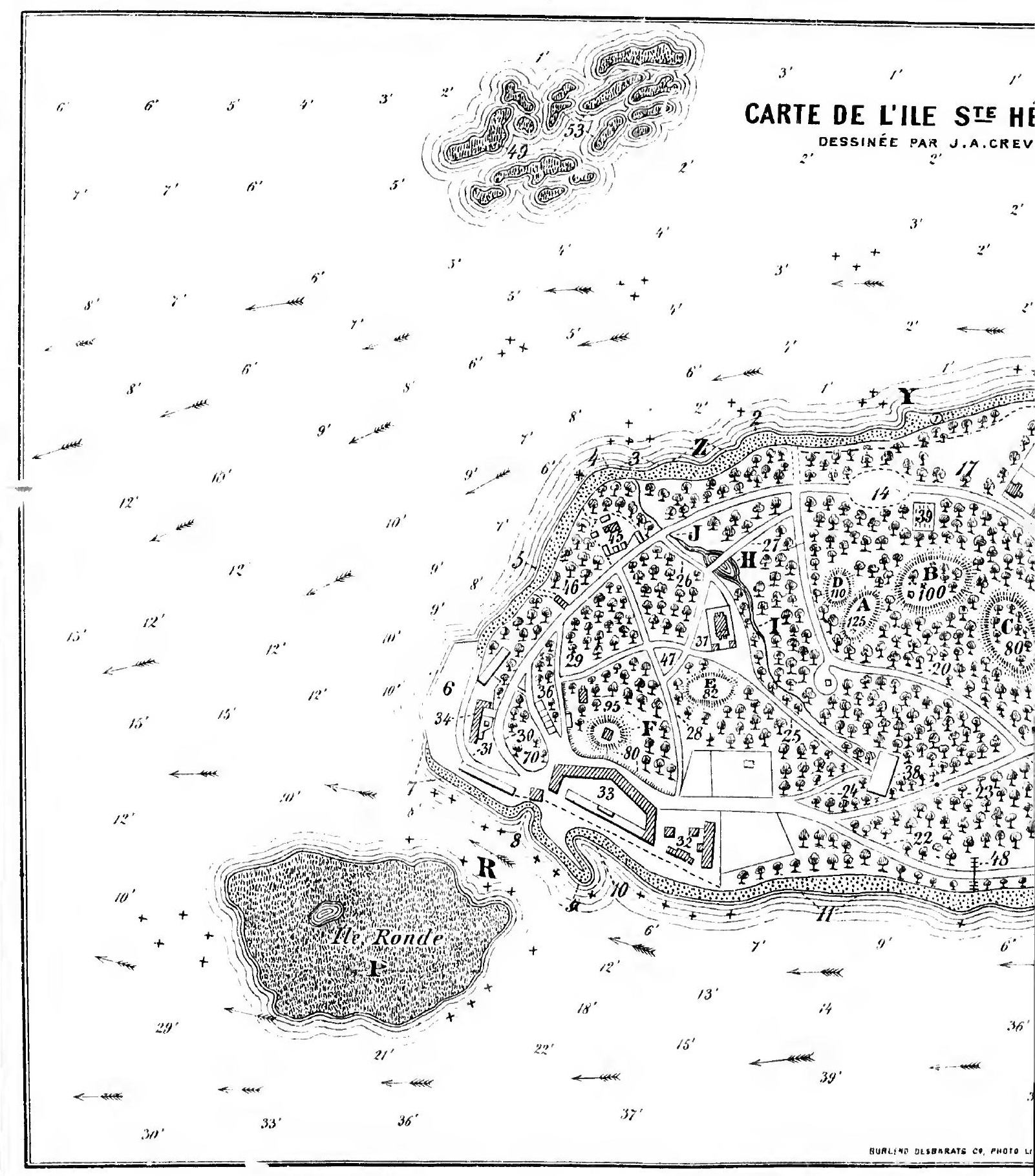
A. Mont Boulé.
B. Mont Chanplain
C. Mont Vaudireuil.
I. Mont St. Sulpice.
E. Mont Moncalm.
F. Mont Wolf.
G. Line Arthur.
H. Lnc Frontennc.
I. Rivière de Bienvillo.
J. Rivière d'Iberville.
K. L'Ause de la Poudrièrs.
L. P'resqu'lle des Rochers.

M. Falaise des Rochers.
N. Grêve aux Eerevisses
O. Ile aux Fraises.
P. Ile Ronde.
Q. Détroit Bunsecours.
R. Détroit d'Hlocheluga.
S. La Pointe des Récifs.
T. Baio des Récifs.
U. Pointe Albert.
V. Baie Viger.
X. Promontoire du Tonnerre.
Y. Pointe Coursol.

M. Falaise des Rochers.

N. Grêve aux Eerevisses

P. lle Ronde

. Detroit Bunsecours.

S. La Pointe des Récif

T. Baio des Récifs.

V. Baie Viger.

Y. Pointe Coursol
Z. Baie des Rapldes.

1. La prairie du Tonnerre.

2. Cap du Rapide.

3. L'Anse de la Rivière d'Iberville.

4. Promontoire Logan.

- La formation d'Helderberg.

5. La Baie du Mess.

6. Quai Militaire.

7. Pointe MIolson.

8. Baie Papineau.

9. Cap Morin.

10. Baie Lafontaine.
11. La Gmnde Grère Ouest. 12. Pointe aux Caillowx. 18. L'Allbe des Ormes 14. Rond-Point-Dufferin. 15. L'Allee Hingston. 18. A vonue de Lévis. 17. Vallé: St. Jean Baptiste. 18. Vallée de Montenic. 18. (bis) Chemin Billings. 19. Vallée de Boucharville. 20. Allée Jac'ques Cartier 21. Chemin Th. Wilson. 


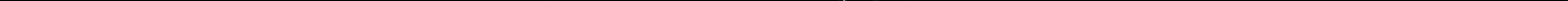

